\title{
2 Grundfiguren
}

Begriffsgeschichten verhalten sich immer korrelativ zu ihren Kontexten, den Kontexten anderer Verwendungen desselben Wortes und den Kontexten anderer Begriffe, die Schnittmengen mit dem jeweiligen Begriff aufweisen, mit diesem aber nicht identisch sind. „Begriffe sind immer in Begriffsnetze eingespannt.“1 Die Beschreibung des Verhältnisses, in das die Begriffe treten, ist damit ein möglicher Weg zur Bestimmung der Heimatsemantik. Da die folgende Arbeit einerseits diesen Weg nicht beschreiten wird, da sich aber andererseits diese Begriffskonstellationen, die teilweise schon aus dem intuitiven Vorverständnis von Heimat nicht herauszuhalten sind, im Verlauf der Arbeit immer wieder bemerkbar machen, soll hier in einem Exkurs, der ebenso als eine Art Einleitung wie als Skizze eines alternativen Zugangs gelesen werden kann, auf einige zentrale Begriffskonstellationen eingegangen werden. Dieser Exkurs erhebt keinen Anspruch auf Vollständigkeit. Außer den hier mit Heimat in Beziehung gesetzten Begriffen Vaterland, Volk, Frau, Fremde, Dichtung - könnten auch eine Reihe anderer untersucht werden: Heimweh, Heimatlosigkeit und Wanderschaft, Welt und Kolonie, Kindheit und Utopie, Grab und Tod, Paradies und Himmel, Haus und Herd oder das Unheimliche beispielsweise. Die sei es auch lückenhafte Arbeit an den Paaren ,Heimat und Vaterland', ,Heimat und Volk', ,Heimat und Frau', ,Heimat und Fremde', ,Heimat und Dichtung' zeigt exemplarisch, dass die Geschichte der Heimat sich nicht im Verhältnis zu anderen Begriffen erzählen lässt, die ihrerseits als Fixsterne am Himmel des 18., 19. oder 20. Jahrhunderts stünden. Mit dem Begriff der Heimat sind auch diese Begriffe in Bewegung.

1 Koselleck 2006, S. 101. Mit Begriffen sind hier einerseits im engeren Sinn Begriffe des semantischen Feldes von Heimat gemeint (Vaterland und Vaterhaus, Zuhausesein und Beheimatetsein, Daheim und Heim, das Heimelige, Heimische und Heimatliche, schließlich auch das Heimweh), andererseits Begriffe, die in topische Konstellationen zu Heimat treten (Heimat und Fremde, Heimat und Welt, Heimat und Front). So wie jeder der einzelnen Begriffe einem historischen Wandel unterliegt, verändern sich auch die Begriffskonstellationen. Bestimmte Begriffe treten beispielsweise erst Mitte des 19. Jahrhunderts in das semantische Feld ein, wie die Muttererde und der (heimische) Herd. Die geradezu exzessiven Kompositabildungen mit Heimat Heimatliebe, Heimatgefühl, Heimaterde, Heimatboden, Heimatflur, Heimatherd - fallen ebenfalls erst ab der zweiten Hälfte des 19. Jahrhunderts auf, wie die vorliegende Studie zeigen wird.

Ә OpenAccess. () 2021 Anja Oesterhelt, publiziert von De Gruyter. (cc))BY-ND Dieses Werk ist lizenziert unter der Creative Commons Attribution-NonCommercial-NoDerivatives 4.0 Lizenz. 


\subsection{Heimat und Vaterland}

Die Geschichte des Begriffs Heimat wird im Kontext von Patriotismus- und Nationalstaatsdiskursen meistens mit der Begriffsgeschichte des Vaterlands assoziiert, ohne dass die eine mit der anderen identisch wäre. Vielmehr ist die Konstellation Heimat - Vaterland historisch seit dem späten 18. Jahrhundert in steter Bewegung und erweist sich als überaus komplex und variantenreich; sie reicht von synonymen bis zu komplementären Bedeutungen.

In den politischen Debatten des 18. Jahrhunderts sucht man den Begriff der Heimat zunächst vergeblich: In den Schriften zu Vaterlandsliebe, Nationalgeist und Patriotismus der ersten zwei Drittel des 18. Jahrhunderts taucht Heimat nicht auf. Trotzdem wird in diesen Schriften eine Debatte ausgetragen, die eine der Bedingungen des späteren Heimat-Diskurses darstellt. Denn erst der grundlegende Wandel, den die Begriffe Patriotismus und Vaterland im Lauf des letzten Drittels des 18. Jahrhunderts erfahren, öffnet deren Bedeutungsgehalt hin aufs Nationale. Erst unter den Vorzeichen dieser Neuformierung wird auch Heimat in die Frage des Nationalen einbezogen. Deswegen wird es im Folgenden zunächst vor allem um die Begriffe Patriotismus und Vaterland gehen, bis Heimat in den 1770er Jahren ins Spiel kommt.

Die im deutschsprachigen Raum des 18. Jahrhunderts geführte Patriotismusdebatte ist kein Vorläufer einer Idee des modernen Nationalismus, ${ }^{2} \mathrm{im}$ Gegenteil. Patriotismus bedeutet im Verständnis der Zeit - das in Teilen dem des 16. und 17. Jahrhunderts gleicht, wie Alexander Schmidt gezeigt hat ${ }^{3}$ - eine bestimmte moralische Haltung und ein daraus sich ergebendes Handeln im Sinn des Ge-

2 Einen Überblick über die Nationalismusforschung gibt Dieter Langewiesche in seinem Aufsatz ,Nation', ,Nationalismus', ,Nationalstaat' in der europäischen Geschichte seit dem Mittelalter. Versuch einer Bilanz. Trotz aller hervorhebenswerten und teils zu wenig beachteten Kontinuitäten in den Prozessen der Nationsbildung in Europa kann der moderne Nationalismus als Resultat der Französischen Revolution klar in seinem spezifischen neuen Charakter bestimmt werden: „Erst im 19. Jahrhundert wurden Nation und Nationalstaat zum obersten handlungsleitenden Wert in der Gesellschaft - nicht für alle gleichermaßen und nicht durchgehend, aber doch in politischen Entscheidungszeiten.“ Langewiesche plädiert daher dafür, „den nachrevolutionären Nationalismus nach seinem Geltungsanspruch, der Breite der gesellschaftlichen Akzeptanz dieses Anspruchs und damit auch nach seiner Handlungsrelevanz für gesellschaftliche Gruppen und staatliche Entscheidungsträger von seinen mittelalterlichen und frühneuzeitlichen Vorläufern scharf abzugrenzen“. Langewiesche: Nation, 2000, S. 13.

3 Alexander Schmidt schlägt vor, den Patriotismusdiskurs des späten 18. und frühen 19. Jahrhunderts auch als Abschluss einer Debatte des 16. Jahrhunderts um die ,amor patriae' als moralische Pflicht einer gottgewollten sozialen Ordnung zu lesen (Schmidt 2010, S. 37). Vgl. dazu v. a. seine Studie Vaterlandsliebe und Religionskonflikt, Schmidt 2007. 
meinwohls. ${ }^{4}$ Dieses Ideal propagieren frühaufklärerische Zeitschriften wie Der Patriot, die erste deutschsprachige Moralische Wochenschrift: „[...] ein Patriot sey ein Mensch, dem es um das Beste des Vaterlandes ein rechter Ernst ist, der seinen GOtt recht erkennet, das Predig-Amt ehret, Wahrheit und Ordnung liebet, die Obrigkeit fürchtet, und dem gemeinen Wesen redlich zu dienen geflissen ist [...]. “5 Die Forderung nach gemeinnützigem Handeln wird als moralische, nicht als sozialkritische verstanden. Sie soll mit den Untertanenpflichten in Einklang stehen. ${ }^{6}$ Noch 1755, etwa dreißig Jahre nach den programmatischen Äußerungen in Der Patriot, preist Isaac Iselin in seinen Philosophischen und patriotischen Träumen eines Menschenfreundes Patriotismus als die höchste menschliche Tugend, die nur durch Gehorsam und Demut zu erlangen sei. Schon in die Wiege des zukünftigen Patrioten sei zu legen, „daß dieses die erste Tugend eines Bürgers sey, wol zu gehorchen“. ${ }^{7}$ Das patriotische Streben bezieht sich dabei immer auf die bestehenden Staatsgrenzen, die im Sprachgebrauch der Zeit jeweils als, Vaterland' gelten. Es ist also die Rede vom hessischen Patriotismus, von der Osnabrücker Vaterlandsliebe und so weiter.

Vaterlandsliebe und Patriotismus werden immer auf ein größeres Ganzes perspektiviert. Deswegen können Patriotismus und Kosmopolitismus für die Frühaufklärer strukturell analoge Konzepte sein. ${ }^{8}$ So soll der Patriot nach Iselin gleichermaßen zu ,einem würdigen Bürger der Erde, des Staates, und des Him-

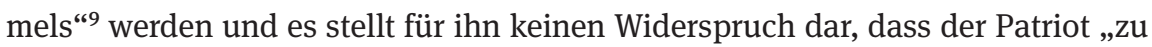
dem Dienste der Welt und des Vaterlands“10 berufen sei. Die Auffassung, „daß wenn es dem Ganzen wol gehet, es auch einem jeden Theile wol gehen müsse“, ${ }^{11}$ ist prinzipiell über jede Landesgrenze hinaus ausdehnbar. Patriotismus und

4 Rudolf Vierhaus bestimmt den Patriotismus des 18. Jahrhunderts als „eine auf das Gemeinwesen bezogene moralisch-politische Gesinnung“, Vierhaus 1987, S. 108. Von einem „im wesentlichen moralischen und vorpolitischen Patriotismusdiskurs des 18. Jahrhunderts“ spricht Alexander Schmidt. Schmidt 2010, S. 35.

5 Der Patriot Nr. 4, 27. Januar 1724, in: Martens 1969-1984, Bd. 1, S. 26.

6 Das Beharren auf Loyalität gegenüber den bestehenden politischen Verhältnissen unterscheidet die deutsche Patriotismusdebatte in der ersten Hälfte des 18. Jahrhunderts und auch noch bis weit in die zweite Jahrhunderthälfte hinein etwa von derjenigen in Frankreich, wo sich Patriotismus schon sehr viel früher mit sozialkritischen Impulsen verband; vgl. Irmtraut Sahmlands Studie Christoph Martin Wieland und die deutsche Nation. Zwischen Patriotismus, Kosmopolitismus und Griechentum, Sahmland 1990. Hier wird der Begriff der Heimat naturgemäß nicht erörtert.

7 Iselin 1758, S. 304-305. Die erste Auflage stammt von 1755, hier zitiert nach der zweiten.

8 Vgl. Oesterhelt 2018.

9 Iselin 1758, S. 304.

10 Iselin 1758, S. 307.

11 Iselin 1758, S. 313. 
Kosmopolitismus legitimieren sich positiv über die Idee eines allgemeinen Besten, nicht aber negativ über Abgrenzung. Für den Patriotismus des frühen 18. Jahrhunderts ist dies besonders hervorhebenswert, denn eben die Funktionsweise der Grenze wird sich gegen Ende des Jahrhunderts grundsätzlich ändern. Zunächst hat die Vaterlandsgrenze die Funktion, den Aktionsradius des (kosmopolitischen) Patrioten zu definieren, so dass der ideelle Kosmopolitismus zu einem handlungsorientierten Patriotismus werden kann. Die Argumentation für patriotisches Handeln ist dabei teilweise eine religiöse, ${ }^{12}$ teilweise eine pragmatische und ökonomische, wie in der Wochenschrift Der Patriot. Hier ist es nicht der Wunsch nach Seelenheil, sondern nach leiblicher Selbsterhaltung und Erhaltung der eigenen Nachkommen, der den Einzelnen im Sinn des Gemeinwohls handeln lässt:

Wie nun ein jeder, welcher sich in einem Schiffe befindet, die Erhaltung des Schiffes zu seinem eigenen Besten zu suchen verbunden ist: eben so viel, ja noch mehr, erfordert es die Schuldigkeit derer, die eine Ring-Mauer vereinet, für das Wohl des Vaterlandes zu sorgen, weil nicht allein ihre eigene Wohlfahrt, wie etwan der Schiffenden, sondern zugleich die Wohlfahrt ihrer Weiber, Kinder und Nachkommen, und zwar mehr, als man glauben sollte, daran hafftet $[. . .]^{13}$

Die Ablehnung der Selbstsucht, die den Patriotismusdiskurs topisch begleitet, ist somit ambivalent. Einerseits tritt der Patriotismus explizit als Gegenkonzept des Eigennutzes auf und wird auch zeitgenössisch so gedeutet, ${ }^{14}$ andererseits ist er zugleich selbst Teil einer wirtschaftlichen Logik, indem immer wieder argumentiert wird, das gemeinnützige Handeln komme am Ende wieder dem ökonomischen Interesse des Einzelnen zugute. Das Bild des ,Schiffs‘ und der ,Ring-Mauer“, das den Radius der persönlichen Abhängigkeit vom allgemeinen Schicksal markiert, ist auch hinsichtlich der Funktion der Grenzziehung bemerkenswert. Die Grenze oder die Mauer ermöglichen die Bestimmung eines konkreten Betroffenheits- bzw. Aktionsradius, sind aber potentiell erweiterbar; auch auf die gesamte

12 Im Sinn des Seelenheils argumentiert Iselin. Es ist bei Iselin der Himmel selbst, der dem Patrioten seine Arbeit „zum Besten des Vaterlandes auferleget“ (Iselin 1758, S. 309), und der Patriot suche in „allen seinen Handlungen [...] nichts als den Beyfall des Himmels, die Glückseligkeit der Menschen, und das Vergnügen, das die Ausübung der Tugend dem Tugendhaften in so reichem Masse gewähret“ (Iselin 1758, S. 312), ja sein Handeln diene nur der „erhabnen Vorbereitung“ auf sein Leben nach dem Tode, in dem er umgeben sein werde von „triumphierende[n] Engel[n]“, die selbst „ehemals auf dieser Erden als Patrioten und tugendhafte Bürger Völker glükselig gemacht hatten“, und „wo er als ein getreuer Knecht die Belohnung seiner Tugend, und die Vergeltung seiner Mühen in reichem Masse erhalten wird.“ (Alle Zitate Iselin 1758, S. 327) 13 Der Patriot Nr. 84, 9. August 1725, in: Martens 1969-1984, Bd. 2, S. 259-265, hier S. 264-265. 14 Vgl. Sahmland 1990. 
menschliche Gesellschaft ließe sich die Schiffs- oder Stadtmauermetaphorik übertragen. Die Grenzmetaphorik zielt aber nicht auf Abwehr eines Fremden. Wo es in der frühen und mittleren Aufklärung einen Blick des Patrioten über die eigenen (Klein-)Staatsgrenzen hinaus gibt, geschieht dies nicht in kompetitiver Hinsicht, sondern im Sinn einer möglichen Ausweitung des im kleineren Rahmen als allgemein nützlich Erkannten, wie in Justus Mösers Patriotischen Phantasien (vgl. II.2.2). ${ }^{15}$

Das ändert sich in den 1760er und 1770er Jahren. Fortan können sich Patriotismus und Vaterland entweder herkömmlich auf den einzelnen konkreten (Klein-)Staat, ja sogar ausschließlich auf den eigenen Geburts- oder Lebensort beziehen $^{16}$ (eine Funktion, die später der Heimatbegriff übernehmen wird) oder aber auf die Idee eines als Nation geeinten Deutschlands. Das produktive Spannungsverhältnis zwischen dem regionalen und dem gesamtstaatlichen Vaterland, zwischen Landesloyalität und Nationalstaatsidee, Föderalismus und Zentralismus wird fortan zum spezifischen Merkmal moderner deutscher Geschichte. ${ }^{17}$ Neu ist, dass die Grenzen des Vaterlands nun nicht mehr pragmatisch, sondern ideell bestimmt werden, die Vaterlandsliebe nicht mehr zum moralischen Wert, sondern zur anthropologischen Notwendigkeit erhoben und mit der Idee eines Nationalgeistes oder Nationalcharakters in Zusammenhang gebracht wird. Hier erst liegen die Ursprünge des modernen deutschen Nationalismus, der dann zu einem Leitparadigma des 19. Jahrhunderts werden sollte. ${ }^{18}$ Dieser moderne Nationalismus bestimmt sich in der Abgrenzung gegenüber Fremdem und setzt sich so auch in Kontrast zum aufklärerischen Kosmopolitismus, der fortan eine antipodische Funktion gegenüber dem neu verstandenen Patriotismus übernimmt. In

15 Deren ganz auf Osnabrück bezogene Perspektive müsse außerhalb dieser Grenzen, so heißt es in der Vorrede, wohl einen „Erdgeschmack“ tragen, könnte gleichwohl vielleicht auch dort dienlich sein. Möser 1780, o.S.

16 In einer anonymen Rezension zu Joseph von Sonnenfels' Über die Liebe des Vaterlandes heißt es, hier schon als klare Gegenposition gegen einen anderen Vaterlandsbegriff formuliert: „Die ewig mißverstandnen Klagen nachgesungen: ,Wir haben kein Vaterland, keinen Patriotismus‘. Wenn wir einen Platz in der Welt finden, da, mit unsern Besitzthümern zu ruhen; ein Feld, uns zu nähren; ein Haus, uns zu decken; haben wir da nicht Vaterland? und haben das nicht tausend und tausende in jedem Staat? und leben wir nicht in dieser Beschränkung glücklich?“ Frankfurter gelehrte Anzeigen vom Jahr 1772, 1. Hälfte, S. 269-271, hier S. 269-270, hier zitiert nach Sahmland 1990, S. 219.

17 Dieter Langewiesche rekonstruiert das Konzept der föderativen Nation als Kennzeichen moderner deutscher Geschichte, vgl. Langewiesche: Nation, 2000. Im europäischen Vergleich unterscheidet sich das Verhältnis der Deutschen zu Nation und Staat damit von den anderen europäischen Staaten, vgl. Schulze 1994.

18 Vgl. Echternkamp 1998 und Wehler 2001. 
Zusammenhang mit dieser Abgrenzungsbewegung wird die Rede vom Vaterländischen und Patriotischen emotionalisiert und pathetisiert. Repräsentativ hierfür steht Johann Georg Zimmermanns viel beachtete Schrift Vom Nationalstolz (1758), welche die Nationalgeistdebatte in Deutschland auslöste. ${ }^{19}$ Der Schweizer Zimmermann definiert Nationalstolz als „ein Gefühl von besondern Vorzügen, die sich ein Volk beimißt, sie mögen nun eingebildet oder wahrhaft heissen“ ${ }^{20}$ Selbst dann, meint Zimmermann, wenn diese Vorzüge bloße Einbildung seien, entspringe ihnen doch ein „Gefühl der Würdigkeit“21 der eigenen Seele, das eine Bedingung moralischen Handelns sei. ${ }^{22}$ Nationalstolz wird also als anthropologisches Phänomen begriffen, das auf seine Funktionsweise und seine Auswirkungen hin befragt wird. Nicht um die tatsächliche Berechtigung des Gefühls nationaler Überlegenheit geht es Zimmermann, sondern um eine Haltung der Selbstachtung, welche durch den Nationalstolz möglich werde. Der deswegen nach seiner Auffassung wünschenswerte Nationalstolz ermögliche dem Einzelnen, sein Handeln an einem positiven Ideal zu orientieren. Gleichwohl beruht dieses Konzept eines anthropologischen und instrumentellen Nationalstolzes bereits auf Abgrenzung und normativer Differenzierung.

Die deutsche Debatte um den Begriff der Nation und für ein „einträchtiges Deutschland“23 initiiert 1765 Friedrich Carl von Mosers Von dem Deutschen national-Geist. Der Text beschwört die Utopie der Einheit und Stärke eines einheitlich repräsentierten deutschen Volkes, ${ }^{24}$ um diese dann mit einer Realität zu

$19 \mathrm{Zu}$ Lebzeiten Zimmermanns erschienen sechs Auflagen sowie eine französische und eine englische Übersetzung, vgl. das Nachwort in Zimmermann 1758, o.S. Zur deutschen Nationalgeistdebatte im 18. Jahrhundert vgl. Seeba 1987, S. 201-206.

20 Seeba 1987, S. 3. Zum Verhältnis von Deutschen und Schweizern vgl. Seeba 1987, S. 86-88. 21 Seeba 1987, S. 95.

22 Dieses Gefühl des Vorrangs vor anderen entwickelt Zimmermann mehr assoziativ als systematisch anhand von zahllosen Beispielen aus allen Zeiten und Kulturkreisen und belegt, dass dieses Gefühl nicht selten auf Einbildung beruhe. Immer laufe es darauf hinaus, dass sich jeder „auf seinem Miste der größte“ (Seeba 1987, S. 8) wähne. Ganz unabhängig aber von der weitläufig entwickelten objektiven Unhaltbarkeit der im Nationalstolz häufig gefühlten und behaupteten Überlegenheit (dass es Nationalcharaktere überhaupt gebe, wird hingegen als zweifelsfrei angenommen, vgl. Seeba 1987, S. 90), zielt Zimmermanns Argument auf die positiven psychologischen und moralischen Effekte des Nationalstolzes.

23 Moser 1765, S. 71.

24 „Wir sind Ein Volk, von Einem Nahmen und Sprache, unter Einem gemeinsamen Oberhaupt, unter Einerley unsere Verfassung, Rechte und Pflichten bestimmenden Gesezen, zu Einem gemeinschaftlichen grossen Interesse der Freyheit verbunden, auf Einer mehr als hundertjährigen national-Versammlung zu diesem wichtigen Zweck vereinigt, an innerer Macht und Stärcke das erste Reich in Europa, dessen Königs-Cronen auf Deutschen Häuptern glänzen [...].“ Moser 1765, 
konfrontieren, welche die Deutschen als „bedaurenswürdiges Volck“ zeigt. ${ }^{25}$ Moser beklagt, dass nirgendwo Einsatz fürs allgemeine Ganze zu sehen sei. Insbesondere die politische Führung der Einzelstaaten mit ihrer Verwaltung denke „separatistisch[]“.26 Überall sehe er den „der wahren Liebe des Vaterlands so äusserst entgegen stehenden Geist des Eigennutzes“. ${ }^{27}$ Vermisst wird von Moser eine „national-Denkungs-Art, eine allgemeine Vaterlandsliebe“, und das nicht nur „bey dem grossem Hauffen des gemeinen Deutschen Mannes, welcher nur den Strich Erde, worauf er gebohren und erzogen ist, vor sein wahres und alleiniges Vaterland hält“. ${ }^{28}$ Das - neue - Anliegen einer gesamtdeutschen Perspektive wird in der analogen Verwendung von Nation und Vaterland sichtbar; die häufig gebrauchten Begriffe von Vaterland und Patriotismus haben einen neuen territorialen Bezugsrahmen, nämlich den einer deutschen Nation. Abgesehen von dieser räumlichen Neubestimmung steht Moser ganz im Selbstverständnis des hergebrachten Patriotismusbegriffs; erstens in dem Sinn, dass politische Verhältnisse nicht umgestürzt werden sollen, sondern eine von einem neuen Geist getragene Reform der Verwaltung unter dem Leitbild des Allgemeinwohls das erklärte Ziel der Schrift ist - das vorangestellte Motto von Iselin betont, dass es dem hier vertretenen Patriotismus um den Gedanken „der allgemeinen Wohlfarth“ gehe, nicht um „den Geist der Unruhen“; ${ }^{29}$ zweitens in dem Sinn, dass die eingeklagte nationale Gesinnung auf ein gemeinnütziges Denken und Handeln zielt, nicht aber auf nationale Exklusivität, wie sie Zimmermann vorgeschlagen hatte.

S. 5. Angespielt wird auf den in den Verträgen des Westfälischen Friedens von 1648 beschlossenen und 1653/54 durchgeführten Reichstag des Heiligen Römischen Reiches Deutscher Nation.

25 ,[...] so, wie wir sind, sind wir schon Jahrhunderte hindurch ein Räthsel politischer Verfassung, ein Raub der Nachbarn, ein Gegenstand ihrer Spöttereyen, ausgezeichnet in der Geschichte der Welt, uneinig unter uns selbst, kraftlos durch unsere Trennungen, starck genug, uns selbst zu schaden, ohnmächtig, uns zu retten, unempfindlich gegen die Ehre unsers Nahmens, gleichgültig gegen die Würde der Geseze, eifersüchtig gegen unser Oberhaupt, mißtrauisch unter einander, unzusammenhangend in Grundsätzen, gewaltthätig in deren Ausführung, ein grosses und gleichwohl verachtetes, ein in der Möglichkeit glückliches, in der That selbst aber sehr bedaurenswürdiges Volck." Moser 1765, S. 5-6.

26 Moser 1765, S. 36.

27 Moser 1765, S. 9.

28 Moser 1765, S. 12-13.

29 „Ein Patriot ist zu groß, eines andern Sclave, er ist zu gerecht, eines andern Herr zu seyn. Er ist daher weder der Anhänger einer Parthie, noch das Haupt einer solchen. Er verabscheuet den Geist der Unruhen; ihn leiten, ihn beherrschen nur das Gesez und der grosse Gedanke von der allgemeinen Wohlfarth; diese allein erfüllen seine edle Seele; diesen allein opfert er alle andere Triebe, alle andere Neigungen seines Herzens auf.“ Iselin 1758, o.S. 
Mosers Text stieß eine breite Debatte über den Nationalgeist an, wobei dieser fast durchweg abgelehnt wurde. Symptomatisch für den Diskussionsstand der Zeit ist deswegen weniger die Perspektive Mosers als die gegen ihn vorgebrachten Argumente. Es wird eingewendet, dass der - durchaus zutreffenden - Gegenwartskritik die Annahme einer vormaligen, angeblich verloren gegangenen Einheit zugrunde liege, die es so nie gegeben habe. In der anonymen Schrift Noch etwas zum Deutschen Nationalgeiste heißt es: „Uneinig sind wir zu allen Zeiten gewesen“ - und zwar so sehr, dass eigentlich eben diese Uneinigkeit das konstitutive Element des deutschen Nationalgeistes sei. ${ }^{30}$ Weiterhin wird kritisiert, dass eine zukünftige Einheit nicht mit den überkommenen Instrumenten des Heiligen Römischen Reichs Deutscher Nation zu bewerkstelligen sein werde. Der Haupteinwand ist, Moser habe sein Thema verfehlt: Es gehe Moser um eine Kritik des Staatsrechts und seiner Vertreter, nicht aber um die viel umfassendere Frage nach einem deutschen Nationalgeist. Will Mosers Nationalgeist den alten Patriotismusbegriff auf eine größere territoriale Einheit übertragen und die Idee der allgemeinen Wohlfahrt (nämlich der aller Deutschen) gegenüber dem real praktizierten eigennützigen Handeln der einzelnen deutschen Staaten einklagen, so wollen seine Kritiker mit dem Begriff des Nationalgeistes etwas über das Wesen des Deutschen erfahren; sie wollen verstehen, was sie als Deutsche zusammenhält, und suchen nach anthropologischen Argumenten für den von Zimmermann angemahnten Nationalstolz. Der bessere Titel, schreibt Justus Möser in seiner Besprechung Mosers, wäre „der Geist der deutschen Höfe“ ${ }^{31}$ denn diesem gelte die Kritik, nicht dem Geist der Gesamtnation:

Allein am Hofe lebt nicht der Patriot, nicht der Mann, der zur Nation gehört, sondern der gedungene Gelehrte, der sich schmiegende Bediente, und der Chamäleon, der allezeit die Farbe annimmt, welche ihm untergelegt wird; und die Gelehrsamkeit überhaupt hat ein solches air étranger, daß sich der Nationalcharakter darunter beinahe ganz verliert. ${ }^{32}$

Möser, für seine mehrbändigen Patriotischen Phantasien (1766 bis 1792) bekannt, ${ }^{33}$ bringt hier einen neuen Ton in die Rede von der Vaterlandsliebe: Sie wird dem

30 Anonym 1766, S. 198. Zu Formen und Funktionen von Anonymität als Phänomen des öffentlichen Diskurses vgl. Pabst 2011.

31 Möser 1986, S. 249. Mösers Rezension erschien zuerst 1768 in der Allgemeinen Deutschen Bibliothek.

32 Möser 1986, S. 249.

33 Der Titel ist hier im weiteren Sinn bezogen auf die zwischen 1766 und 1792 verfassten Beiträge für die Wöchentlichen Osnabrückischen Intelligenzblätter. 1774 gab er einen Teil davon unter dem Titel Patriotische Phantasien heraus. Zur Einordnung Mösers in den Nationalstaatsdiskurs vgl. Carl 2001. 
Staatsdiener und Gelehrten ab- und dem einfachen, unverbildeten Volk zugesprochen. Zahlreiche weitere kritische Stimmen betonen in der Reaktion auf Moser, dass sie unter Nationalgeist einen Volksgeist verstanden wissen wollen, der gerade nicht auf eine politische Führungsschicht und ihre Lakaien zu beschränken sei, sondern das Volk in seiner Gesamtheit charakterisiere. Hier wird auch einer der progressiven Impulse des neuen Nationalstaatsdiskurses sichtbar: Er zielte insgesamt auf eine Überwindung der ständischen Gesellschaft und verband sich insbesondere durch die Französische Revolution mit der Idee von Gleichheit und Freiheit. ${ }^{34}$

Die verstärkt ab den 1770er Jahren einsetzende Suche nach einem Nationalund Volksgeist geht viele Wege, die auch einen semantischen Wandel von Vaterland und Patriotismus nach sich ziehen. Die Neubesetzung der Begriffe findet, von Christoph Martin Wieland abgesehen, ${ }^{35}$ weitgehend ohne Reflexion der älteren Bedeutung statt. Ihr überkommener Sinn wird meist implizit in Form einer Kritik des Kosmopolitismus hinterfragt. Dieser wird als ,kalt' und ,berechnend“ charakterisiert und den ,volksfernen“ Aufklärern zugeschrieben. Der Generationenkonflikt wird dabei auch als vorgeblicher Schichtenkonflikt ausgetragen, insofern die Aufklärer jenen Gebildeten zugerechnet werden, die den Kontakt zum ,Volk' verloren hätten, wobei meist verschwiegen wird, dass auch die Kritiker Gebildete und ökonomisch Bessergestellte sind. Die Neukonzeptualisierung des Patriotismus basiert nun immer häufiger auf der Abgrenzung gegenüber einem Fremden, das abgewertet werden muss, um das Eigene aufwerten zu können. Dem Kosmopolitismus fehle, so die Kritik, die Fähigkeit der Differenzbildung. Anschaulich wird dies anhand von Johann Georg Schlossers Politischen Fragmenten, die 1777 in der dem Hainbund nahestehenden Zeitschrift Deutsches Museum von Heinrich Christian Boie publiziert werden:

\footnotetext{
Wem alles zu Hause wohl steht, oder wem's zu Hause nicht mehr gefällt, oder wer keine Heimat hat, der werde ein Kosmopolit! - Wer's ist, nahe nie meinem Vaterlande!

Der Jedermannsbürger ist wie der Jedermannsfreund.

Patriotismus hebt die Menschenliebe nicht auf; aber Menschenliebe und Vaterlandsliebe
}

34 Alexander Schmidt zeigt, wie die Revolution die „Debatte über die Möglichkeit eines Patriotismus in Monarchien neu entfacht und auch in Staaten wie Preußen kontrovers geführt" wird. „Mainzer Klubisten verkündeten in ihren Texten offensiv, daß sich Vaterlandsliebe nur auf eine Republik beziehen könne“. Schmidt 2010, S. 48. Schon der Patriotismus- und der Naturrechtsdiskurs des 18. Jahrhunderts arbeiteten diesen Debatten vor, vgl. Schmidt 2010, S. 50; Vierhaus 1987; Klippel 1976.

35 Vgl. Christoph Martin Wielands Patriotischen Beitrag zu Teutschlands höchstem Flor (wenn es will) (1780 -1786), und Über teutschen Patriotismus (1793). Wieland geht als einziger der Zeitgenossen auf den Bedeutungswandel der Begriffe ein. 
müssen untergeordnet seyn.

Stolz auf seine Nation seyn, ist besser als keine haben; und die andern Nationen, im Gefühl seiner Freyheit und seines Werths, verachten, ist besser als den andern dienen, oder den andern nachäffen. ${ }^{36}$

Der Kosmopolit liebt nach Schlosser zuerst den Menschen, er hat keinen Nationalstolz, sondern dient anderen Nationen oder ahmt sie nach. Der Patriot liebt zuerst das Vaterland, sein Nationalstolz verbindet sich mit der Verachtung der anderen Nationen. Im neuen, emotionalisierten Ton der 1770er Jahre wird ,Vaterland' zur Pathos-Formel, die sich in Imperativen, Invokationen und Interjektionen ausdrückt. Der Begriff der Heimat, der hier im Zitat verwendet wird, wobei dies in den 1770er Jahren im politischen Kontext eine Ausnahme ist, wird ein Stück weit von dieser Emphase erfasst. Denn selbst wenn dem Juristen Schlosser Heimat als juristischer Terminus technicus vor Augen stand, setzt er ihn hier in emotionalisierender Funktion ein.

Die aufklärerische Kritik am neuen Verständnis von Patriotismus und Vaterland hält bis zum Ende des 18. Jahrhunderts an und verliert nichts von ihrer Geltung. ${ }^{37}$ Die sukzessive Bedeutungsverschiebung des Begriffs und die emphatische Konzeptualisierung von ,Vaterland“ kann sie aber nicht aufhalten. Immer öfter wird im Namen des Vaterlands die Obrigkeit kritisiert, ein Opfer gefordert, das Fremde ab- und das Eigene korrelativ aufgewertet.

Die Semantik von Patriotismus und Vaterlandsliebe kann ab den 1770er Jahren erstmals eine deutliche Kritik an der Obrigkeit enthalten: nicht so sehr in dem Sinn Mosers, Fürsten und ihre Verwaltung würden zu wenig für das Allgemeinwohl handeln, sondern im Sinn einer grundsätzlichen Infragestellung der politischen Strukturen und Machtverhältnisse. Bei Schlosser besteht die Rubrik „Der Patriot“ einzig aus zwei knappen Sätzen: „Frey muß der Staat seyn, jeder Bürger sich Theil des Staats fühlen, wo Patrioten möglich sind. - Was reden wir nun davon?“38 Freiheit jedes einzelnen Bürgers wird hier zur (uneingeholten) Bedingung des Patriotismus. Die aufklärerische Idee eines grundsätzlich funktionierenden, wenngleich reformbedürftigen Gemeinwesens (Moser) wird aufgekündigt; die Grenze verläuft nun zwischen den Herrschenden und dem Volk. Zu Ersteren wurden meist auch die Gebildeten gezählt. ${ }^{39}$

36 Schlosser 1777, S. 106.

37 Vgl. Christoph Martin Wielands Über teutschen Patriotismus (1793).

38 Schlosser 1777, S. 106.

39 Sicher zu Unrecht, wie sich an der durch De la littérature Allemande (1780) von Friedrich II. ausgelösten Debatte ablesen lässt, vgl. Johann Karl Wezel: Über Sprache, Wissenschaften und Geschmack der Teutschen (1781). 
Neu ist auch die Forderung nach Opferbereitschaft fürs Vaterland; nicht im aufklärerischen Verständnis einer Partizipation am Gemeinwesen, sondern im Sinn der exzeptionellen Handlung, der Bereitschaft, sein Leben fürs Vaterland zu lassen, wie in Thomas Abbts ausgesprochen einflussreicher Schrift Vom Tode fürs Vaterland (1761). ${ }^{40}$ Obwohl die Schrift selbst noch die unbedingte Loyalität zum Herrscher fordert, ${ }^{41}$ wurde diese in der Rezeption zur Loyalität gegenüber dem Vaterland umgedeutet. Die Definition von Vaterland ist bei Abbt, noch ganz im Sinn des frühaufklärerischen Verständnisses von Patriotismus, der Staat in seinen schon bestehenden Grenzen, hier also Preußen, und setzt das grundsätzliche Einverständnis des Untertanen mit seinem Staat und dessen Ordnung voraus:

\begin{abstract}
Was ist wol das Vaterland? Man kann nicht immer den Geburtsort allein darunter verstehen. Aber, wenn mich die Geburt oder meine freye Entschließung mit einem Staat vereinigt, dessen heilsamen Gesetzen ich mich unterwerfe; Gesetzen, die mir nicht mehr von meiner Freiheit entziehen, als zum Besten des ganzen Staats nöthig ist: alsdann nenne ich diesen Staat mein Vaterland. ${ }^{42}$
\end{abstract}

Ebenfalls im Anschluss an den hergebrachten Patriotismus-Diskurs bedeutet Liebe zum Vaterland ein Handeln im Sinn der Wohlfahrt aller, hinter der eigensüchtige Interessen zurücktreten müssten, ${ }^{43}$ welches am Ende aber gewinnbringend auch für jeden Einzelnen sei. ${ }^{44} \mathrm{Neu}$ ist der Grad der eingeforderten Opferbereitschaft fürs Vaterland - der eigene Tod - und der evokative Ton, der nicht nur auf rationale, sondern stärker auf emotionale Überzeugung setzt. Der vaterlandsliebende Untertan wird zum Helden: aus Loyalität, aber auch aus innerer Notwendigkeit, die eigenen Vorväter vor Augen, die ihrerseits schon als ,aufopfernde[] Patrioten“ gestorben seien. Aufgrund dieses Heldenmutes, so heißt es, „durchwandern wir ihre Provinzen [die der Vorväter] mit einer geheimen Ehrfurcht“. ${ }^{45}$ Neu ist drittens, dass der hier ins Spiel kommende Begriff der Nation synonym mit Vaterland, d.i. hier also Preußen, verwendet wird. ${ }^{46}$ Die Forderung

$40 \mathrm{Zu}$ Abbts Schrift im historischen Kontext zwischen Ende des ,Alten Reichs“ und neuem Nationalismus informiert ausführlich Wolfgang Burgdorfs Aufsatz „Reichsnationalismus“ gegen „Territorialnationalismus“. Phasen der Intensivierung des nationalen Bewußtseins in Deutschland seit dem Siebenjährigen Krieg, vgl. Burgdorf 2000.

41 Abbts während des Siebenjährigen Krieges verfasste Schrift richtet sich ausdrücklich an den preußischen Untertan und fordert dessen unbedingte Loyalität bis hin zur Bereitschaft, fürs Vaterland zu sterben.

42 Abbt 1761, S. 17.

43 Vgl. Abbt 1761, S. 46.

44 Vgl. Abbt 1761, S. 18.

45 Beide Zitate Abbt 1761, S. 49-50.

46 Vgl. Abbt 1761, S. 49-50. 
nach der Bereitschaft, fürs Gemeinwesen zu sterben, ist deswegen nicht mehr nur die logische Konsequenz des herkömmlichen Patriotismusbegriffs in kriegerischen Zeiten. Nicht mehr das Seelenheil und auch nur noch zum Teil der Pragmatismus nachhaltigen Eigennutzes begründen den Tod fürs Vaterland, sondern die Berufung auf eine spezifische Zugehörigkeit, die sich aus der Genealogie von Generationen fürs eigene Vaterland kämpfender und sterbender Vorfahren ergibt und mit dem Begriff der Nation assoziiert wird.

Die Widersprüchlichkeit der Schrift, die sich insbesondere aus der Beanspruchung des Nationenbegriffs ergibt, ist offensichtlich, da Preußen im Siebenjährigen Krieg u.a. gegen die Reichsarmee des Heiligen Römischen Reiches, gegen das Kurfürstentum Sachsen und gegen die Kaiserliche Armee der österreichischen Habsburgermonarchie kämpfte. Gerade der Siebenjährige Krieg war für viele Deutsche Anlass, Vorstellungen von Vaterland und Nation zu hinterfragen. ${ }^{47}$ Auch Moser hatte in seinem ebenfalls in Reaktion auf den Siebenjährigen Krieg entstandenen Deutschen Nationalgeist die Notwendigkeit des Krieges angezweifelt und den Bruderkrieg beklagt. ${ }^{48}$

Die Patrioten der 1770er Jahre im Umfeld des Göttinger Hainbunds dagegen übergehen den Widerspruch, dass Abbts Tod für das Vaterland mit seiner Forderung nach absoluter Loyalität des preußischen Untertans in seiner Konsequenz in Kauf nimmt, dass Deutsche gegen Deutsche kämpfen. Mit der Verehrung Abbts als Kämpfer für die vaterländische - und das heißt in der neuen Zuschreibung: gesamtnationale - Sache ${ }^{49}$ wird in diesen literarischen Gruppierungen an einen enthusiastischen Vaterlandsbegriff appelliert, der sich auf einen aufopferungsvollen Heldenmut der Vorfahren beruft. ${ }^{50}$ Im Rahmen dieser Einbettung des Vaterlands in kriegerisch-heroische Zusammenhänge wird das Vaterland auch rhetorisch zum Objekt männlicher Begierde stilisiert: Es sind die Jünglinge und Männer, die sich ihm weihen und ihre Liebe zu ihm der zu den Frauen überordnen: „O Vaterland! o Vaterland! / Mehr als Mutter, und Weib, und Braut!“51 wird in Klopstocks Hermanns Schlacht von 1769 gerufen. ${ }^{52}$

47 Vgl. Johann Karl Wezels Lebensgeschichte Tobias Knauts, wo gegen die „Mode, fürs Vaterland zu sterben“ polemisiert wird. Es seien ganz andere Ursachen, die zum Eintritt in die Armee führten, dann aber „mit allen den schönen Phrasen von Ehre und Vaterlandsliebe“ verbrämt würden. Beide Wezel 1971, Bd. 2, S. 8-9.

48 Vgl. Moser 1765, S. 42- 43.

49 Vgl. Blum 1775, S. 14.

50 Zu den literarischen Diskursen ums Vaterland als Teil des neuen Nationalismus vgl. die Studie von Hans-Martin Blitz: Aus Liebe zum Vaterland. Die Nation im 18. Jahrhundert, vgl. Blitz 2000. 51 Klopstock 2009, S. 80.

52 Das Vaterland trägt bei Klopstock weibliche Attribute, seine männlichen Protagonisten sehnen sich „[i]n des Vaterlands Schooß“. Friedrich Gottlieb Klopstock: Der Zürchersee (1750), in: 
Hatte sich Abbt noch auf antike Beispiele heldenmütigen Sterbens berufen, etablieren die ,teutonisierenden' Patrioten (Wieland) der 1770er Jahre die Idee einer mythologischen Urgeschichte der Deutschen. In den verschiedenen Bearbeitungen des Arminius-Stoffs durch Klopstock von 1769, 1784 und 1787 wird der nun exzessiv verwendete Begriff des Vaterlands in Bilder des heroischen Selbstopfers gekleidet. Der Kampf gilt einem äußeren und einem inneren Feind, der äußere ist der antike Römer, der innere der Vaterlandsverräter, der mit dem Feind koaliert. Zugehörigkeit wird auch hier vornehmlich durch Exklusion erreicht.

Die Notwendigkeit der Abwertung anderer zugunsten des Vaterlands wird vom Wiener Professor für Polizey- und Kameralwissenschaft Joseph von Sonnenfels 1771 theoretisch begründet. Der Schutz der Gesetze und eine gute Regierung erzeuge Anhänglichkeit ans Vaterland, aber noch nicht die Vaterlandsliebe selbst. Man müsse darüber hinaus auch für sein Vaterland „partheyisch seyn“. ${ }^{33}$ Vaterlandsliebe sei „eine Erscheinung der Eigenliebe. Wir suchen unser eignes Beste, indem wir das Beste des Vaterlands suchen, wir lieben in dem Vaterlande uns selbst.“54 Sonnenfels dünkt es besser, „von andern Nationen mit Geringschätzung, als von der seinigen mit Gleichgültigkeit" ${ }^{\text {“55 }} \mathrm{zu}$ denken. Dabei geht es nicht um eine objektive Begründung, im Gegenteil:

\footnotetext{
Einigermassen ist es auch kaum möglich, einen hohen Grad von Vaterlandsliebe ohne Beymischung einer Verachtung gegen alles Auswärtige zu begreifen, sie mag nun billig seyn, oder nicht, diese Verachtung, auf wahre Vorzüge gegründet, oder auf eingebildete, oder auf bloß vorgespiegelte. In diesem Stücke vielleicht hauptsächlich, ist es offenbar, wie sehr die Eigenliebe der Hauptbestandtheil der Vaterlandsliebe ist. Die Eigenliebe ist beständig mit sich beschäfftiget, bey den offenbarsten Unvollkommenheiten findet sie einen Ausweg, um in der Vergleichung wohl noch zu gewinnen; oder um sich die Demüthigung eines Geständnisses zu ersparen, drückt sie die Augen fest zu; wie jene Eule am hellen Mittage gethan, damit sie sagen konnte: es ist Nacht. Die wechselweisen Nationalvorwürfe haben keinen andern Ursprung. Eine Nation erhebt immer, was die andre tadelt, und jede tadelt das
}

Klopstock 2010, S. 95-97, hier S. 97. Die Liebe zum Vaterland erscheint als erotisches Verhältnis zwischen dem hingebenden Mann und dem weiblich attribuierten Vaterland. „Ich liebe dich, mein Vaterland!“, ruft der Jüngling dem Vaterland mit umkränztem „Haupt“ und „sanfte[m] Lächeln“ zu, bevor er stirbt (alle Zitate Friedrich Gottlieb Klopstock: Vaterland [1768], in: Klopstock 2010, S. 320). Andersherum wird bei Klopstock dann auch der unmännliche, weil das Vaterland verkennende Mann von der Frau verstoßen: „Ich bin ein deutsches Mädchen! / [...] / Du bist kein deutscher Jüngling! / Mein ganzes Herz verachtet dich, / Der’s Vaterland / Verkennt, dich Fremdling! und dich Thor!“ Friedrich Gottlieb Klopstock: Vaterlandslied (1770), in: Klopstock 2010, S. 324.

53 Sonnenfels 1771, S. 11.

54 Sonnenfels 1771, S. 13-14.

55 Sonnenfels 1771, S. 21. 
was ihr mangelt. Gestände sie ein, daß es ein Vorzug wäre, so gestünde sie ja, daß ihr dieser Vorzug fehlte. ${ }^{56}$

Was Sonnenfels im Dienst politischer Instrumentalisierbarkeit analysiert, setzen die vaterländisch bewegten Dichter von Klopstock bis zu den Göttinger Hainbündlern mit den ästhetischen Mitteln der Empfindsamkeit um, und die so installierte Vorstellung eines nationalen Vaterlands, das allen anderen Nationen überlegen ist und für das man, wenn nötig, sein Leben lässt, setzt sich im weiteren historischen Verlauf durch.

$\mathrm{Zu}$ einer schärferen Profilierung dieses neuen Vaterlandsbegriffs trägt Heimat insofern entscheidend bei, als der Begriff eine Spaltung in ein kämpferisch eingefordertes Vaterland und eine empfindsam geliebte Heimat möglich macht. Diese Profilierung ist noch keine Sache Klopstocks, aber dann schon der um eine Generation jüngeren Mitglieder des Hainbunds. In Klopstocks Drama HermannsSchlacht (1769), in dem unablässig jene gepriesen werden, „die ihr Vaterland mehr als ihr Leben liebten“, ${ }^{57}$ gibt es noch keine ,Heimat'. Klopstocks Heimaten sind noch rein religiöse, ${ }^{58}$ und das heißt, dass Heimat für Bearbeitungen des ArminiusStoffs im 18. Jahrhundert - das gilt aus anderen Gründen auch für Möser und Wieland - nicht disponibel ist. ${ }^{59}$

Heimat spielt im Umfeld des Göttinger Hainbunds in der neuen Semantik von Vaterland und Nation eine zwar gemessen an den weiteren Entwicklungen noch untergeordnete Rolle. Ihre zukünftige Funktionalisierung als weiblich codierter Part innerhalb eines nationalen Vaterlandsdiskurses zeichnet sich aber schon ab, wie das Gedicht Mein Vaterland, an Klopstock (1779) des Hainbündlers Friedrich Leopold zu Stolberg-Stolberg zeigen kann.

Das Gedicht setzt ein mit Bildern der Größe, Kraft und Erhabenheit; der Adler, der Schwan, die donnernde Woge untermalen den ,stolzen` Gesang, der dem Vaterland gilt:

56 Sonnenfels 1771, S. $23-24$.

57 Klopstock 2009, S. 80. Schon 1752 verwendet Klopstock den Arminius-Stoff für die Ode Hermann und Thusnelda, in der auch schon blutig, aber schön gestorben wird. Vgl. Friedrich Gottlieb Klopstock: Hermann und Thusnelda, in: Klopstock 2010, S. 124.

58 Im Messias wird Heimat durchgängig im Sinn einer himmlischen Heimat verwendet, vgl. Klopstock 1769, S. 213 und S. 253; Klopstock 1773, S. 61, S. 74 und S. 153.

59 Schon Justus Möser hatte in seinem Arminius von 1749, allerdings unter gänzlich anderen Vorzeichen, die „germanische Urgesellschaft“ als Idealbild menschlicher Gesellschaft entworfen. Weitere Hermann-Bearbeitungen gibt es von Johann Elias Schlegel, Freiherr von Schönaich und Wieland, auch diese kommen ohne Heimat aus. Das gilt auch noch für Heinrich von Kleists Hermannsschlacht von 1808. Zum Arminius-Stoff allgemein vgl. Essen 1998 und Wagner-Egelhaaf 2008. 
Das Herz gebeut mir! fiehe, fchon fchwebt, Voll Vaterlandes, ftolz mein Gefang! Sturrmender fchwingen fich Adler Nicht, und Schwåne nicht to̊nender!

An fernem Ufer raufchet fein Flug! Deß ftaunt der Belt und zürnet und hebt Donnernde, fchåumende Wogen; Denn ich finge mein Vaterland! ${ }^{60}$

Das Vaterland wird in den folgenden Strophen mit „alter Treue“, mutigen Männern, sittsamen Mädchen und „Zucht“ in den Hütten verbunden, also mit der Zuschreibung eines Nationalcharakters. ${ }^{61}$ Das sich steigernde Pathos kulminiert im Ausruf des lyrischen Subjekts: „Ich bin ein Deutscher! (Stürzet herab / Der Freude Thränen, daß ich es bin!)“ und fügt hinzu:

\author{
Von dir entfernet weih' ich mich dir, \\ Mit jedem Wunfche, heiliges Land! \\ Grüffe den füdlichen Himmel \\ Oft, und feufze der Heimat zu! \\ Auch greifet oft mein nerviger Arm \\ Zur linken Hưfte; manches Phantom \\ Blutiger Schlachten umflattert \\ Dann die Seele des Sehnenden. \\ Jch hơre fchon der Reifigen Huf, \\ Und Kriegsdrommete! fehe mich fchon, \\ Liegend im blutigen Staube, \\ Růhmlich fterben fưr's Vaterland! ${ }^{62}$
}

Das Vaterlandspathos wird hier religiös gesteigert und in Erhabenheitsformeln mit dem Nationalcharakter der Deutschen verbunden. In diese dominante Vaterlandsmetaphorik wird auch Heimat eingetragen. Sie ist Teil des Enthusiasmus fürs Vaterland, allerdings anders konnotiert. Für das Vaterland stirbt das Subjekt des Gedichts, der Heimat ,seufzt' es ,zu' ${ }^{63}$ Heimat wird im weiteren Umfeld des Göttinger Hainbundes, etwa beim Schweizer Autor Johann Gaudenz von SalisSeewis, mit dem Code der Empfindsamkeit zusammengeführt: Gefühl und Idylle,

60 Stolberg-Stolberg 1779, S. 60.

61 Stolberg-Stolberg 1779, S. 61.

62 Beide Zitate Stolberg-Stolberg 1779, S. 62-63.

63 Stolberg-Stolberg 1779, S. 62. 
Sittlichkeit und Natur, Wehmut und Seelenfülle beginnen sich mit Heimat zu verbinden. ${ }^{64}$

Dass Texte wie die von Stolberg-Stolberg und Salis-Seewis allerdings erst an der Schwelle zu einer neuen Heimatsemantik stehen, zeigt sich darin, dass Vaterland im Umfeld des Hainbunds noch Aspekte umfasst, die sich in der Folge in die Semantik von Heimat verschieben. Im Gedicht Vaterlandsliebe (1794) von Voß umschließt das Vaterland sozusagen noch alle Aspekte, die sich später in einen Bedeutungsgehalt von Vaterland hier und einen von Heimat dort ausdifferenzieren werden. Das Gedicht beginnt mit einer polemischen Abrechnung mit einer aufgeklärt-kosmopolitischen Haltung:

Ein edler Geist klebt nicht am Staube;

Er raget über Zeit und Stand:

Ihn engt nicht Volksgebrauch noch Glaube, Ihn nicht Geschlecht noch Vaterland.

Die Sonne steig und tauche nieder;

Sie sah und sieht ringsum nur Brüder:

Der Kelt und Griech und Hottentott

Verehren kindlich einen Gott.

Dieser Haltung haftet ein ,Umsonst‘ an; der Mensch bleibt, ob er will oder nicht, dem ,Erdenkloß` verbunden, ,der ihn gebar‘, so die zweite Strophe. Vaterlandsliebe assoziiert sich also mit dem Leiblichen, Gebärenden, Erdigen und, wie die dritte Strophe zeigt, auch mit dem Vertrauten, den Menschen, Gegenständen und Sitten des Herkunftsortes - also mit all dem, was wenige Jahre später immer der Heimat-, nicht der Vaterlandsliebe zugeordnet werden wird. Mit des „heimischen Gefildes Raum“ wird Heimat eben unter Vaterland subsumiert:

Er liebt die traute Vaterhütte,

Den Ahorntisch, des Hofes Baum,

Die Nachbarn und des Völkleins Sitte,

Des heimischen Gefildes Raum.

Er liebt die treuen Schulgenossen,

Der Jugendspiel harmlose Possen,

Das angestaunte Bilderbuch,

Der Mutter Lied und Sittenspruch.

Auch Sprache, Sehnsucht und Weinen, die in der vierten Strophe beschrieben werden, sind Aspekte, die hier noch dem Vaterland zugeordnet sind:

64 Vgl. dazu ausführlicher das Kapitel II.1.2. Salis-Seewis wurde durch Johann Heinrich Voß publiziert. 


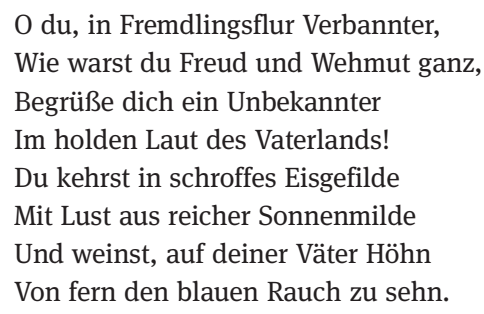

„Dann lieber arm im Vaterland / Als fern in Sklavenprunk verbannt!“, resümiert die fünfte Strophe. „Glückselig“ bezeichnet die letzte Strophe denjenigen, der „daheim“ als Vorbild eines „guten Bürger[s]“ gelte; hier sind noch Rudimente des alten Patriotismusbegriffs zu finden, der die Wohlfahrt der Allgemeinheit im Blick hat:

\footnotetext{
Nicht eigensüchtig wirbt er Seines;

Sein Herz, entbrannt für Allgemeines,

Verschwendet Kraft und Fleiß und Gut

Und, gilt es Wohlfahrt, gern das Blut. ${ }^{65}$
}

Das Heimische - als das „daheim“ und „des heimischen Gefieldes Raum“ - steht mit der „Vaterlandsliebe“, dem „Vaterland“, der „Vaterhütte“ und der „Väter Höhn" hier noch in keinem antipodischen Verhältnis.

Insofern steht dieses Gedicht erst am Beginn einer Ausdifferenzierung von Vaterland und Heimat, die in den folgenden Jahrzehnten intensiv vonstattengeht. Denn was hier noch teilweise Ähnliches meint, trennt sich im weiteren Verlauf in zwei klar aufeinander bezogene, aber doch ebenso klar unterschiedene Ideen: Der Geist, der bei Voß noch negativ konnotiert für den kosmopolitischen steht, wird dann positiv der Vaterlandsliebe zugeschrieben, die als abstraktere, intellektuellere Idee des größeren Ganzen gilt. Die Emotion gilt der Heimat, die mit der Erde, dem Leiblichen und Vegetativen verknüpft ist. Besonders an Ernst Moritz Arndt wird sich zeigen lassen, wie sich Vaterlandsliebe als aktives, intellektuelles, aggressives, politisches und männliches Konzept und analog Heimat als passives, gefühlvolles, befriedendes, (vorgeblich) unpolitisches und weibliches Konzept etabliert (vgl. II.1.2).

Die Spaltung des neuen Patriotismus in eine Vaterlandsliebe als Bereitschaft zum Tod und eine Heimatliebe als sentimentale Bindung geht mit einer geschlechtsspezifischen Polarisierung einher (vgl. I.2.3). Der männliche Teil tritt als aktiv Liebender in Erscheinung (nämlich als Vaterlands- und als Heimatlieben-

65 Johann Heinrich Voß: Vaterlandsliebe, in: Voß 1983, S. 261-262. 
der) und der weibliche als passives Korrelat: Die Heimat wird geliebt. Auch das Vaterland wird in dieser Polarität zum Gegenstand, aber zu einem, der seinerseits männlich codiert ist. Denn der Liebhaber des Vaterlands muss ja gerade seine individuelle Liebe zu einer individuellen Frau überwinden, um für das Vaterland kämpfen und sterben zu können: „O Vaterland! o Vaterland! / Mehr als Mutter, und Weib, und Braut!" ${ }^{66}$ Um die Heimat, die öfter mit der Mutter als mit der Geliebten konnotiert ist, darf auch der männliche Held weinen. Aus dieser Codierung ergibt sich einerseits ein Gefälle von Vaterland und Heimat - die sentimentalen Gefühle zur Heimat müssen zurückgestellt werden, um dem größeren Ganzen des Vaterlandes zu dienen (vgl. II.1.2) -, andererseits aber auch ihre Zusammengehörigkeit: Vaterland und Heimat sind wie Mann und Frau dann Polaritäten, die einander ergänzen.

Zusammengehörigkeit wie Hierarchie zwischen Vaterland und Heimat macht Friedrich Rückerts Zeitgedicht Des Rheinstroms Lied (1816) anschaulich, in dem der deutsche Sieg in den sogenannten Befreiungskriegen als Nukleus neuer politischer Einheit erscheint. Diese Einheit überwindet das Partikulare. Die deutschen Flüsse von der Saar bis zur Elbe werden als heimkehrende Krieger vorgestellt, die von ihrem Vater, dem Rhein, empfangen werden. Er gibt ihnen den Rat mit auf den Weg, sich das neue Bewusstsein der Zusammengehörigkeit zu bewahren: „Wenn ihr denn als einzle Glieder / In die Heimat fahret, / Denket zu dem Rheine nieder, / Wo ein Leib ihr waret. “67 Während die vielen Heimaten partikular und verstreut sind, ist das Vaterland der eine ,Leib` - dieses größere Ganze bleibt aber auf das Einzelne verwiesen.

Von dieser dominanten Verhältnisbestimmung zwischen regionaler Heimat und nationalem Vaterland gibt es nur wenige Ausnahmen. Eine dieser Ausnahmen artikuliert sich bei Friedrich Ludwig Jahn. In Deutsches Volksthum von 1810 wird das Gefälle zwischen Vaterland und Heimat so ins Extrem getrieben, dass Heimat nicht länger eine Vorstufe oder das Komplement des Vaterlands ist, sondern bloßer Ausdruck der Kleingeistigkeit der „Kleinstädter“, die immer „denselben Koth durchtreten“ und dieselben „Klöße“ essen. Jahns Utopie ist die Überwindung solcher „Landsmannschaftsucht“. ${ }^{68}$ Nicht „kindisches Zurückverlangen nach der Erdscholle“, sondern „Sehnsucht nach dem Vaterlande“ als „Wohnsitz alles Geliebten“:69 Und dieses Geliebte soll das ganze Deutschland

66 Klopstock 2009, S. 80.

67 „Einzeln seid ihr doch nicht besser / Als die Wiesenbäche; / Aber wenn ihr, deutsche Flüsse, / Strömet eure Wassergüsse / In ein Bett, in eines, / Dann ists groß, ich mein’ es.“ Friedrich Rückert: Des Rheinstroms Lied, in: Rückert 2009, S. 368-372, hier beide Zitate S. 372.

68 Alle Zitate Jahn 1810, S. 118-119.

69 Alle Zitate Jahn 1810, S. 270 - 271. 
sein. Das ,Heimische‘ sucht Jahn umzudeuten: Nicht der einzelne Fleck, sondern eben der ganze - noch utopische - Nationalstaat soll dem Menschen „heimisch, wie die Geburtsstätte unsers Daseins “70 werden. Dieses Ziel verbindet Jahn mit der Idee des Wanderns: Im Wandern könne der Deutsche sich viele Gegenden heimisch machen. Und das „auswärts gesehene Gute“ könne der Wanderer „in die Heimath [...] verpflanzen“. ${ }^{71}$ Wer dagegen nicht reise, erweise sich als „halb blöde“, wie Jahn u.a. etymologisch und anhand von Sprichwörtern nachzuweisen sucht. Auch Heimat kommt in diesen sprachhistorischen Überlegungen ausgesprochen schlecht weg:

Noch jetzt beurkunden Sprichwörter des Reisetriebs Deutschheit. „Er ist nicht hinter dem Ofen der Mutter weggekommen;“ „Er weiß nicht ein Mahl wo Barthel Most hohlt;“ „Er ist so dumm als der Nagel in der Wand;“ „Er hat sich keinen Wind um die Nase wehn lassen;“ und so viele andere schmähen auf das Ungereisetsein. Ja bei unsern fernsten Stammvettern den Isländern „hatte (nach Schlözer's Nordischer Geschichte Seite 557) der dumme, der abgeschmackte, der hämische, der dummdreiste Mensch, der sich vor andern immer etwas herausnimmt, und der Ungereisete Einen Namen: Alle hießen HEIMSKR (Heimlinge) von HEIMA daheim; und es ward ein Sprichwort: HEIMSKT ER HEIMALIT BARN, Kinder die bloß zu Haus erzogen werden (HIEMFÖDNINGE), sind dumm. "So das Schwedische HEMSK, halb blöde, halb schwermüthig, wie das Sassische blott. Aber gegen eine unverständige Aushäusigkeit eifern Sprichwörter eben so sehr: „Es flog ein Gänschen über den Rhein / Und kam als Gigak wieder heim. “72

Jahn will keine ,Heimlinge‘, die zu Hause sitzen und nur in den Grenzen ihres Dorfes denken, sondern über die (damaligen) Landesgrenzen hinausschauende Deutsche, denn nur so lernten sie, sich als Nation zu begreifen. Sein Weckruf an die ,verspätete Nation' (Helmuth Plessner) zielt darauf, regionale Identitäten zu überwinden, um eine nationale zu gewinnen. Auch wenn Jahn ein Vermittlungsangebot zwischen Heimat und Nation macht - das größere Nationale könne „uns heimisch, wie die Geburtsstätte unsers Daseins“73 werden, wenn wir es kennen lernten -, wertet er andererseits das Regionale recht drastisch ab. Diese Argumentationsfigur, regionale Heimat und nationales Vaterland gegeneinander auszuspielen, ist so gut wie einmalig in den Nationalstaatsdiskursen des 19. Jahrhunderts, die im Gegenteil für Heimat eine der Nation zuarbeitende

70 Jahn 1810, S. 442.

71 Beide Zitate Jahn 1810, S. 443. „Wandern, Zusammenwandern, erweckt schlummernde Tugenden, Mitgefühl, Theilnahme, Gemeingeist und Menschenliebe. Steigende Vollkommnung, Trieb nach Verbesserung, gehen daraus hervor, und die edle Betriebsamkeit das auswärts gesehne Gute in die Heimath zu verpflanzen.“ Jahn 1810, S. 443.

72 Jahn 1810, S. 444- 445.

73 Jahn 1810, S. 442. 
Funktion vorsehen. ${ }^{74}$ Zwar dominiert im politischen Kontext eine Hierarchie zwischen Heimat und Vaterland, aber das Verhältnis zwischen beiden wird in der Regel immer als Bedingungs-, nicht als Ausschlussverhältnis definiert.

Die Position Jahns zeigt ein Potential des Verhältnisses von Heimat und Vaterland/Nation, das strukturell eigentlich sehr naheliegend ist, real aber kaum ausgeschöpft wurde: nämlich ein tatsächlich antagonistisches. Ein solches die Gegensätzlichkeit betonendes Verhältnis ist andersherum - also gegen die Nationalidee - gewendet auch beim Pädagogen Friedrich August Finger (vgl. II.3.1) $\mathrm{zu}$ finden, der in seiner Heimatskunde von 1844 Heimatkunde als empirisch fundierte Aneignung des die lernenden Kinder unmittelbar umgebenden Raums versteht und explizit von religiöser ebenso wie von nationaler Gesinnungsbildung abgrenzt. Heimat lasse sich nicht „nach politischen Rücksichten“, ${ }^{75}$ sondern ausschließlich nach geographischen erkunden, und so sei es selbstverständlich, dass der Heimatkundeunterricht beispielsweise in Saarbrücken auch französisches Gebiet umfasse. Heimat erscheint hier nicht als die kleinste Einheit des (National-)Staates, sondern als eine gerade nicht an politische Grenzen gebundene Größe. Finger ist einer der ganz wenigen Autoren, gleich welcher Disziplin, die Heimat gegen nationalstaatliche Interessen in Stellung bringen. Historisch hat sich diese plausible Möglichkeit genauso wenig manifestiert wie Jahns umgekehrter Ansatz, die Idee des Nationalstaats gegen Heimat auszuspielen.

Intrikat zeigt sich das Verhältnis von regionaler, lokaler Heimat und gesamtdeutscher Idee auch in Bezug auf die rechtliche Seite von Heimat. Denn das regional geltende Heimatrecht führte in Zeiten zunehmender Migration zu immer größerer Existenzbedrohung insbesondere der Armen. Die Verwerfungen des Heimatrechts wurden über Jahrzehnte als Problem des politischen Partikularismus diskutiert, man fand aber zu keiner Lösung. „Für Deutschland wird übrigens der Wunsch eines allgemeinen deutschen Heimatgesetzes immer dringlicher und vielleicht in keinem Zweige der Gesetzgebung wirkt die Verschiedenheit so nachtheilig“", ${ }^{76}$ notiert die Allgemeine deutsche Real-Encyklopädie für gebildete Stände 1845 - das Problem dauerte an und auch die Reichsgründung 1871 vermochte nicht, hier einheitliches Recht einzuführen (vgl. II.2.1).

Statt aber die theoretisch plausible und praktisch teils erfahrene Gegensätzlichkeit von Heimat und Nation hervorzukehren, ist die dominante rhetorische Strategie des 19. Jahrhunderts im Gegenteil die, beide in ein Bedingungsverhältnis

74 Vgl. für die historische Forschung Applegate 1990 und Confino 1997; für die literaturwissenschaftliche Forschung Schumann 2002.

75 Finger 1876, S. 4.

76 Anonym 1845, S. 2. 
zu überführen: „Aus Heimatliebe wächst die Vaterlandsliebe.“77 Das darin zum Ausdruck kommende teleologische Denken findet sich etwa auch in den zeitgenössischen Geschichtswissenschaften. Geschichte erscheint hier als eine Bewegung von Heimat zu Nation, etwa beim Althistoriker Ernst Curtius (1814-1896): „Je freier der Horizont, desto kühner geht der Blick auf das Große und Ganze“, schreibt er über die historischen Entwicklungen im antiken Griechenland, „aus der Heimath wird ein Vaterland, wo Leute aus verschiedenen Gauen sich mit einander einleben und ihrer großen Gemeinschaft bewußt werden“78 (vgl. auch II.3).

Gustav Freytags Geschichtsepos Die Ahnen wird in dieser Studie ausführlich unter dem Aspekt der Rede von Heimat zum (höheren) Zweck der Nationalstaatsbildung untersucht (vgl. II.3.1.2). An der Freytag-Rezeption sieht man exemplarisch, wie in diesem Zusammenhang mit organologischen Metaphern gearbeitet wird, die Heimat als Boden, Erde oder Wurzelgrund vorstellen, aus der der Mensch oder das Volk hervorgehen und dem Vaterland entgegenwachsen. ${ }^{79}$

Die Rhetorik der in der Heimat wurzelnden Vaterlandsliebe (zur Geschlechtscodierung dieses Bildes vgl. I.2.3) findet sich in allen gesellschaftlichen Bereichen insbesondere der zweiten Hälfte des 19. Jahrhunderts, etwa auch in der Pädagogik. Der Pädagoge Friedrich Heußner stellt eine aufsteigende Linie von der Heimat- zur Vaterlandsliebe, die der Schulunterricht zu entwickeln habe, in solchen Metaphern her. In der Heimatliebe sei

ein fester Ausgangspunkt für eine Theorie des Lehrplans, für ein Lehrplansystem gewonnen, um von da aus die Fäden zu den andern Unterrichtsstoffen hinüberzuspinnen, ein machtvolles, lebendig wirkendes Centrum des Unterrichts, von dem aus gleichsam unzählige Saugwurzeln und Arme den neu sich darbietenden Stoffen aus der Sinnen- und Geisteswelt, mögen diese auch noch so weit entlegenen Gebieten anzugehören scheinen, sich entgegenrecken, um sie zu erfassen, an sich zu ziehen, sich zu assimilieren und in den Dienst eines neuen geistigen Wachstums zu vollerer, vertiefter und geläuterter Auffassung und zu vollerem Verständnis vaterländischen Lebens und Wesens zu ziehen. ${ }^{80}$

77 Mollberg 1916, S. 7.

78 Curtius 1875, S. 376.

79 Der Begriff des Organismus wird schon im 18. Jahrhundert in Gesellschafts- und Geschichtsmodellen verwendet; vgl. Metzger 2002. Zu den wechselseitigen Beeinflussungen biologischer, philosophischer und soziologischer Organismus-Terminologien vgl. Töpfer 2011. Die Rhetorik des Organischen in Bezug auf Heimat wird mit Wilhelm Heinrich Riehl in der zweiten Hälfte des 19. Jahrhunderts omnipräsent. Zur völkischen Metapher vom (Heimat-)Boden als Wurzelgrund des Volkes vgl. Mosse 1991, S. 34.

80 Heußner 1892, S. 4. 
Während die Ausbildung von ,Heimatgefühl` nach Heußner im Zentrum der pädagogischen Bemühungen stehen soll, liegt deren Ziel in der Entwicklung von Vaterlandsgefühl. Der Pädagoge bereitet in diesem Bild den Boden für das Wachstum seiner Schützlinge. Durch die Metaphorik des Spinnens, Streckens, Fassens und Saugens wird suggeriert, es handle sich um einen sich zwingend vollziehenden, gleichsam natürlichen Vorgang (vgl. II.3.1.2).

Andreas Schumann hat in seiner Studie zum Zusammenhang von Heimat und Nation im 19. Jahrhundert anhand von Anthologien, Almanachen und Jahrbüchern literarischer Vereine belegt, dass die literarischen Heimaten dieses Epochenzusammenhangs sich auffällig gleichen. Heimat sei ein so gut wie austauschbares Stereotyp, in das wahlweise die Nordsee oder die Alpen eingesetzt werden könnten. Das ist wesentlich für Schumanns Argument, Heimat sei in den Dienst des Nationalen gestellt worden. ${ }^{81}$ Andersherum gibt es in dieser Logik nicht nur die vielen regionalen, letztlich aber austauschbaren Heimaten, sondern verstärkt ab 1900 auch solche, die Anspruch erheben, Heimat aller Deutschen zu sein, wie ein Reiseführer für Weimar mit dem Titel Weimar. Eine Wallfahrt in die Heimat aller Deutschen nahelegt. ${ }^{82}$ In einem Sängerpass des Deutschen Sängerbundes, in dem die Zugehörigkeit $\mathrm{zu}$ bestimmten Männergesangsvereinen ${ }^{83}$ nachgewiesen wurde, ist auf der ersten Seite die Wartburg abgebildet, begleitet von Versen, die die „Heil'ge Heimat“ besingen - auch hier also eine Heimat, die sich an ein im 19. Jahrhundert ausgebildetes Nationalstaatssymbol anschmiegt, das für alle Deutschen ,Heimat‘ sein soll. Heimat steht damit für den Vertreter

81 Vgl. Schumann 2002.

82 Vgl. Schrickel 1926; ein Reiseführer, der kein konventioneller sein will, es gehe um „die Seele“ der Stadt, nicht um Sehenswürdigkeiten. Der Leser solle das „hinter den Gegenständen stehende, ewig Unvergängliche, ewig gestaltenden Leben schauen“ und eine religiöse Haltung einnehmen: „[W]ir wenden uns an die Pilger, die nach innen leben, und die nicht sehen, sondern schauen wollen.“ Alle Zitate Schrickel 1926, Vorwort, o.S.

83 Ina-Maria Greverus spricht der Männergesangsbewegung die entscheidende Rolle für die Breitenwirkung des Heimatdiskurses in Verbindung mit dem deutschen Nationaldiskurs zu: „In der ersten Hälfte des 19. Jahrhunderts hatte Deutschland zahlreiche Heimatbegriffe, die von mehr oder weniger kleinen elitären Gruppen getragen wurden. Zwischen der Sehnsuchtsheimat der Romantiker und dem kleinen Heimatglück des ,zufriedenen Landmanns‘ eines Joh. Peter Hebel, zwischen der mit altgermanischen Helden bevölkerten Vaterlands-Heimat der politisch Engagierten und der biedermeierlichen ,Familienglück'-Heimat eines resignierten Bürgertums, zwischen der Kulturnational-Heimat der Nationalromantiker und der Archiv- und Dorflebensheimat der Regionalforscher bestanden wenig Verbindungslinien, und somit ergaben sich auch wenig Möglichkeiten einer Breitenwirkung in das in all diesen Heimatbegriffen des Mittelstandes doch immer wieder anvisierte ,Volk‘. Die erste Breitenwirkung erlangten diese verschiedenen Heimatbegriffe, unter Betonung des Vaterländischen, in der deutschen Männergesangsbewegung.“ Greverus 1972, S. 303-304. Zur Rolle der Gesangsvereine vgl. auch Kap. II.1.2. 
Wilhelm Vieweg, geboren im sächsischen Mylau, nicht mit dieser regionalen Zugehörigkeit in Zusammenhang, sondern mit der Thüringer Wartburg als Symbol gesamtnationaler Identität (Abb. 18).

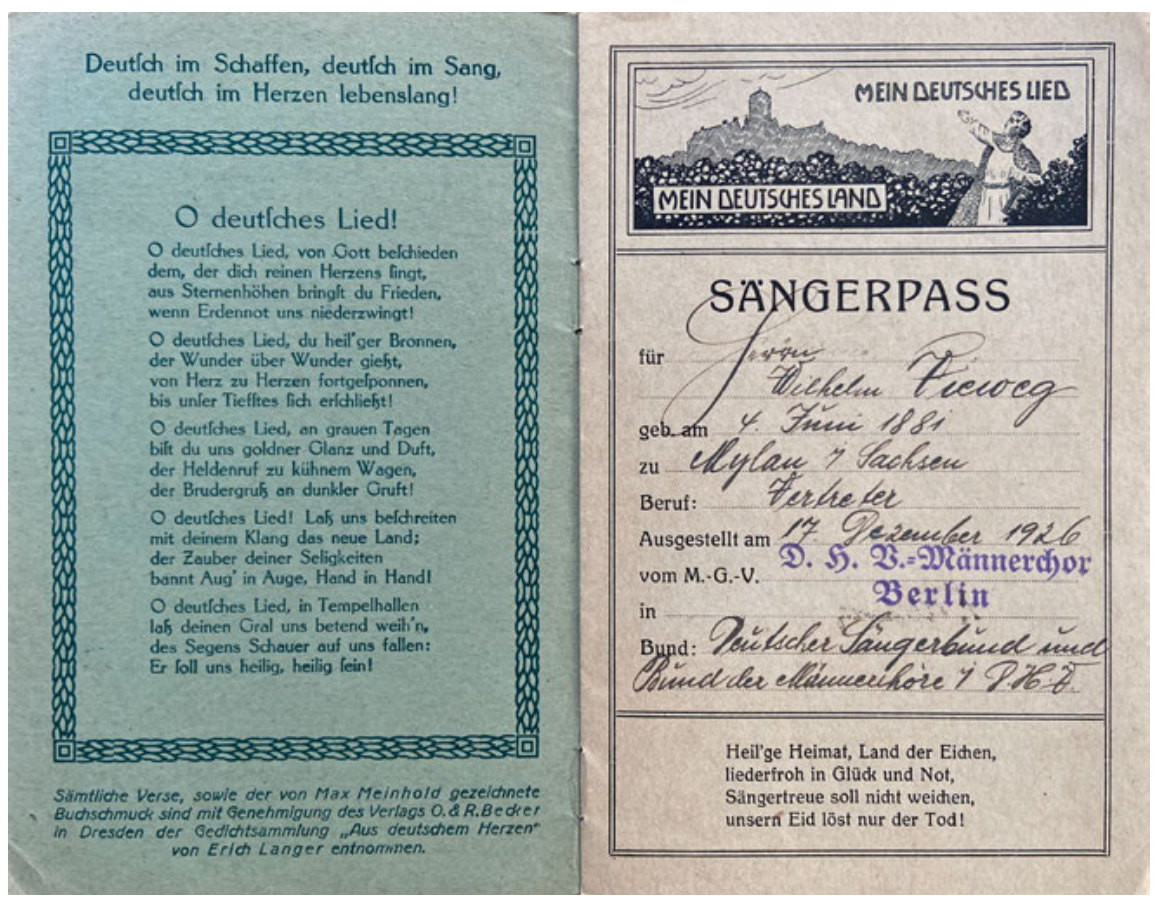

Abb. 18: Sängerpass des Deutschen Sängerbundes von Wilhelm Vieweg, ausgestellt am 17.12.1926 (Privatbesitz Anja Oesterhelt)

Es ist sicher kein Zufall, dass das Hierarchiegefüge zwischen Heimat und Vaterland sich nach der Reichsgründung von 1871, also der Verwirklichung der Nation als Staat, ein weiteres Mal verschiebt, und zwar im Sinn einer zunehmenden Identifizierung von Heimat, Vaterland und Nation. Die Heimatsemantik diffundiert in die von Staat und Nation, so dass Heimat im föderativen Nationalstaat immer öfter geradezu als Repräsentantin der Nation erscheint. ${ }^{84}$ Das

84 Für die Beziehung zwischen Heimat- und Nationaldiskurs ab 1871 vgl. Confino 1997. Der Historiker Alon Confino untersucht in seiner exemplarisch am Verhältnis von Württemberg zum Deutschen Reich entwickelten Studie The Nation as a Local Metaphor. Württemberg, Imperial Germany, and National Memory, 1871-1918 die ,Idee‘ der Heimat einerseits als vermittelndes Konzept zwischen lokalem Leben und abstrakter Nation, andererseits als Repräsentantin der 
Bekenntnis zum Regionalen stand dabei nicht im Widerspruch zum Nationalstaat. ${ }^{85}$ Die Besinnung auf Heimat wird zu dem Zeitpunkt am stärksten eingefordert, als sich die politische Idee des nationalen Vaterlandes verwirklicht hat. Die erreichte politische Einheit in Form des Deutschen Reiches muss in der politischen Rhetorik der Zeit nun noch ,beseelt‘ werden, und dafür eignet sich der gemütsschwangere Begriff der Heimat besser als der kämpferische des Vaterlands. So schreibt Julius Langbehn in seinem u. a. auch für die sogenannte Heimatbewegung einflussreichen Buch Rembrandt als Erzieher, wieder in die Metaphorik des Bodens gekleidet, die politische Heimat - hier also verstanden als der Nationalstaat - sei gefunden, die künstlerische noch nicht. Nur diese künstlerische Heimat, die sich bei Langbehn mit Seele und Gemüt verbindet, könne den Deutschen aber zu sich selbst kommen lassen. Nur „durch ein Eingehen auf den besonderen lokalen Charakter der einzelnen Gegenden Deutschlands“ könne wieder „zur Verschiedenheit, Mannigfaltigkeit, Naivität der künstlerischen Produktion“ und auf diese Weise auch zum „Deutschthum“ gelangt werden:

Die irrende Seele der Deutschen, welche sich künstlerisch jetzt in allen Erd- und Himmelsgegenden umhertreibt, muß sich wieder an den heimathlichen Boden binden; der holsteinische Maler soll holsteinisch, [...] malen: durch und durch, innerlich und äußerlich, gegenständlich wie geistig. Auf dieses uralte Volksrecht muß man zurückgreifen; eher wird eine Wendung zum Bessern nicht eintreten; eher wird der Deutsche, der politisch eine Heimath gefunden, eine künstlerische Heimath nicht finden.“"86

Nation. Confino versteht Heimat als Teil des Moderne-Projekts, als Suche nach einer Koexistenz von lokaler und nationaler Identität. Ergebnisse seiner Studie sind im Aufsatz Konzepte von Heimat, Region, Nation und Staat in Württemberg von der Reichsgründungszeit bis zum Ersten Weltkrieg zusammengefasst, vgl. Confino 2000. Zur nationalidentitätsstiftenden Funktion von Heimat für die Zeit um 1900 vgl. Hartung 1991.

85 „Der historisch überkommene Föderalismus hat mit der Nationalstaatsgründung seine Zielrichtung radikal geändert. Föderativer Nationalismus richtete sich jetzt nicht mehr gegen einen Nationalstaat, der die historisch gewachsene staatliche Vielfalt überwindet, indem er die Einzelstaaten zu Ländern mediatisiert. Im Gegenteil, weil er regionale und einzelstaatliche Traditionen kulturell verteidigte, trug der föderative Nationalismus nun wesentlich dazu bei, daß der neue Nationalstaat in der deutschen Gesellschaft breit und schnell akzeptiert wurde. Man wuchs in den Nationalstaat hinein, indem man sich als Föderalist oder Regionalist bekannte. Die Heimatbewegungen stritten nicht gegen den Nationalstaat, sondern machten ihn annehmbar, weil sie ihn föderativ ausgestalteten.“ Langewiesche: Föderativer Nationalismus, 2000, S. 241.

86 Alle Zitate Langbehn 1890, S. 19. Das Buch erlebte innerhalb der ersten zwei Jahre nach Erscheinen im Jahr 1890 neununddreißig Auflagen. Hier ist nach der neunten Auflage zitiert. 
Wie hier bei Langbehn wird allerorten die Rolle des Künstlers und Dichters für die Bildung von Heimatbewusstsein herausgehoben. ${ }^{87}$

Auch das Verhältnis zwischen der Heimat und dem Tod für das Vaterland ändert sich. Am Anfang des langen 19. Jahrhunderts starb man, wie bei StolbergStolberg und Arndt, fürs Vaterland und seufzte nach der Heimat. 1870 untertitelt die Gartenlaube eine Illustration von Paul Thumann mit den Worten: „Wie unsere Leute draußen im Feld in die Heimath schreiben“ (Abb. 19). Hier ist schon ein Zusammenhang von Heimat und Krieg hergestellt, aber die Differenz bleibt: Die Soldaten sterben im dem Bild zugeordneten Text immer noch ausschließlich für Volk und Vaterland, ${ }^{88}$ während sie im Bild während einer Kampfpause in die Heimat schreiben. ${ }^{89}$

Am Anfang des 20. Jahrhunderts wird genauso häufig wie für Volk, Nation und Vaterland für die Heimat gestorben: Das Volksliederbuch für gemischten Chor, hg. auf Veranlassung seiner Majestät des deutschen Kaisers Wilhelm II., so heißt es im Vorwort Max Friedländers von 1915, will die „Liebe zur Heimat“ befördern, vor „der Gefahr eines Gesinnung und Kunst bedrohenden, verwässernden Kosmopolitismus“ bewahren und das deutsche Volk ,in den schweren Schicksalsstunden des deutschen Vaterlandes“ stärken. ${ }^{90}$ Waldemar Bonsels, der Autor der Biene Maja, von der noch die Rede sein wird, bringt seine Kriegsberichte aus dem Ersten Weltkrieg unter dem Titel Heimat des Todes. Empfindsame Kriegsberichte (1916) heraus. Die „Parole Heimat“ (Abb. 20) wird das Motto der Feldpost des Ersten Weltkriegs, unter dem ganze Postkartenserien stehen (Abb. 21-22). Der Schriftleiter der Zeitschrift Die Heimatkunst, Ernst Ludwig Schellenberg, ge-

87 Die herausgehobene Stellung des Dichters wird etwa auch in einem Text Roseggers für den Heimgarten von einer seiner fiktiven Figuren betont: „Wer sollte uns sagen von Heimat und Vaterland, von Kaiser und Reich, wenn nicht des Dichters Wort, des Sängers Lied, des Künstlers Gestalten? Wer sollte uns begeistern im Kampf gegen den Feind, daß wir freudig Gut und Blut hingeben fürs Vaterland? Das Lied.“ Rosegger 1889, S. 702.

88 Der Gartenlaubentext von Ludwig Pitsch beschreibt die Geschehnisse kurz nach dem Einmarsch der Deutschen in Versailles. „Als der in seiner markigen Anrede an die Soldaten hinwies auf die Größe dieses Augenblickes, und seine stolze Freude gestand, sie die für Deutschland so heroisch gekämpft, geblutet und gesiegt hätten, gerade hier an dieser Stelle, unter dem stolzen Bilde des Übermüthigen alten und schlimmen Feindes ihres Volks und Vaterlandes, mit den wohlverdienten geweihten Zeichen schmücken zu können, mit welchen der oberste Kriegsherr die Thaten der Deutschen ehre, sah man auch jene festen, eisernen Männer ringsum von der tiefsten Bewegung ergriffen und erschüttert." Pitsch 1870, S. 750.

$89 \mathrm{Zu}$ Bild-Text-Bezügen in Zeitschriften des 19. Jahrhunderts vgl. Podewski: Abbilden und veranschaulichen, 2016 und Podewski: Mediengesteuerte Wandlungsprozesse, 2016.

90 Alle Zitate Friedländer 1915, o.S. Das Liederbuch enthält die Rubriken „Ernstes und Erbauliches“, „Vaterland und Heimat“, „Natur“, „Wandern und Abschied“, „Lieder für Soldaten, Jäger, Schiffer und andere Stände“, „Gesellige und Trinklieder“, „Liebeslieder“. 


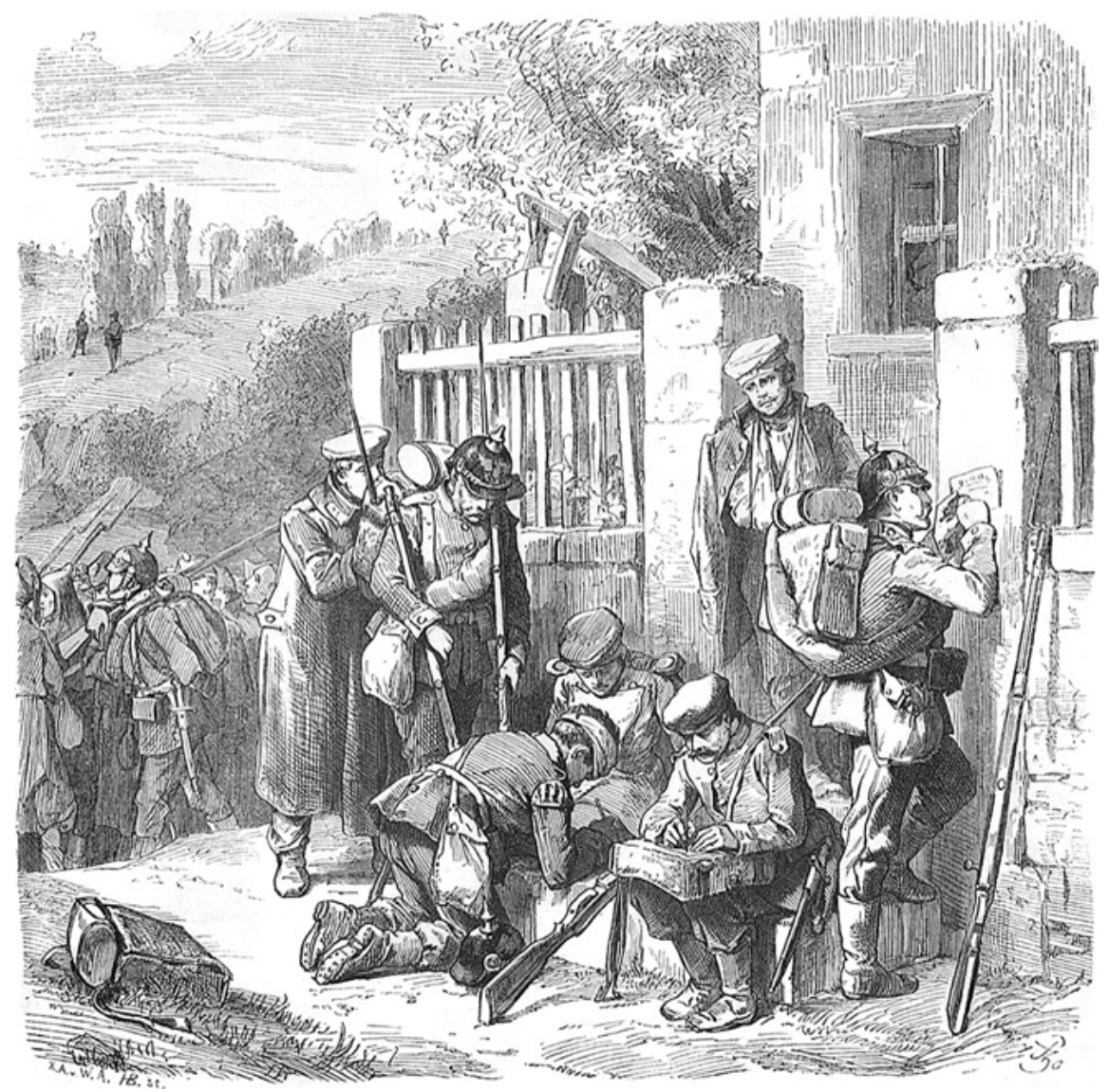

Abb. 19: „Wie unsere Leute draußen im Feld in die Heimath schreiben. Auf der Landstraße nach Wörth aufgenommen von Prof. P. Thumann.“ In: Gartenlaube Heft 45 (1870), S. 749 (gemeinfrei über Wikimedia commons). Der Illustrator Paul Thumann war im Krieg 1870/71 im Hauptquartier der III. Armee als Zeichner tätig.

braucht 1922 eine inzwischen gewöhnliche Formulierung, wenn er es als „Lehre“ für den Deutschen bezeichnet, „daß die Heimat sein höchstes Gut bildet, das zu verteidigen bis zum letzten Tropfen Blutes eines jeden Willen sein müßte“.91 Gestorben wird dann auch noch im zweiten großen Krieg des 20. Jahrhunderts für

91 Beide Zitate Schellenberg 1922. 
Heimat, Vaterland und Nation. ${ }^{92}$ Zumindest im Tod kommen die Begriffe nun zur Deckung.

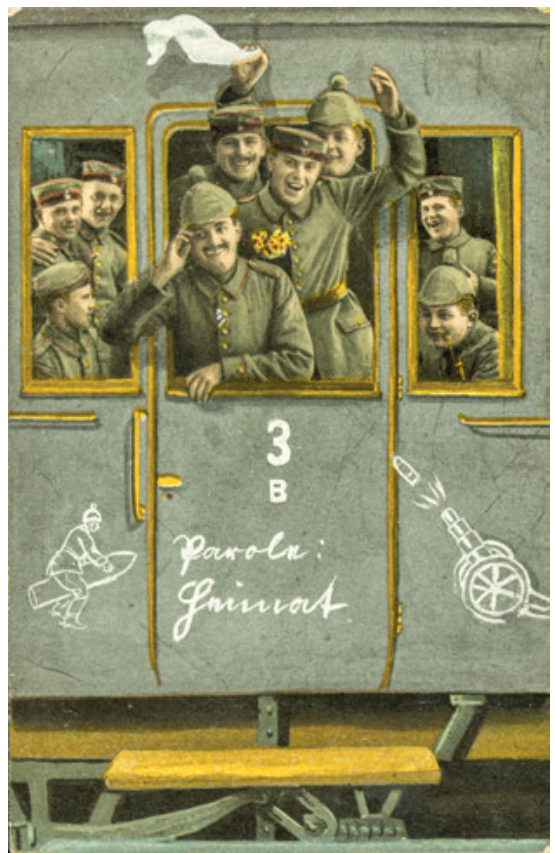

Abb. 20: „Parole Heimat“: Feldpost, gelaufen 18.12.1918 (Historische Bildpostkarten Universität Osnabrück Sammlung Prof. Dr. Sabine Giesbrecht)

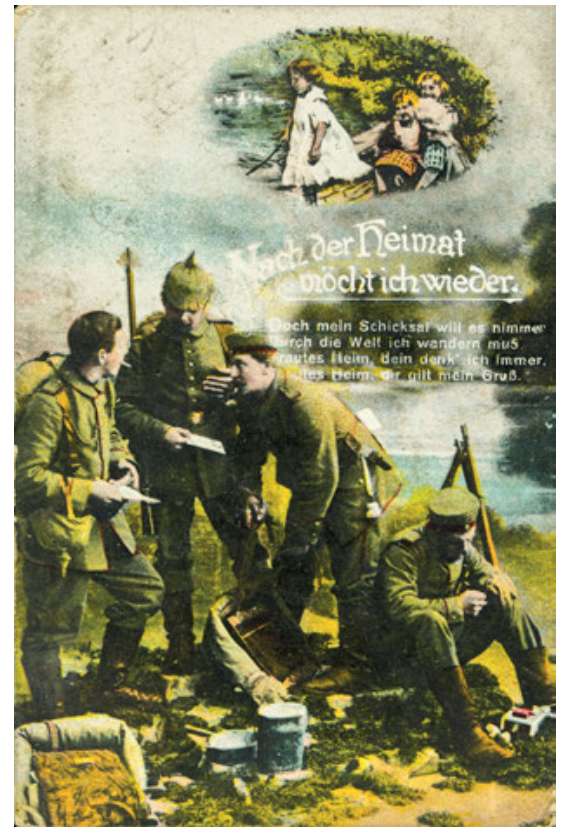

Abb. 21: „Nach der Heimat möcht ich wieder“ (Serie), Feldpost, gelaufen 04.06.1916 (Historische Bildpostkarten - Universität Osnabrück Sammlung Prof. Dr. Sabine Giesbrecht)

92 Heimat und Vaterland kommen wie schon im Ersten Weltkrieg auch im Nationalsozialismus in der Aufforderung zur Deckung, wahlweise für das eine oder andere zu sterben: „Nun gilt es die Heimat zu verteidigen. Nun wird der Pflug, nun wird die Sense zum Schwert. Und der Bauer, der als Nährstand aufs Feld hinausging - er erhebt sich jetzt als Wehrstand zur Verteidigung der Heimat. Diese Schwertarbeit ist Mannesarbeit. [...] Die Väter waren's, die mit Leib und Leben, mit ihrem Blut das Leben der Heimat verbürgten. So wuchs aus dem Heimatleben der männliche Vaterlandsgedanke heraus, und Pflug und Schwert wurden zum symbolhaften Ausdruck dieser Trutzwelt.“ Th. Scheffer: Von Heimat und Vaterland, in: Kretzschmann 1933, S. 208-214, hier S. 212. Der Nationalsozialistische Deutsche Frontkämpferbund (Stahlhelm) gab die Schriftenreihe ,Soldat und Heimat' heraus und schuf damit eine neue formelhafte Verknüpfung von Heimat und Krieg. Der erste Band der Schriftenreihe, Heimat unterm Joch. Eine thüringische Soldatenchronik aus der Rheinbundzeit (1935) von Karl Henniger, behandelt die Zeit zwischen 1807 und 1815, in der ein schwarzburg-rudolstädtisches Kontingent unter französischem Kommando Aufstände in Spanien niederschlagen musste. 


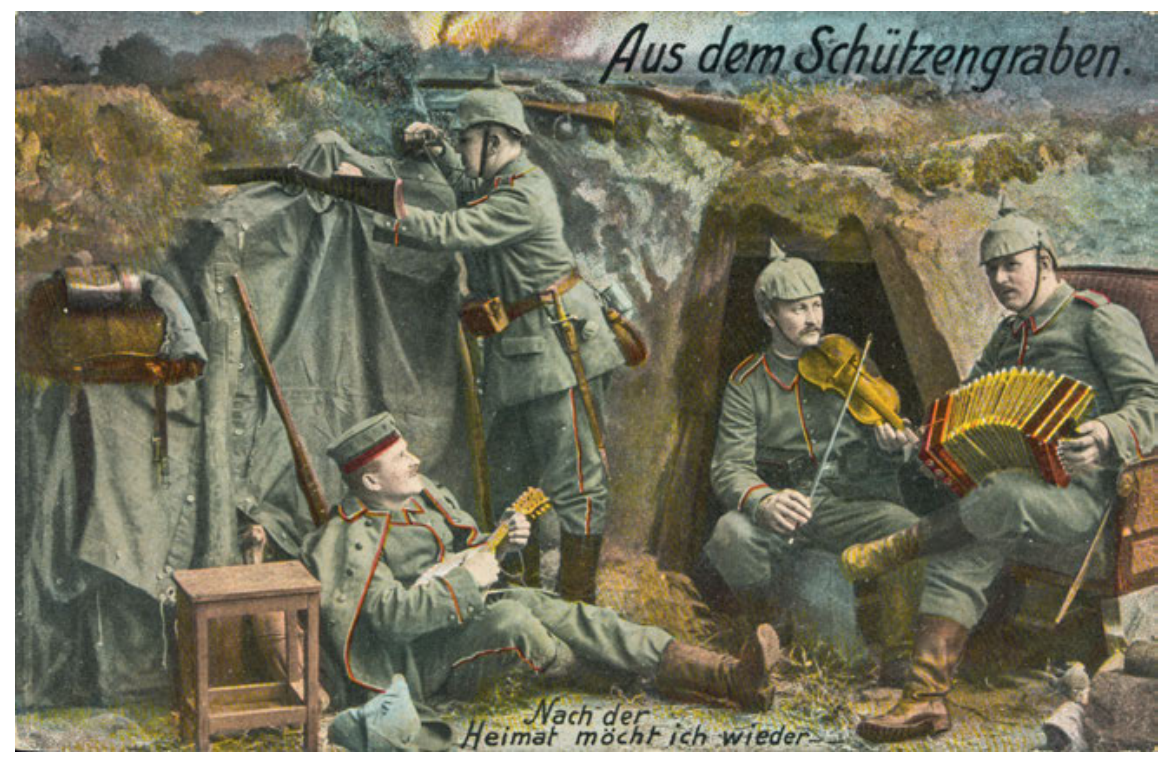

Abb. 22: „Nach der Heimat möcht ich wieder“ (Serie) Feldpostkarte, unfrankiert, datiert 18.02.1916 (Historische Bildpostkarten - Universität Osnabrück Sammlung Prof. Dr. Sabine Giesbrecht)

\subsection{Heimat, Volk und Biene}

Das Verhältnis von Volk und Heimat wäre einen genauso umfangreichen Abriss wert wie das von Vaterland und Heimat. ${ }^{93}$ Es ist ähnlich komplex und vielschichtig wie dieses und keinesfalls deckungsgleich mit ihm, weist aber viele Parallelen auf und soll hier deswegen stärker exemplarisch an einem einzelnen Beispiel vorgeführt werden. Alle hier ausgewählten Texte haben eins gemeinsam: Sie setzten sich mit Volk und Heimat am Bild der Biene auseinander, und die unterschiedliche Art und Weise, wie sie das tun, bringt einiges in Bezug auf das historisch jeweils differente Verhältnis von Volk und Heimat auf den Punkt.

Vom Jesuiten Friedrich Spee (1591-1635), der vor allem für seine deutschsprachigen Kirchenlieder bekannt ist, liegt mit Lob deß Schöpffers / darin ein kleines / wercklein seiner weißheit / nemblich die wunder liebliche handthierung der

93 Eine Studie zum Verhältnis von Volk und Heimat liegt meines Wissens noch nicht vor. Gewöhnlich geht es um eine Klärung des Verhältnisses von Volk und Nation, vgl. exemplarisch die Beiträge in Bormann 1998. 
Immen oder Bienen beschrieben wird (1654) ein stark auf die spätere physikotheologische Dichtung eines Barthold Heinrich Brockes verweisendes Gedicht vor, in dem das Lob der Bienen als Teil von Gottes Werk dem Lob Gottes dient. Das Langgedicht endet entsprechend mit einer Ansprache an den Leser und die Leserin: „Steigt auff / und steigt hinunder / In allen wercken sein: / Rufft uberall / wie wunder / Muß er doch selber seyn. / Ruff uberall / wie wunder / Seind alle Wunder sein // Wie wunder / und wie wunder / Muß er dan selber sein!“94 Das Leben der Bienen mit seinen verschiedenen Tätigkeiten wird in dem Text ausführlich beschrieben. Innerhalb dieser genauen Behandlung des Bienenlebens wird auch der Schwarmtrieb der Bienen zur Gründung eines neuen Staats im Frühsommer thematisiert. Bei Spee wird dieser Schwarmtrieb als ein Ade-Sagen an die Heimat umschrieben. Damit liegt hier übrigens eines der wenigen Beispiele von geistlichen Texten des Barock vor, in denen Heimat eine rein weltliche Bedeutung hat:

31. Wan dan die schöne jugent

Sich nehret allgemach;

Sie gleich der vätter tugent/

Und freyheit strebet nach.

Sie sich von mitgenossen

Im schwarm zertheilen ab/

Von hauß mit fremden stossen

In vollem flügel-trab.

32. Starck blasen sie zum lermen/

Gar schwirig von geblüt:

In stoltzem zug und schwermen/

Daß munter bürßlein wüt.

Ade du süsses heimet;

Ade du mutter-schoß;

Hinaussen ungezeimet

Sich waget unser stoß;

Hinaussen ungezeimet

Sich waget unser stoß.

33. Schaw da/wie schön muntiret/

Wie schon gebutzer hauff!

In lüfften er braviret/

Zun wolcken schwebet auff:

Frisch hin und her sich schwencket

Die gülden-gelbe schaar/

94 Spee 1654, S. 105. 
Nach frembden land gedencket/

Ihr hauß verlasset gar. ${ }^{95}$

Das Verlassen von „heimet“, „mutter-schoß“ und „hauß“ wird bei Spee als natürlicher, gottgewollter Vorgang beschrieben, der mit dem Streben nach „Freyheit“ im Sinn der eigenen „vätter“ verbunden wird. Dass die Bienen sich nach „frembden land“ orientieren, steht in Einklang mit der göttlichen Ordnung; die Heimat wird hier nach dem Plan Gottes verlassen. Als Volk wird der Bienenschwarm an keiner Stelle bezeichnet, dagegen kommt der Begriff des Volkes im Plural und bezogen auf die Menschen an etwas späterer Stelle ins Spiel. In der abschließenden Ansprache an den Leser heißt es, die vielen Völker, verstanden als Gesamtheit der Menschheit, sollten Dankbarkeit gegenüber Gott empfinden:

43. Ihr völcker vil auff erden/

Ihr menschen alle gar;

Frisch/frölich in geberden

Vor ihm euch stellet dar:

Ihm dancket seiner gaben/

Der vöglien wunder fein/

Deß wachs/und honig waben/

So wunder süß und rein. ${ }^{96}$

Das Volk bezeichnet demnach keine nationale oder ethnologische Differenz, sondern dient im Plural als Sammelbezeichnung für die Menschheit an sich.

Etwa einhundert Jahre später thematisiert das (selbständig erschienene) Langgedicht Der Frühling (1749) Ewald Christian von Kleists ebenfalls das Bienenleben, in der Absicht, mit den Wundern der Natur ihren göttlichen Schöpfer zu loben.

[...]. Zerftreute Heere von Bienen

Durchfäufeln die Lüfte, fie fallen auf Klee und blühende Stauden

Und hängen glänzend dar an wie Thau vom Mondfchein vergüldet;

Denn eilen fie wieder zur Stadt die ihnen im Winkel des Angers

Der Landmann aus Körben erbaut. Rechtfchaffner Weltweifen Bildnifs

Die fich der Heymath entziehn, der Menfchheit Gefilde durchfuchen,

Und denn heimkehren zur Zelle mit füffer Beute beladen

Und liefern uns Honig der Weisheit. ${ }^{97}$

95 Spee 1654, S. 102-103.

96 Spee 1654, S. 105.

97 Kleist 1749, S. 34-35. 
Heimat wird hier bezogen auf die Bienen anders verstanden, nämlich nicht als etwas, das zugunsten eines Neuen notwendig und für immer verlassen werden muss, sondern als Ort, zu dem man immer wieder zurückkehrt. Um im Bild bleiben zu können, wird nicht das Schwärmen, sondern das tägliche Sammeln von Pollen und Nektar beschrieben, das mit einer Rückkehr in den Bienenkorb endet. Stärker allegorisch als bei Spee wird dieses Ausfliegen und Heimkehren als Bild für diejenigen „Weltweisen“ gebraucht, die sich für eine Zeit „der Heymath entziehn“, um den anderen „mit süsser Beute“ - ihrer „Weisheit“ - zu dienen. Das hier im Vergleich zu Spee sehr viel stärker humanisierte und moralisierte Bienenbild kehrt die mit Heimat verbundene Bewegungsrichtung um: nicht weg von, sondern zurück zur Heimat. Der Begriff des Volkes kommt auch hier nicht bezogen auf die Bienen vor, dafür aber in der Preisung des - national völlig unbestimmt bleibenden - Volkes, das „ohne Stürme des Unglücks / Das Meer des Lebens durchschifft"“.98

Fünfzehn Jahre später bezieht sich Johann Gottfried Herder in seinem Text Über den Fleiß in mehreren gelehrten Sprachen (1764) auf diesen Text von Ewald Christian von Kleist; 1767 reformuliert er denselben Gedanken noch einmal in Über die neuere deutsche Literatur:

\footnotetext{
Bienen nach,

--- die in zerstreueten Heeren,

Die Luft durchsäuseln, und fallen auf Klee und blühende Stauden

Und denn heimkehren zur Zelle mit süßer Beute beladen und liefern uns Honig der Weisheit.
}

Nicht um meine Sprache zu verlernen, lerne ich andre Sprachen, nicht um die Sitten meiner Erziehung umzutauschen, reise ich unter fremde Völker; nicht um das Bürgerrecht meines Vaterlandes zu verlieren, werde ich ein naturalisierter Fremder: denn sonst verliere ich mehr, als ich gewinne. Sondern ich gehe bloß durch fremde Gärten, um für meine Sprache, als eine Verlobte meiner Denkart, Blumen zu holen: ich sehe fremde Sitten, um die meinigen, wie Früchte, die eine fremde Sonne gereift hat, dem Genius meines Vaterlandes zu opfern. Wenn ich mich meiner Heimat entziehe, und mich in fremden Sprache weide, ahme ich Kleists

Ich setze zwei Schriftsteller zusammen, von denen der eine in seiner Sprache, der andere in einer fremden toten Sprache schreibt: wer von ihnen kann größer werden? ${ }^{99}$

Herder verwendet das Zitat von Ewald Christian von Kleist für sein Argument, der Schriftsteller müsse in seiner eigenen Sprache, der „Muttersprache“, ${ }^{100}$ schreiben, um Großes zu leisten. Wie in Kleists Bild dient die Figur des Auszugs und der

98 Kleist 1749, S. 21.

99 Herder 1985, S. 408-409.

100 Herder 1985, S. 408. 
Rückkehr in die Heimat der Idee, dass die Fremde nicht das eigentliche Ziel darstellen könne. Ihre Kenntnis diene vielmehr der Vervollkommnung des Eigenen. Ein Schriftsteller, der dies nicht beherzigt, so Herder,

irret in fremden Gegenden, ohne Vaterland und Hausgötter: er kann nie ein Originalschriftsteller werden, bei dem Gedanke und Ausdruck sich zusammen drängen, um ein vollständiges Bild seiner Seele zu sein. / Ein Originalschriftsteller im hohen Sinne der Alten, ist, wenige Beispiele ausgenommen, beständig ein Nationalautor. ${ }^{101}$

Die Heimat und das Vaterland - hier synonym gebraucht - müssen der Bezugspunkt des schriftstellerischen Schaffens bleiben, und dies kann nach Herder nur in der eigenen Sprache gelingen. Ein großer Gedanke dränge nur in der eigenen Sprache ans Licht. „Schriftsteller, die in einer Gegend sich verirren, in die sie nicht zu Hause gehören“, können keine Originalschriftsteller werden, dafür bedürfe es der „bekannte[n] und sichere[n] Mutter Erde“. ${ }^{102}$ Herders Projekt einer Rettung der Muttersprache ist getragen von der Vorstellung, dass nur in der eigenen Sprache Höchstes und Originäres geleistet werde. ${ }^{103}$ Er verfolgt seinen Ansatz dann in seinem Volksliedprojekt der 1770er Jahre weiter: ${ }^{104}$ Andere Völker haben Vor-

101 Herder 1985, S. 409.

102 Beide Zitate Herder 1985, S. 411.

103 Auch Lessing ist auf der Suche nach einer Volksdichtung als Impulsgeberin einer deutschen Nationalliteratur. In seinem Einleitungstext zum Grenadierlied von 1758 wird die einfache Sprache des Volkes zum Ausdruck einer ursprünglichen deutschen Denkart und die hieraus erwachsene ungekünstelte Volksdichtung zur Voraussetzung für eine hohe deutsche Nationalliteratur. Das Ziel einer deutschen Nationalliteratur, verwirklicht durch ein Anknüpfen an die eigenen (literarischen) Ursprünge, wird von Lessing dann $1759 \mathrm{im}$ 17. Literaturbrief ausführlicher entwickelt. Zu Lessings wesentlichem Einfluss auf Herder vgl. Gaier 1990.

1041773 wird von Herder der Terminus ,Volkslied‘ eingeführt, von 1774 stammt seine erste Sammlung Alter Volkslieder, in deren Vorwort die Suche nach dem Nationalen sich in einer emphatischen Verteidigung des Volkes ausdrückt. 1778/79 erscheint eine weitere Volksliedsammlung. Herders Volksliederprojekt hat Teil an der Besinnung auf eine nationale Identität der Deutschen, es unterscheidet sich aber von verwandten Bemühungen wie denjenigen Klopstocks dadurch, dass die Kategorie des Ursprungs als anthropologische Kategorie aufgefasst wird. Nicht der Kampf gegen einen im Zeitgeist meist römischen respektive französischen Gegner, mithin nicht die Abgrenzung gegenüber einem Fremden, bildet die Grundlage für Identitätsbildung, sondern die zivilisationskritische Berufung auf eine dem Einfachen, Ursprünglichen und Unverbildeten eigene originäre Kraft. Das Volk (und dessen Erscheinungsform im Volkslied) wird zur emanzipatorischen Ursprungskategorie und in diesem allgemeinmenschlichen Ursprünglichen ist das Göttliche anschaubar. Neben der nationalen gibt es also immer eine allgemeinmenschliche Bedeutung des Volksbegriffs bei Herder. In der Volksliedsammlung von 1778/79 mischt Herder ohne Rücksicht auf die regionale Herkunft Volkslieder der Weltliteratur, auch hier wird das anthropologische Interesse am Volkslied deutlich, vgl. Gaier 1990. 
bildfunktion in ihrer nationalen Ursprungssuche - die vermeintliche Bardendichtung eines Ossian, andere englische und nordeuropäische Vorbilder, insbesondere aber Homer sollen die Suche nach dem Eigenen anleiten. Die Rückkehr zum Eigenen, die über die Auseinandersetzung mit Homer erhofft wird, zielt auf ein deutsches ,Volk‘ als nationalen ,Gesamtkörper‘, der erst dann entstehen könne, wenn sein Zusammenhang mit dem ,einfachen Volk‘ begriffen sei: „für Nation! Volk! einen Körper, der Vaterland heißt!“.${ }^{105}$ Die Idee des Volkes, die sich bei Herder mit seiner nationalen Ursprungssuche verbindet, ist also wesentlich von der Idee getragen, die eigenen kulturellen Ursprünge zu würdigen, sich nicht in ein nachahmendes Verhältnis $\mathrm{zu}$ anderen Kulturen $\mathrm{zu}$ setzen, sondern eine originär schöpferische Beziehung zur eigenen Gegenwart auf der Grundlage der eigenen kulturellen Ursprünge zu entwickeln. Der Volksbegriff wird bei Herder also stark aufgewertet, ohne aber mit einer Abwertung anderer Völker einherzugehen; aus der Differenzbildung geht keine Hierarchisierung hervor. Der Konnex von Heimat und Volk ist bei Herder indes nur über die verbindende Idee des Bienen-Textes (Rettung der Muttersprache) und seines Volkslied-Projekts herzustellen. Die Begriffe fallen bei Herder nie im Zusammenhang, insgesamt beschränkt sich Herders Verwendung von Heimat auf seinen Bienen-Text.

Die Tradition des Sammelns und Bewahrens alter deutschsprachiger Schätze, die Herder mit seinem Aufruf zur Sammlung deutscher Volkslieder begründete, wird durch Jacob und Wilhelm Grimm mit ihren Märchen-, Sagen- und Volksliedsammlungen und auch durch Achim von Arnims und Clemens Brentanos Des Knaben Wunderhorn fortgesetzt. Auch Brentanos Neuherausgabe der von ihm bearbeiteten Gedichte Friedrich Spees gehört dazu. Seine Übertragung von Trutz Nachtigal von 1817 enthält auch das den Bienen gewidmete Gedicht, das er - nicht selbstverständlich für ihn - sehr nah am Original belässt. ${ }^{106}$

105 Herder 1990, S. 20. Das Zitat stammt aus Herders Vorrede in Alte Volkslieder von 1774. In rousseauistischer Tradition wird dieses einfache Volk (und dessen Erscheinungsform im Volkslied) als Authentisches und zugleich allgemeinmenschliches Ursprüngliches gefasst, in dem das Göttliche sichtbar werde. Vgl. Gaier 1990, S. 867 sowie insgesamt den Abschnitt „Volk und Völker“, S. $865-878$.

106 „Wann dann die schöne Jugend / Sich mehret allgemach, / Sie gleich der Väter Tugend / Und Freiheit strebet nach. / Sie sich von Mitgenossen / Im Schwarm zertheilen ab, / Von Haus mit Freuden stoßen / In vollem Flügeltrab. // Starck blasen sie zum Lärmen, / Gar schwierig von Geblüt / In stolzem Zug und Schwärmen, / Das munter Bürschlein wüt’t. / Ade du süßes Heimet, / Ade du Mutterschoos! / Hinaußen ungezäumet / Sich waget unser Stoß.“ Clemens Brentano: Lob des Schöpfers, darin ein kleines Werklein seiner Weisheit, nemlich die wunderliche Handthierung der Immen oder Bienen beschrieben wird [Übertragung des Textes aus Friedrich Spees Trutz Nachtigal], in: Brentano 2009, S. 138-150, hier S. 146-147. 
Die sich im Anschluss an Herder und die Romantiker ab den späten 1850er Jahren langsam herausbildende wissenschaftliche Volkskunde, die für die Genese von Heimat von entscheidender Bedeutung ist (vgl. II.3.2), wird ein anderes Verhältnis von Volk und Heimat etablieren. Schon gar nicht im Sinn eines Friedrich Spee, nach dem es göttlicher Wille ist, die Heimat zu verlassen, um Neues zu beginnen. Aber auch in vielem anders als Herder, bei dem Heimat, Vaterland und Volk zwar für die emphatisch eingeforderte Rückbesinnung auf das Eigene stehen, bei dem das Plädoyer für mehr Selbstkenntnis und Selbstbewusstsein aber im Einklang mit einer Humanitätsidee steht, die das Individuum ins Zentrum rückt.

Dagegen wird die Idee des Volkes im Laufe des 19. Jahrhunderts zunehmend eine anti-individualistische, innerhalb deren die Heimat die metaphorische Rolle eines ,Nährbodens' spielt, in dem das als pflanzenhaft-organische Einheit begriffene Volk wurzele. Symptomatisch ist etwa Gustav Freytags mehrteiliges Epos Die Ahnen, in dem sich die Wortbildung vom ,Heimatvolk‘ findet: Die individuelle Heimatliebe der einzelnen Protagonisten transzendiert sich demnach, von ihnen ungewusst, in ein größeres Ganzes und verbindet sie über Grenzen und Zeiten hinweg zu einem Volk (vgl. II.3.1.2). Am Ende des Jahrhunderts erscheint Heimat im Umfeld der ,Heimatschutzbewegung‘ als so etwas wie der seelische ,Nährboden` des Volkes (vgl. II.3.2). Beim klassischen Philologen und Volkskundler Albrecht Dieterich etwa übernimmt Heimat die Funktion einer „von unten“ kommenden Kraftquelle, die Bedingung für die Gesundung des durch die Moderne von sich selbst entfremdeten deutschen Volkes sei:

Und daß die ,Gebildeten“ des ,Volkes‘, ihres Volkes wieder ,kundig‘ werden, aus dem sie ja doch alle als aus dem mütterlichen Boden emporgewachsen sind, das ist desto notwendiger, je mehr sich die Wege der Bildung verirren und verwirren, von Natur und Leben zu pedantischer Systematik und totem abstrakten Denken. [...] Wenn wir alle, die Gebildeten und Gebildetsten, wieder fühlen könnten, daß wir zum Volke mit Leib und Seele gehören, daß das Volk unserer Heimat Fleisch ist von unserem Fleisch, Blut von unserem Blut, dann fühlten wir es auch, daß aus dem Heimatboden und dem Heimatvolke jedem Sproß dieser Heimat neue gesunde Kraft kommt: allein von unten in diesem Sinne konnte von je nur gesunden die krank gewordene Bildung. ${ }^{107}$

Die antagonistischen Paare - hier das Pedantische, Tote, Abstrakte, Kranke, dort das Leibliche und Seelische, Gefühlte, Gesunde - entsprechen einer diagnostizierten Spaltung der Bevölkerung, die erst wieder zum ,Volk ${ }^{`}$ werden müsse. ,Heimat‘ steht zunächst für das (positiv besetzte) ,Unten‘, im Bild des gesunden und mütterlichen (vgl. I.2.3) Heimatbodens gefasst. Wenn sich auch die ,oben`

107 Dieterich 1902, S. 3-4. 
wieder dieses Ursprungs bewusst würden, könne ein ,Heimatvolk‘ entstehen, das das ,Kranke‘ überwunden habe. Die biblischen Anspielungen (1 Mose 2,23) unterstreichen diese Einheits- und Verschmelzungsphantasien, die sich dann unmittelbar in der Amalgamierung von Heimat und Volk zum „Heimatvolke“ niederschlagen.

Um aber auf die Bienen zurückzukommen, so lässt sich in diesem Kontext das populärste Beispiel für die Verbindung von Heimat, Volk und Biene anführen: Waldemar Bonsels' Kinderbuch Die Biene Maja und ihre Abenteuer von 1912, das Bonsels schlagartig zu einem der erfolgreichsten Kinderbuchautoren seiner Zeit machte und bis heute in Form der Zeichentrickverfilmung ausgesprochen populär ist. Die Freiheitsliebe der Biene Maja, die sich von ihrem Bienenvolk trennt, um die Welt kennenzulernen - ihre „Flucht aus der Heimatstadt“, ${ }^{108}$ entpuppt sich am Ende der Geschichte zwar als notwendig, aber nicht im Sinn individuellen Autonomiegewinns, sondern insofern, als diese Flucht indirekt zum Überleben ihres Volkes beiträgt. Maja erfährt in der Not, in die sie gerät, worauf es tatsächlich ankommt: auf die Zugehörigkeit zu Heimat und Volk. Nur weil sie am Ende bereit ist, für diese zu sterben, kann sie wieder von ihrem Volk aufgenommen werden.

Neben vielen anderen freundlichen und auch merkwürdigen Tieren, mit denen Maja im Laufe ihrer Abenteuer zusammentrifft, muss sie auch die Hornissen und Wespen kennenlernen, ein „unnützes Räubergeschlecht ohne Heimat und Glauben“, ${ }^{109}$ wie ihr schon ihre Erzieherin Kassandra beigebracht hat. Als sie in den Regen gerät, erinnert sie sich ihrer „verlassenen Heimat“ und sehnt sich „nach dem Schutz und der starken Gemeinschaft des Bienenstocks“. Sie malt sich aus, wie „ruhig und beschaulich“110 es an Regentagen in ihrem Bienenstock zugeht:

Aber allmählich zog es ihre Gedanken doch nach ihrer verlassenen Heimat, nach dem Schutz und der starken Gemeinschaft des Bienenstocks. Dort saßen sie nun beieinander, des Ruhetags froh, bauten vielleicht hier und da ein wenig an den Zellen oder fütterten die kleinen Maden. Aber im allgemeinen war es recht ruhig und beschaulich im Stock an Regentagen. Nur zuweilen flogen Kundschafter aus, sahen nach dem Stand des Wetters und erforschten, von welcher Seite der Wind kam. Die Königin ging im Reiche umher, von Etage zu Etage, prüfte alles, lobte oder tadelte, legte wohl hin und wieder ein Ei und beglückte alle durch ihre königliche Gegenwart. Wie froh machte es, einen Blick von ihr aufzufangen oder ein huldvolles Wort. Es kam vor, daß sie den jüngeren Bienen, die ihre ersten Leistungen hinter sich hatten, freundlich über die Köpfchen strich oder sich nach ihren Erlebnissen erkundigte. Ach, wie glücklich machte es, sich dazu rechnen zu dürfen, sich von allen geachtet zu

108 Bonsels 1949, S. 7.

109 Bonsels 1949, S. 11.

110 Alle Zitate Bonsels 1949, S. 39 
wissen und den starken Schutz der Gemeinschaft genießen zu können. Hier an ihrem einsamen und ausgesetzten Platz war sie gefährdet und fror. ${ }^{111}$

In das Tierleben humanisierenden Bildern wird hier die Vorstellung eines Bienenlebens entworfen, in dem der bürgerliche Wertekanon gilt: Leistung verdient Lob, zum Prinzip Arbeit gehört auch der Ruhetag, an dem es beschaulich zugeht und nur „hier und da ein wenig an den Zellen“"112 weitergebaut wird.

Als Maja nach vielen anderen Abenteuern von den Hornissen gefangen genommen wird und durch Zufall von deren Plan erfährt, die Bienen anzugreifen, erwacht in ihr das Bewusstsein, Teil einer größeren Gemeinschaft zu sein, für die sie zu sterben bereit ist. Volk und Heimat werden in einem Atemzug genannt: „,Mein Volk‘, schluchzte sie, ,meine Heimat!‘ Sie preßte ihre Hände an den Mund, um nicht zu schreien, ihre Verzweiflung war grenzenlos. ,Ach, wäre ich gestorben, ehe ich dies hören mußte‘, wimmerte sie." ${ }^{\text {"113 }}$ Maja wird sich ihrer Verantwortung für ihr Volk bewusst:

Es war, als vergäße sie ganz die lange Zeit der Trennung von den Ihren und der Heimat, sie fühlte sich ihnen zugehöriger als je, und die neue Verantwortung, die plötzlich auf ihr ruhte, weil sie den Plan der Hornissen kannte, verlieh ihr große Entschlossenheit und viel Mut. Müssen die Meinen unterliegen und sterben, so will ich es auch, dachte sie, aber vorher will ich nichts ungetan lassen, sie zu retten. ${ }^{114}$

Sie kann sich befreien und den Hornissen zuvorkommen, es gelingt ihr, die Bienen zu warnen:

Es galt für sie nur eines: sie mußte, so rasch als ihre Kräfte und Sinne zuließen, den Stock der Ihren finden, ihr Volk, ihre bedrohte Heimat. Sie mußte die Ihren warnen, daß sie sich gegen den Überfall rüsten konnten, den die furchtbaren Räuber an diesem Morgen planten. O, das Volk der Bienen war stark und wohl befähigt, den Kampf mit den überlegenen Gegnern aufzunehmen, wenn sie sich wappnen konnten und zur Verteidigung vorbereiten. ${ }^{115}$

Maja fühlt ihre „Todesbereitschaft“ und es überkommt sie ein „beseligter Opferwille“116 beim Gedanken an ihre Königin, ihre Heimat und ihr Volk. Der aus-

111 Bonsels 1949, S. 39-40.

112 Bonsels 1949, S. 39.

113 Bonsels 1949, S. 140.

114 Bonsels 1949, S. 141.

115 Bonsels 1949, S. 149-150.

116 „Und nun, da die kleine Biene an die Kraft und Stärke der Ihren dachte, an ihre Todesbereitschaft und ihre Treue gegen die Königin, überkam sie ein hoher Zorn gegen die Feinde und 
führlich beschriebene Kampf zwischen Bienen und Hornissen fordert viele Todesopfer. Die Bienen gewinnen gegen die an Kraft und Körpergröße überlegenen Hornissen am Ende nur deshalb, weil sie sich dutzendweise für ihr Volk opfern und sich freiwillig für die vorderste Front melden, im Bewusstsein, dort ihr Leben zu lassen. Maja überlebt und wird von der Königin für ihre Treue ausgezeichnet: „Du hast deine Heimat und dein Volk nicht vergessen, und im Herzen warst du treu. So wollen auch wir dir Treue halten." ${ }^{117}$

Volk und Heimat verschmelzen zu einem großen kollektiven Ganzen, das für das Gegenteil von Autonomie und Individualität steht. Zu Beginn des 20. Jahrhunderts, und das ist der große Unterschied zu dem Verständnis von Volk und Heimat der Befreiungskriege zu Beginn des 19. Jahrhunderts, wird für die Heimat auch gestorben. Vaterland und Heimat, die das 19. Jahrhundert getrennt hatte in dasjenige, für das man kämpft und stirbt, und dasjenige, nach dem man weint, sind im Begriff des Volks wieder zur Deckung gekommen. Fortan gelten Todesbereitschaft und Opferwille auch für die Heimat. ${ }^{118}$

Der Erfolg der Abenteuer der Biene Maja im Ersten Weltkrieg verwundert vor diesem Hintergrund kaum. Bonsels' weitere Karriere als Schriftsteller beruht auf dem Erfolg der Biene Maja, zum Bestseller wird das Buch durch den Feldbuchhandel, was darauf schließen lässt, dass nicht vor allem Kinder, sondern Soldaten das Buch gelesen haben dürften, 90.000 Exemplare sind am Ende des Krieges verkauft. ${ }^{119}$ Zur Verbreitung von Bonsels' Namen hat auch beigetragen, dass er im Krieg in der Auslandsabteilung der Obersten Heeresleitung neben Hans Grimm (dem späteren Autor von Volk ohne Raum), Börries Freiherr von Münchhausen (dem späteren Herausgeber der Vierteljahresschrift Volk und Rasse), Arthur Moeller van den Bruck (dem späteren Autor von Das dritte Reich) und anderen ausgesprochen einflussreichen völkisch-nationalistischen Intellektuellen als Kriegsberichterstatter arbeitete. Aus dieser Tätigkeit geht 1916 der Band Heimat des Todes. Empfindsame Kriegsberichte hervor, dessen stark literarisierte und vermutlich ebenso stark fiktive ,Berichte‘ ausnahmslos Soldaten darstellen, die die „Majestät des Krieges“120 beschwören und deren höchstes Ziel es ist, für Volk

zugleich ein beseligter Opferwille und ein beglückender Mut ihrer begeisterten Liebe.“ Bonsels 1949, S. 150.

117 Bonsels 1949, S. 172.

118 Bernhard Viels problematische Analyse des Romans besagt, dass nicht die Bienen, sondern die Hornissen angreifen und die an sich als friedliebend dargestellten Bienen nur ihren Staat verteidigen: „Von Kriegsbegeisterung indessen kann in dieser Erzählung nicht die Rede sein. “ Viel 2016, S. 142.

119 Hanuschek 2012, S. 7.

120 Waldemar Bonsels: Der Vater, in: Bonsels 1918, S. 58-67, hier S. 63. 
und Heimat zu sterben, ${ }^{121}$ denn: „[S]ind wir nicht eigentlich für diese Augenblicke geboren?"122 Wie im Titel ist die Semantik von Heimat auch in den einzelnen Texten deutlich religiös konnotiert. ${ }^{123}$ Es ist aber der Tod selbst, der hier sakralisiert wird. ${ }^{124}$

\subsection{Heimatboden und Frauenleib}

In der Lyrikanthologie Heimaterde. Der Heimat Lob in Liedern von 1901 (Abb. 23) wird eigentlich nur eine einzige Bildidee für die knapp dreißig ganzseitigen Gedichtillustrationen $\mathrm{zu}$ den Themen Abschied, Heimweh und Heimkehr variiert. Alle stammen von dem Maler und Graphiker Ernst Liebermann. Für die Gedichte, in denen es um Abschied geht, wählt Liebermann eine männliche Figur im Bildvordergrund, die gedankenvoll und melancholisch auf eine ländlich-dörfliche Szenerie zurückblickt (Abb. 24) oder sich trauernd von ihr abgewendet hat (Abb. 25). Das Thema Heimweh gestaltet er im Bildvordergrund mit einem Mann, der gedankenvoll-melancholisch Richtung Betrachter des Bildes, Richtung Horizont oder Richtung eigene Füße blickt, im Hintergrund eine ländlich-dörfliche Szenerie (Abb. 26). Und Gedichte, die Heimkehr thematisieren, werden mit einer

121 „Heimat“ ist für den beschriebenen Soldaten das, „dafür zu sterben“ er „,bereit sei[]“. Waldemar Bonsels: Heimkehr, in: Bonsels 1918, S. 51-57, hier S. 54.

122 Waldemar Bonsels: Die eiserne Heimat, in: Bonsels 1918, S. 68-76, hier S. 72-73.

123 In einer Erzählung gehen dem Betrachter eines Sterbenden nur zwei Dinge durch den Kopf: dass der Sterbende, in dessen Augen er „ein warmes Licht“ wahrnimmt, nun „in der Heimat“ verweilen werde, und der Gedanke: „Mein Volk wird siegen.“ Waldemar Bonsels: Der Tod des Hauptmanns, in: Bonsels 1918, S.151-159, hier S. 157 und S. 158. In einer anderen Erzählung ist es „die Hoffnung der Heimat und das Anrecht an Frieden und Glück, das die Zukunft des Volkes“ von der „Kraft“ des Soldaten „erflehe“, Waldemar Bonsels: Bilder von der Front, in: Bonsels 1918, S. 120 - 127, hier S. 127. Sven Hanuschek stuft die Beiträge als „Kriegspropaganda“ ein. Hanuschek 2012, S. 8.

124 Diese Sakralisierung des Todes im Namen von Volk und Heimat ist dann ein typisches Element der späteren Blut-und-Boden-Literatur. In Hans Christoph Kaergels Drama Volk ohne Heimat (1922), das den Kampf der Deutschen gegen die Polen in Schlesien behandelt, fallen im Schlussmonolog der sterbenden, von Polen meuchlings ermordeten Hauptgestalt Adamschek Heimat, Vaterland und Deutschland wörtlich im Blut und im Boden zusammen: „Meine Kinder und die tausend, tausend Kinder, mein - deutsches Vaterland - das - das [...] Ich liege in der Erde. Ach, du Mutter, beug dich doch ganz zu mir. [...] Das ist Erde meiner Mutter - meines Blutes. Deutsche Erde. [...] Das ist deutsch! Geht jetzt immer über mich in unsere Heimat. Wenn man's mit Blut tränkt, gibt es keine Grenzen.“ Kaergel 1922, S. 77-79. Das Schauspiel erschien in der Reihe „Deutsche Heimatspiele“ im Verlag des Bühnenvolksbundes (Patmos-Verlag). Zur Konnotation von Heimat, Erde und Mutter vgl. das folgende Kapitel I.2.3. 
männlichen Figur im Bildvordergrund illustriert, die melancholisch auf eine ländlich-dörfliche Szenerie hinblickt (Abb. 27) oder - einzige Ausnahme - deren Körperhaltung beschwingte Fröhlichkeit auszudrücken scheint, wobei das Gesicht abgewendet ist und man nach all den anderen Bildern vermuten möchte, dass das Gesicht doch mindestens eine leise Melancholie enthalte (Abb. 28).

Augenfällig ist neben der Ähnlichkeit der idyllisch-ländlichen Motive und dem verbindenden melancholischen Grundzug der Figuren die Tatsache, dass sich im Bildvordergrund stets Männer befinden - und das natürlich, weil ausnahmslos sie es sind, die aufbrechen, wandern, sich sehnen und wiederkommen. Frauen sind, wenn überhaupt, meist im Bildhintergrund als Teil der ländlichdörflichen Szenerie dargestellt, teils befinden sie sich zusätzlich noch in einem Innenraum, gerahmt vom Fenster des Hauses (Abb. 28). Heimat ist damit im ganz konkreten Sinn der Ort der Frau, während der Ort des Mannes sich variabel zu dieser Heimat verhält. Die Frau verharrt, der Mann bewegt sich im Raum, und es ist seine Perspektive, durch die wir Heimat sehen. Heimat ist der Gravitationspunkt des männlichen Aktionsradius, aber die männliche Figur (und mit ihr auch der Bildbetrachter) ist nicht eins mit diesem Punkt, sondern setzt sich zu diesem in Bezug, indem sie sich von ihm entfernt, sich nach ihm sehnt und gegebenenfalls zu ihm zurückkehrt - und so entsteht ja auch erst die Geschichte im Kopf des Betrachters, die Geschichte von Fernweh, Abschied, Wanderschaft, Heimweh und Rückkehr.

Die Illustrationen Liebermanns zeigen, wie sehr Heimat um 1900 einem polaren Geschlechterbild unterliegt, in dem Heimat nicht nur der Ort der Frauen ist, sondern selbst das Weibliche darstellt, so wie es zeitgenössisch verstanden wird: statisch, ruhend, verlässlich, passiv, empfangend und eine Größe, die männlichen Akteuren die Gelegenheit gibt, sich zu ihr ins Verhältnis zu setzen - als diejenigen, die dableiben oder weggehen, kalt bleiben oder sich sehnen, wegbleiben oder wiederkommen. ${ }^{125}$ Auch die Emotionen, die sich mit Heimat verknüpfen, gehen in diesem Sinn nicht von Heimat aus, sondern entstehen durch die Bezugnahme des männlichen Akteurs auf sie. Die Figurationen, die das 19. Jahrhundert für das Heimweh entwarf, sind vom Schweizer Söldner bis zum romantischen Wanderer damit allesamt als männliches Begehren lesbar und die Dialektik von Heimat, der zufolge Heimat für den Rückkehrenden nicht mehr dieselbe ist (vgl. I.2.3), offenbart sich in diesem Sinn als männlich codierte Erfahrung. Dass diese Geschlechtscodierung nicht den Realitäten entsprach, un-

125 „Strangers or returnees tend to be male, whereas the nostalgic Heimat of childhood is generally associated with the mother and in metaphorical extension with the maternal earth", so Elisabeth Boa und Rachel Palfreyman in ihrem Kapitel The Maternal Heimat as Threshold between Nature and Culture, Boa/Palfreyman 2000, S. 26. 

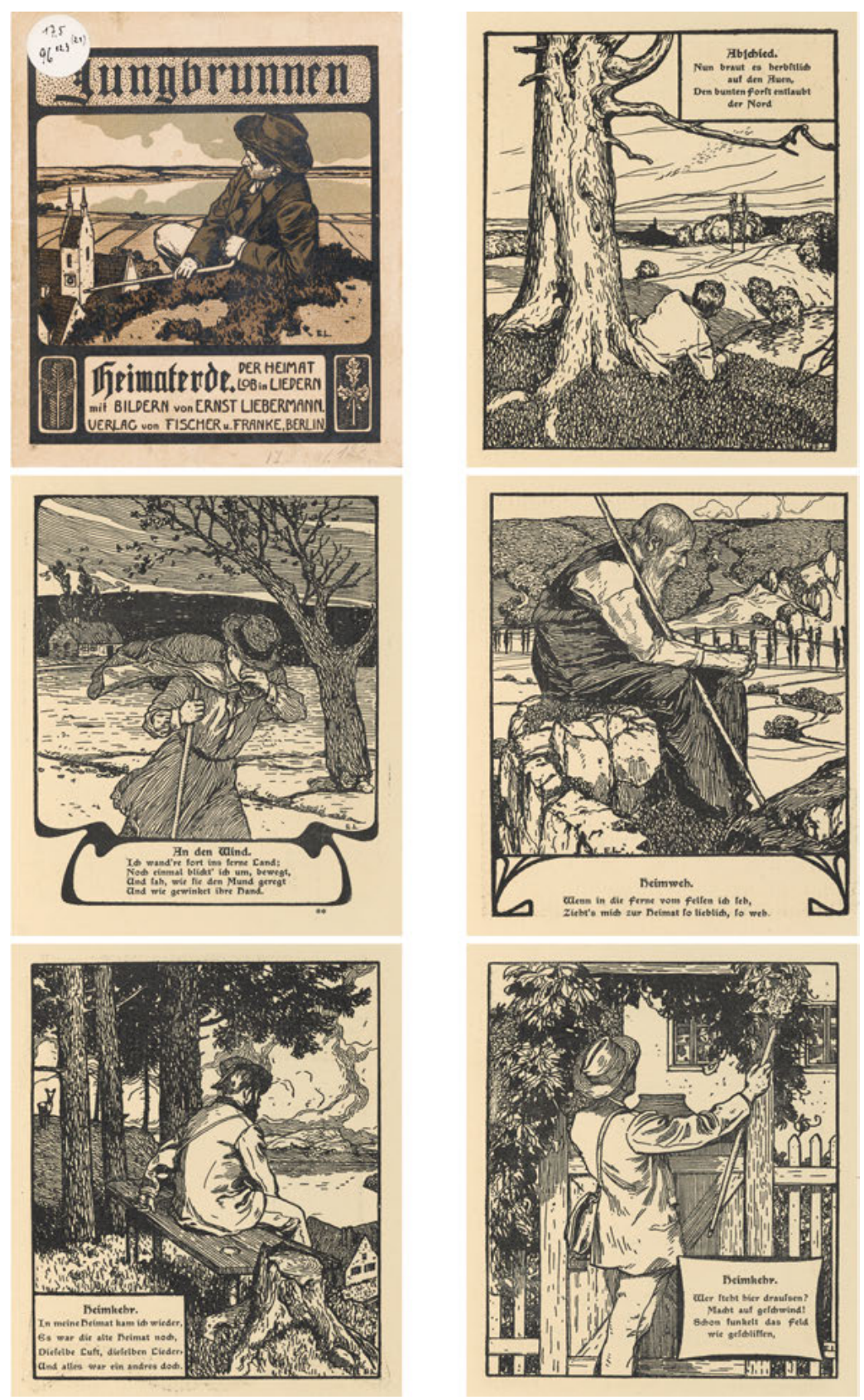

Abb. 23-28: Illustrationen der Lyrikanthologie „Heimaterde. Der Heimat Lob in Liedern“, Berlin 1901, von Ernst Liebermann (Klassik Stiftung Weimar) 
terstreicht nur die kulturgeschichtliche Wirkmächtigkeit dieser Figurationen: Tatsächlich haben Mediziner ja das pathologische Heimweh nicht nur bei Soldaten, sondern auch bei Dienstmädchen beobachten können ${ }^{126}$ - aber während das Heimweh der Schweizer Söldner zum literarischen, musikalischen und bildkünstlerischen Topos wurde, ${ }^{127}$ ist weibliches Heimweh eben nicht oder erst sehr spät in die Kulturgeschichte des 19. Jahrhunderts eingegangen; erst Johanna Spyri schuf mit Heidi's Lehr- und Wanderjahren (1880) eine prominente weibliche Heimwehkranke. ${ }^{128}$ Und während es im rechtlichen Sinn sehr viel häufiger die Frauen waren, die ihre ursprüngliche Heimat verloren - denn jede Eheschließung hatte automatisch die Annullierung der eigenen Heimatrechte zur Folge (vgl. II.2) -, hat sich auch diese weibliche Erfahrung des Heimatverlusts kulturgeschichtlich nicht in künstlerischen Darstellungen manifestiert.

Die Geschlechtscodierung von Heimat findet sich vereinzelt schon vor der modernen Geschichte des Heimatbegriffs, aber anders. Christian Hoffmann von Hoffmannswaldau assoziiert in einem Gedicht von 1695 Heimat mit dem weiblichen Schoß, und benennt „diese[] heymat“ als Ziel menschlichen (wohl männlichen) Triebes:

Vor allen aber hat der menfch den trieb empfangen

Und unfere vernunfft vermehret das verlangen;

126 Der Begriff des Heimwehs stammt aus der Medizingeschichte und sein erstes Auftauchen wird in der Regel mit der in Basel erschienenen Dissertatio medica de Nostalgia, oder Heimwehe des Schweizer Mediziners Johannes Hofers aus dem Jahr 1688 datiert. Diese und zahlreiche folgende medizinische Schriften beschrieben eine Reihe von Symptomen wie Nahrungsverweigerung, Apathie, Wahnsinn und Tod an Schweizer Soldaten, die fern ihres Geburtsortes stationiert waren, als pathologisches Phänomen, das als Heimweh bezeichnet wurde. Aber die sogenannte ,Schweizerkrankheit‘ oder ,morbus helveticus‘ bezog sich tatsächlich auf ein Phänomen, das schon früh auch in anderen kulturellen Umkreisen beschrieben worden ist, etwa bei den Lappen. Der Lappe, so Erasmus Francisci, bleibe, „wenn die Wahl bey ihm ftehet“, stets „lieber daheim“, müsse er „feiner Heimat entbehren“, sterbe er „in fehr kurtzer Zeit“. Francisci 1676, S. 325. Zum Heimweh als Teil des ,Heimatphänomens‘ aus kulturanthropologischer Sicht vgl. Greverus 1972, S. 33-35 und bezogen auf die ,Soldatenkrankheit‘ vgl. Greverus 1972, S. 97-130. Die Medizin und Kriminalistik des 19. Jahrhunderts diagnostizierte auch bei Dienstmädchen, die bei ihren Herrschaften mit dem Motiv Feuer legten, zurück nach Hause zu dürfen, pathologisches Heimweh, vgl. Jaspers 2019.

127 Vgl. vor allem Bunke 2009, sowie Starobinski 1963, Kittler 1986, Gröf 2000.

128 Heidi erhält in Frankfurt die ärztliche Diagnose, an Heimweh erkrankt zu sein, und muss zurück auf die Alm, um nicht daran zu sterben. Simon Bunkes Analyse erweist, dass Spyri in der Beschreibung der Symptome sehr genau auf die zeitgenössischen medizinischen Theorien zum Heimweh als pathologischem Phänomen Bezug nimmt, vgl. Bunke 2009, S. 541-576; vgl. auch Pfeifer 2019. Das Wort Heimat kommt im Roman übrigens fast nicht vor, vgl. Rutschmann 2008, S. 3. 
Die auch viel eyfriger nach diefer heymat ftrebt Und fich nicht eh vergnůgt als biß man daran klebt. Wie der magnet mit macht das eifen an fich ziehet Wie nach dem norden-pol die nadel fchlågt und fiehet So ift der liebften fchooß der nord und der magnet Wohin der gantze wunfch warhaffter menfchen geht. ${ }^{129}$

Sexueller Trieb statt sublimiertes Begehren, Lebenszugewandtheit statt Vergänglichkeitsbewusstsein - es ist bekannt, dass das nur die eine Seite des Barock ist, aber die weibliche Heimat ist hier eben interessanterweise der unbeschwerten Seite, dem carpe diem zugeordnet. So unverhohlen und direkt geht es in der Literaturgeschichte mit dem Begriffspaar Frau und Heimat aber nicht weiter.

In der Neuinterpretation religiöser Semantisierungen von Heimat durch Hölderlin und die Frühromantiker fällt in Bezug auf Weiblichkeitskonzepte zunächst auf, dass das Streben nach der Heimat zwar wie bei Hoffmannswaldau mit dem Streben nach der Frau zusammenhängt, das Begehren aber uneingelöst bleibt. Insofern die in der Literatur entfalteten Heimaten die religiöse Bedeutung des Begriffes in sich aufnehmen, enthält Heimat fortan immer ein Uneinlösbares, das sich einerseits mit einem sentimentalischen Verhältnis zur Vergangenheit, andererseits mit einem utopischen Verhältnis zur Zukunft verbindet - und dies gilt auch in Bezug auf das ,Weibliche‘. In Hölderlins Texten ist es das Begehren nach Geborgenheit in der (teils mütterlichen, teils familiären, teils körperlichen) Liebe, die mit Heimat assoziiert wird. In Clemens Brentanos Heimatentwürfen werden die Heimat repräsentierenden Frauengestalten vergöttlicht und die sexuellen Konnotationen durch ihre Madonnenhaftigkeit sublimiert (vgl. II.1.2).

In diesem Zusammenhang muss man sich vergegenwärtigen, dass Heimat in religiösen Kontexten bis 1800 in aller Regel (eine Abweichung bildet die katholische Marienverehrung ${ }^{130}$ mit Gottvater und Gottessohn männlich konnotiert

\section{Hoffmannswaldau 1695, S. 171.}

130 Die Verknüpfung von (himmlischer) Heimat und Mutter(gottes) findet sich im theologischen Kontext im vierten Mariendogma der katholischen Kirche. Folgt man der Interpretation des Dogmas von der leiblichen Aufnahme Marias in den Himmel durch Doris Brockmann, so unterliegt dessen Formulierung durch Papst Pius XII. im Jahr 1950 einer Logik, nach der eben auch himmlische Heimat erst als weibliche Heimat zu sich selbst findet: „Die in den Himmel erhöhte Maria vermag als Inbegriff ,wahrer Mütterlichkeit‘ Gewähr dafür zu bieten, daß das Ziel ,vollkommener Geborgenheit‘ erreicht werden kann. Diese Zielvorgabe ist auch im Deutungsmuster der ,himmlischen Heimat' angelegt, und zwar insofern es das durch Christus verheißene und zugleich verbürgte endzeitliche ,Bei-Gott-Sein` als einen Zustand ewiger Seligkeit beschreibt. Doch offenbar hat die Wirk- und Überzeugungskraft des Deutungsmusters von der ,himmlischen Heimat' sich in seiner bisherigen allgemeinen Form als unzureichend erwiesen und damit eben jene Präzisierung notwendig gemacht: Wenn ,Heimat‘ auf Ursprüngliches verweist und Herkunft 
war. Das Kirchenlied von Paul Gerhardt - „Ich wandre meine Straßen, / Die zu der Heimat führt, / Da mich ohn alle Maßen / Mein Vater trösten wird.“131 - bis Heinrich Bone - „Nun segne, Herr, uns allzumal / Mit deiner Vaterhand! / Und leit' uns durch dies Erdenthal / Zum ew’gen Heimatsland.“132 - verbindet die himmlische Heimat ausschließlich mit Vatergestalten (vgl. II.1.1). Insofern kann man die Neusemantisierungen von Heimat, die um 1800 in der Literatur einsetzen, unter anderem auch als geschlechtsspezifische Neucodierung religiöser Heimatvorstellungen lesen: Mit deren Säkularisierung um 1800 geht auch eine Effeminierung des Heimatbegriffs einher (vgl. II.1.2).

Die semantischen Verschiebungen des Heimatbegriffs um 1800 muss man in Bezug auf Geschlechtercodierungen einerseits in ihren religiösen Kontexten beleuchten, andererseits und teils damit zusammenhängend als Teil eines zeitgenössischen Wandels von Patriotismus- und Nationalstaatsdiskursen. Denn auch die Nation, das Vaterland, das Volk oder die Heimat wurden in diesen Diskursen mit Geschlechtercodes belegt. Während die literarischen Texte Klopstocks das Wort Heimat noch gar nicht verwenden und durchweg das Vaterland als begehrtes Objekt erscheint - „O Vaterland! o Vaterland! / Mehr als Mutter, und Weib, und Braut!“133 - findet ein erster, tastender Einbezug von Heimat als weiblich codierter Part innerhalb des literarischen Nationaldiskurses in der nächsten Dichtergeneration statt, etwa bei Friedrich Leopold zu Stolberg-Stolberg. Heimat beginnt, Teil des Enthusiasmus fürs Vaterland zu werden, und zwar als komplementärer, empfindsam codierter Part des Vaterlandes. Texte wie die von Stolberg-Stolberg und Salis-Seewis stehen allerdings erst an der Schwelle zu einer neuen Heimatsemantik (vgl. I.2.1). Die Ausdifferenzierung, die in den folgenden Jahrzehnten intensiv vonstattengeht und im Zuge derer Heimat als weiblicher Part innerhalb eines männlich codierten nationalen Vaterlandsdiskurses funktionalisiert wird, zeigt sich besonders eindrucksvoll bei Ernst Moritz Arndt (vgl. II.1.2).

Aus dieser Codierung ergibt sich einerseits ein Gefälle von Vaterland und Heimat - die sentimentalen Gefühle für die Heimat müssen zurückgestellt werden, um dem größeren Ganzen des Vaterlandes zu dienen -, andererseits aber

im Sinne von Familiarität thematisiert, ergibt sich für die Rede von der ,himmlischen Heimat‘, daß sie erst dann voll und ganz ihre Bedeutung und Plausibilität gewinnt, wenn die himmlische Wirklichkeit vorstellbar wird als eine Wirklichkeit, in der - neben dem göttlichen Vater und Sohn - auch die ,Gottesmutter einen festen Platz hat. Indem ihre Anwesenheit im Himmel sichergestellt ist, kann dieser erst recht als heimatlicher Ort imaginiert werden, als der Ort, wo das pilgernde Gottesvolk sein eigentliches Zuhause findet.“ Brockmann 1997, S. 90.

131 Paul Gerhardt: Ich bin ein Gast auf Erden, in: Gerhardt 1957, S. 369.

132 Bone 1851, S. 312.

133 Klopstock 2009, S. 80. 
auch ihre Zusammengehörigkeit: Vaterland und Heimat sind wie Mann und Frau dann Polaritäten, die einander ergänzen - entsprechend der Neudefinition der männlichen und weiblichen Sozialcharaktere, wie sie sich seit Ende des 18. Jahrhunderts auszubilden beginnen. ${ }^{134}$ An die Stelle von Standesschranken trat die „geschlechtsspezifische Segmentierung der bürgerlichen Lebenswelt““. ${ }^{135}$ Mit dieser Segmentierung ging auch eine gegenderte Codierung von weiblicher Heimat einher, die sich mit Erde, dem Vegetativen, Passiven, der natürlichen Neigung, dem Befriedenden und Unpolitischen zu verbinden beginnt, während sich das männliche Vaterland mit der abstrakten Idee, der Ratio, Pflicht und Notwendigkeit, Aggression, Aktivität und dem Politischen verknüpft - ein ausgesprochen prägendes Schema, das unterschiedliche Variationen erfuhr.

Der so verstandenen Heimat konnte beispielsweise utopisches und erlösendes Potential zugeschrieben werden, wie bei Richard Wagner, der seine „Sehnsucht nach der deutschen Heimat“ auf ein „geahntes und gewünschtes Neues, Unbekanntes, Erstzugewinnendes“ bezieht, als eine Sehnsucht „nach dem erlösenden Weibe“, das ihm im Sinne eines „weibliche[n] Element[s] überhaupt vorschwebte“. Dieses weibliche Element sieht Wagner als direkten „Ausdruck der Heimat, d.h. des Umschlossensein's von einem innig vertrauten Allgemeinen“, 136 aber einem noch unbekannten, nur ersehnten Allgemeinen (vgl. II.1.3.3). Dieses Heimatverständnis ist gar nicht so weit entfernt vom bürgerlichen Biedersinn seiner Zeit, wie Wagner vermutlich selbst gemeint hätte; seine „Sehnsucht nach der Heimat, Haus, Herd und - Weib“137 verweist jedenfalls auch auf den Zusammenhang von Heimat mit den bürgerlichen Bereichen der Frau.

Im vorherrschenden Heimatdiskurs gehen spätestens ab Mitte des 19. Jahrhunderts Idealisierung und Limitierung des Weiblichen Hand in Hand. ${ }^{138}$ Der Historiker Heinrich von Sybel erklärt 1870 nicht unangefochten, aber durchaus dem allgemeinen Zeitgeist entsprechend: „Das Gebiet der Frau ist das scheinbar enge und einförmige des inneren häuslichen Lebens; die Domaine des Mannes ist die Welt da draußen, die Wissenschaft, die Rechtsordnung, der Staat.“ So habe „es die Natur gewollt““, ${ }^{139}$ denn da die Frau zur Mutterschaft geboren sei, gebe es

134 Vgl. Karin Hausens einschlägigen Aufsatz zur Polarisierung der Geschlechtscharaktere, Hausen 1977.

135 Frevert 1986, S. 66.

136 Wagner 2004, S. 89-90.

137 Wagner 2004, S. 88.

138 Auch Peter Blickles Interesse im Zusammenhang von Heimat und Weiblichkeit ist es, „[to] trace the social implementation of this process of idealization and limitation of woman“; Blickle 2002, S. 83.

139 Sybel 1870, S. 13. 
gar keine anderen Möglichkeiten der Arbeitsteilung. Dass an der Ausbildung dieses bürgerlichen Selbstverständnisses der Geschlechter genauso die Frauen selbst arbeiteten, zeigt Elise Polkos für Frauen verfasstes Buch Unsere Pilgerfahrt von der Kinderstube bis zum eignen Herd von 1862 - eine Mischung aus Ratgeberliteratur und Lyrikanthologie, ein ausgesprochen erfolgreiches Buch, das 1909 in der 9. Auflage immer noch sehr gut verkauft wurde. Hier wird das Dreigestirn Mann, Schwert und Vaterland des ,bürgerlichen Wertehimmels ${ }^{\mathbf{1 4 0}}$ um das Dreigestirn Frau, Herd und Heimat ergänzt. Das „Martyrium“141 der Mutterschaft ist das Telos dieses Frauenlebens. Es besteht darin, die geliebten Töchter an deren Ehemänner abzugeben und die geliebten Söhne in die Welt hinausziehen zu lassen. Den in die Welt entlassenen Söhnen werde in ihrem Wanderleben die „himmlische Geduld, Güte und Großmuth“142 der verlassenen Mutter bewusst, was Elise Polko mit einem Gedicht Carl Siebels untermalt, das aus der Perspektive des ausgezogenen Sohnes geschrieben ist, der die Liebe zur Heimat, so der Titel des Gedichts, erkennt: „[...] / Und am Fenster zum Garten / Seh’ ich die Mutter. / Auf ihren Knieen / Ruhet ein Buch - / Sie liest in dem Buche. / Ich seh' es genau, / Es ist das Buch, / Das einst dem Sohne / Mit Thränen sie schenkte, / Und das der Sohn, / Als er fortging, / Vergaß. [...]. Wehmüthig über das Meer / Klingen die Glocken der Heimath.“ Polko schlussfolgert aus dem Gedicht: „Deine Macht ist doch groß, Mutterherz! Die Saat, die du unter frommen Gebeten sätest, sie geht doch einmal auf, früher oder später, - dein Sohn wird nicht verloren sein. “143 Der Zusammenhang von Heimat und der auf das Innen ausgerichteten Lebenswelt der Frau - sowohl im räumlichen Sinn des Hauses als auch im übertragenen Sinn der Intimität des Familienlebens, für die sie verantwortlich ist - drückt sich auch in den ab der zweiten Hälfte des 19. Jahrhunderts allerorten begegnenden Komposita mit Heimat aus - Heimatherd, Heimatort, Heimatliebe, Heimatgefühl. Der Konflikt der sich im Heimatbegriff kristallisierenden Klassenmoral mit einer Frauenemanzipation, die sich gerade nicht auf Häuslichkeit und Innerlichkeit festlegen lassen wollte, wird gegen Ende des Jahrhunderts dann auch in literarischen Texten offengelegt. ${ }^{144}$

140 Vgl. Hettling/Hoffmann 2000.

141 Hier zitiert nach der sechsten Auflage von 1877; Polko 1877, S. 282.

142 Polko 1877, S. 274.

143 Polko 1877, S. 275-276.

144 In einem erfolgreichen Theaterstück der wilhelminischen Ära, Hermann Sudermanns Heimat (1893), bezeichnet Heimat tatsächlich nichts anderes als die Ansprüche bürgerlicher Ehr- und Sittenmoral, die, konfrontiert mit den Ideen der Frauenemanzipation, in ein tragisches Ende münden. Das Theaterstück wurde 1893 in Berlin uraufgeführt, es folgten Aufführungen auf vielen Bühnen, auf denen das Stück „einen außerordentlich glänzenden Erfolg“ errang, „der durch die 
Neben dem Verständnis weiblicher Heimat als Bereich des Erlösenden (Wagner) und als Bereich des Innerlichen (Polko) ist ein drittes diskursiv wirkmächtiges Verständnis von Heimat das des Vegetativen. Auch das illustrieren die ab der Jahrhundertmitte inflationären Komposita von Heimatboden, Heimaterde oder Heimatflur. Einerseits verknüpfen sich die in diesem Kontext gewählten organologischen Bilder mit der Idee der Heimat als ,Wurzelgrund“ der Nation (I.2.1) oder des Volkes (vgl. I.2.2), andererseits und teils damit zusammenhängend insbesondere um 1900 dann mit Gesundungsphantasien einer von sich selbst erschöpften Moderne: In Wilhelm von Polenz' Büttnerbauern (1895) ist der Bauer „verwandt mit der Erde, die er bebaut. Er hängt mit ihr zusammen wie das Kind mit der Mutter vor der Trennung. Er empfängt von ihr geheimnisvolle Lebenskräfte, und ihre Wärme ist auch die seine." ${ }^{145}$ Die im Roman als Folge des Kapitalismus entstehende „Heimatlosigkeit“ von immer größeren Teilen der Landbevölkerung steht dagegen für den Verlust der „mütterlich nährende[n] Kraft“ der Scholle. ${ }^{146}$ Diese vielfach variierte Bildlichkeit von Heimat als einem nahrungund lebenspendenden und insofern mütterlichen Acker ist zugleich die zentrale Metapher für zahlreiche Heimattheorien um 1900, die im Heimatboden zugleich ein Bild für die ,gesunde Wahrheit' gefunden zu haben glauben. ${ }^{147}$ Gerade indem Heimat durch ihre zunehmende Verbindung mit der Erde, der Scholle, dem Boden zum Inbegriff der Selbstheilungswünsche der materialistischen und kapitalisti-

rasche Aufeinanderfolge von zehn Auflagen der Buchausgabe nur bestätigt wurde“. Ernst Troeltsch: Sudermanns Heimat, in: Troeltsch 2009, S. 341-358, hier S. 341. Der Anspruch der emanzipierten Magda, „um [i]hrer selbst willen dazusein“, wird ausgerechnet vom Pfarrer abgewiesen. Nicht den Ansprüchen ihrer Familie nachzukommen, einen ungeliebten Mann zu heiraten, wäre eine Versündigung an der Heimat: „Daß der alte Mann [gemeint ist der Vater] das nicht überleben würde, nun das versteht sich von selbst. Und was für Ihre Mutter dann bleibt, und was aus Ihrer armen Schwester wird - Fräulein Magda, das ist ja, wie wenn Sie mit eigner Hand Feuer an dies Haus legten und alles verbrennen ließen, was drin ist. Und dies Haus ist doch Ihre Heimat. [...] Aber tun Sie, was Sie wollen. Verderben Sie Ihre Heimat, verderben Sie Vater und Schwester und Kind, und dann versuchen Sie, ob Sie den Mut haben, um Ihrer selbst willen dazusein“ (Sudermann 1893, S. 144). Magda leitet dagegen ihre Freiheit als Frau und Künstlerin daraus ab, sich nicht unter „das Schutzdach irgendeiner Heimat, die aus den Händen des Vaters schlankweg in die des Mannes übergeht“ zu begeben, von der nicht nur das „Brot“, sondern auch noch die „Ideen“ und der „Charakter“ empfangen werden. Sudermann 1893, S. 163.

145 Polenz 1895, S. 138.

146 Beide Polenz 1895, S. 315.

147 „Heimat ist ein fester Boden mit Wurzeln und Knollen, mit Pflanzen und Leben, mit Organismen; und ein Versenken in ihre gesunde Wahrheit und Wärme ist Rettung vor Mechanismus und konstruierten Problemen, falls es mit rechter Reife geschieht. Sollte nicht der Weg zu Leben und Beseelung jeder Art weit eher über frisches Land gehen als durch die Zimmer der Theorie?“ Lienhard 1901, S. 197. 
schen Moderne wurde, kamen auch wieder Frauenbilder des Nahrungspendenden, Heilenden und Erlösenden ins Spiel, die sich genauso in Rudolf Herzogs Kriegsgedicht Frauen der Heimat (1916) finden; hier ,ward das ganze Heimatland/ Zur deutschen Frauenerde“. ${ }^{148}$ Der Begriff der ,Heimatfront‘, eine Wortneubildung des Ersten Weltkriegs, ${ }^{149}$ die das ursprüngliche Gegensatzpaar Heimat und Front verschmolz, war ebenfalls dem Bereich der Frauen zugeordnet, die hinter den eigentlichen Frontlinien den Männern den Rücken stärken sollten.

Das Bild des vegetativen, erdnahen Wesens der ,Frau' wird von der zeitgenössischen Naturwissenschaft und Medizin verstärkt ${ }^{150}$ und bleibt auch in literaturwissenschaftlichen Kontexten des 20. Jahrhunderts präsent. So erklärt der Literaturhistoriker Werner Mahrholz 1926 die angebliche Affinität weiblicher Autoren zur Heimatliteratur der Jahrhundertwende mit „größerer Erdnähe und Stammesverbundenheit des weiblichen Geschlechtes in einer Zeit, die die Männer von der Scholle zu treiben und in die Großstadt zu verpflanzen geeignet war““. ${ }^{151}$ Insbesondere der Aspekt der mütterlichen Heimat wird in den 1920er, 1930er und 1940er Jahren besonders dominant. Das Staatslexikon notiert 1927 in seinem Artikel zu ,Heimat‘: „Heimat ist mütterlich, ist Lebensschoß.“152 Die Verbindung von Frau, Heimat und Erde, die auch zur Ideologie des Nationalsozialismus zählte, war keine Erfindung des NS und blieb auch nach 1945 weiter bestehen, wie Ina-Maria Greverus 1972 ausführt und damit in der Heimat-Forschung die Verbindung von Heimat- und Frauenbildern erstmals in einer ideologiekritischen Perspektive betrachtet: „Dieser ,Mutter Erde‘-Kult, in den mit zahlreichen vagen Vorstellungen die Spekulationen der romantischen Naturphilosophie, Bachofens ,Mutterrecht' und Jungs Archetypus der ,Großen Mutter' eingingen, hatte sich bereits vor der nationalsozialistischen Hypertrophierung - zu einem ,Mutter ErdeHeimat'-Mystizismus entwickelt, der in einer populären bürgerlichen Weltanschauung zu einem zentralen, richtungsweisenden Ethos wurde und auch gegenwärtig noch vielfach Anhänger hat. “153

148 Rudolf Herzog: Frauen der Heimat, in: Herzog 1928, S. 380 - 381.

149 Die Inlandspropaganda verwendete den Begriff ab 1917, vgl. Flemming/Ulrich 2014, S. 17. Zur ,Heimatfront' als Aspekt der Begriffssemantik von Heimat im Kontext des Ersten Weltkriegs vgl. Gebhard/Geisler/Schröter 2007, S. 28-33 und im Kontext des Zweiten Weltkriegs vgl. Korfkamp 2006, S. 61-64.

150 Vgl. die Studie von Heinz-Jürgen Voß zu Dekonstruktionen des Geschlechts aus biologischmedizinischer Perspektive; Voß 2010.

151 Mahrholz 1926, S. 176. Karlheinz Rossbacher kann in Bezug auf dieses Zitat richtigstellen, dass von den 116 von ihm erfassten Heimatautoren zehn weiblich sind und damit ein für die Jahrhundertwende typisches Geschlechterverhältnis repräsentieren, vgl. Rossbacher 1975, S. 68. 152 Anonym: Heimat, 1927, S. 57.

153 Greverus 1972, S. 373. 
Tatsächlich wird das Paar Heimat und Mutter in den 1950er, 1960er und 1970er ungebrochen weiterverwendet, wenn von Heimat als „Lebensschoß“154 und „mütterliche[r] Lebenslandschaft“155 gesprochen wird und von einem Heimatgefühl, das „in seinem innersten Kern der Drang zur Mutter“156 sei. Die Literatur- und Geisteswissenschaften der 1980er Jahre, die zwar insgesamt eine ideologiekritische Haltung zu Heimat einnehmen, sind in aller Regel auf dem Gender-Auge blind und übernehmen solcherlei Wortbildungen unreflektiert. ${ }^{157}$

$\mathrm{Zu}$ der bis heute im Vergleich zur Flut der Veröffentlichungen sehr zurückhaltenden Auseinandersetzung mit diesem Aspekt von Heimat trägt die feministische Forschung seit den 1990er Jahren nur einige wenige Ansätze bei. Sie bewertet die kulturhistorische Allianz von Heimat und Weiblichkeit dabei teils konträr. Elisabeth Bütfering beklagt unter dem Titel Die Heimatlosigkeit ist weiblich den Ausschluss der Frauen aus ,Heimat': „Die Heimat der Männer sind die Frauen. Wo aber ist der Frauen Heimat? Bei den Männern? Wohl kaum. “158 Sie stellt der patriarchalen Heimat eine programmatische Heimatlosigkeit bzw. das ,Vagabundieren' als angemessene weibliche Identitätssuche entgegen, um eigene, spezifisch weibliche utopische Räume überhaupt erst aufzufinden und „alternative Heimaten wenigstens zu denken“. ${ }^{159}$ Damit stellt sie ihr Anliegen, ohne dies zu thematisieren, in eine mit Nietzsche eingeführte und dann seit Beginn des 20. Jahrhunderts durchaus prominent gewordene Tradition der Aufwertung von Heimatlosigkeit (vgl. III), die teils auch aus dezidiert weiblicher Perspektive vorgebracht wurde, etwa in Ilse Frapans Roman Wir Frauen haben kein Vaterland (1899), in dem die Protagonistin zum radikalen Bruch mit den herrschenden Verhältnissen auffordert: „Brechen mit allem und mit allen: Hinunter in das

154 Köhler 1959, Sp. 57. „Gerade die Passivität des Sich-in-der-Heimat-geborgen-Wissens und die Passivität der in sich ruhenden Heimat selbst geben der Heimat eine nur ihr eigene Integrationskraft [...].“

155 Moebus 1954, S. 41.

156 Röhrig 1959, S. 28.

157 Die vorangehenden Zitate von Oskar Köhler, Gerhart Moebus und Herbert Röhrig werden z.B. mehr oder weniger unkritisch übernommen in Bredow/Foltin 1981, S. 28-29. Auch Peter Blickle diagnostiziert eine weitgehende Kontinuität der Funktionalisierung von Heimat auch noch im 20. Jahrhundert: „Heimat is the shining bride or shining motherhood. But as such, Heimat is strongly implicated in two centuries of bourgeois subjection (that is, subjugation and subjectification) of women." Blickle 2002, S. 82.

158 Bütfering 1990, S. 416. Den Titel wählt sie in Anlehnung an das Gedicht Die Heimatlosigkeit ist weiblich von Dagmar Bielstein, Nachweis Bütfering 1990, S. 416.

159 Bütfering 1990, S. 428. Mit der Idee des feministischen Vagabundierens schließt Bütfering an Christina Thürmer-Rohr an, vgl. Thürmer-Rohr 1987. Zur feministischen Konzeption des nomadischen (weiblichen) Subjekts vgl. auch Braidotti 1994. 
Namenlose, zu den Rechtlosen, zu den Enterbten. Dorthin gehör' ich ja, ich und alle Frauen, Heimatlose, Vaterlandslose“. ${ }^{160}$ Bütfering bleibt bei dieser Affirmation von Heimatlosigkeit nicht stehen; letztlich geht es ihr darum, neue, alternative Heimaten für die Frau zu entdecken.

Gisela Ecker, die 1997 mit einem Sammelband zum Zusammenhang von Heimat und Weiblichkeit einen weiteren feministischen Blick auf das Thema wirft, diagnostiziert die „deutlich erkennbare ödipale Spur“, ${ }^{161}$ die sich durch die Diskurse um Heimat ziehe. Texte weiblicher Schriftstellerinnen zeigten auf, dass Heimat als Ort des (männlichen) Begehrens „Produkt weiblicher Anstrengungen“ und weiblichen Leidens sei und „daß die ödipale Konstruktion der Realitätsprobe nicht standhalten kann“. ${ }^{162}$ Im Gegensatz zu Bütfering hält sie die Suche nach weiblicher Heimat aber nicht für produktiv, sondern den Begriff für historisch diskreditiert. ${ }^{163}$ Auch für Peter Blickle ist Heimat so eng mit geschlechtsspezifischen Machtverhältnissen verbunden, dass sie sich jeglicher Neubesetzung entzieht. ${ }^{164}$ Der Blick auf den Zusammenhang von ,power and gender“ offenbare, dass „Heimat conceptualizations at any given time are closely linked to the class and gender interests of a narcissistically conceived masculinized self, a male subject, a male ego. Heimat usually represents an idealized loser in gender or class questions (woman or peasants), but always from the point of view of the winner (the bourgeois male). "165 Abgesehen davon, dass Blickles Diagnose genauso wie die seiner Vorgängerinnen teils mit vereinfachenden Stereotypen ar-

160 Frapan 1899, S. 153.

161 Ecker 1997, S. 10.

162 Ecker 1997, S. 22 und 23; als Beleg werden u. a. die Autorinnen Ilse Aichinger, Marieluise Fleißer, Maria Beig und Anna Wimschneider herangezogen.

163 „Die affektiven Besetzungen, die sehr viel mit dem ödipalen Grundmuster zu tun haben, entsprechen einfachen, infantilen Begehrensmustern, die schnell aufrufbar sind, und sie konstruieren darüber hinaus über das Familienmodell einen unschuldigen Ort. Im Gegensatz zu ,Nation‘ und ,Vaterland', die mit Schuld belastet sind, ermöglicht ,Heimat‘ den Rekurs auf einen Ort der Unschuld, über den neue Setzungen von Sinn und Identität legitimiert und kontinuierlich gestiftet werden können. Der Preis dafür ist das Verschwinden und die Tilgung von Differenz/en.“ Ecker 1997, S. 31.

164 Blickle widmet sich 2002 in seiner Studie zu Heimat von 2002 ausführlicher der Frage nach ,Heimat and the Feminine'. Neben seinen ausführlichen Referaten von Bütferings Aufsatz und Eckers Sammelband geht er auch auf weitere feministische Auseinandersetzungen mit ,Heimat" ein, die aber entweder keinen wissenschaftlichen Anspruch haben oder ,Heimat' nur im übertragenen oder weit entfernten Sinn thematisieren und deswegen hier nicht genannt werden. Noch 2002 stellt Blickle fest, dass die wissenschaftliche Beschäftigung mit dem Zusammenhang von Heimat und Gender ganz am Anfang stehe: „It is clear that research on the formative aspects of gender in Heimat is just beginning." Blickle 2002, S. 107.

165 Blickle 2002, S. 71. 
beitet, die sie vorgibt zu beschreiben, ist im Rückblick interessant, dass sowohl Ecker als auch Blickle gern mit freudschen Erklärungen arbeiten. Die Wende zum 20. Jahrhundert mit ihrem Kult des Heimatbegriffs beschreibt Blickle mit Sigmund Freuds Theorien zum Geschlechterverhältnis, insbesondere zum „Oedipus complex“. 166

Tatsächlich ist besonders Freuds Theorie des Unheimlichen von 1919 einschlägig für die Frage nach Heimat und Weiblichkeit um 1900:

Es kommt oft vor, daß neurotische Männer erklären, das weibliche Genitale sei ihnen etwas Unheimliches. Dieses Unheimliche ist aber der Eingang zur alten Heimat des Menschenkindes, zur Örtlichkeit, in der jeder einmal und zuerst geweilt hat. ,Liebe ist Heimweh;, behauptet ein Scherzwort, und wenn der Träumer von einer Örtlichkeit oder Landschaft noch im Traume denkt: Das ist mir bekannt, da war ich schon einmal, so darf die Deutung dafür das Genitale oder den Leib der Mutter ersetzen. Das Unheimliche ist also auch in diesem Falle das ehemals Heimische, Altvertraute. Die Vorsilbe ,un an diesem Worte ist aber die Marke der Verdrängung. ${ }^{167}$

Während Freuds Theorie aus heutiger Perspektive allerdings doch eher selbst als Teil eines historischen Diskursgefüges von Heimat und Gender gelesen werden sollte - nämlich bezüglich des Umstands, dass hier erstens die Frau bzw. ihr Genital mit Heimat gleichgesetzt wird und zweitens die männliche Irritation in Bezug auf die so verstandene Heimat pathologisiert wird -, wird Freud von Ecker bis Blickle interessanterweise aber als Erklärer, nicht als Symptom des Komplexes von Heimat und Frau behandelt.

Die neueste feministische Forschung zum Thema knüpft eher an Bütfering als an Ecker und Blickle an, insofern nach einer weiblichen Heimat gefragt und eine spezifisch weibliche Perspektive auf Heimat behauptet wird: „Female authors’ texts, then, are worth exploring precisely because they provide a counterpart to a discourse that needs to be understood as constituting a male perspective. " $168 \mathrm{Im}$ Anschluss an neue kulturwissenschaftliche Zugriffe auf Heimat - etwa die Arbeiten von Friederike Eigler ${ }^{169}$-, die Heimat nicht mehr ideologiekritisch, sondern

166 „The thematization of the woman is everywhere. The Oedipus complex has much to recommend it as a symbol (or a symptom) of the period between about 1880 and 1910, at least within a bourgeois context. Heimat during this period is an imagistically processed Oedipus complex in which the son's incestuous longings to reenter the mother (as in nature) become a socially shared and accepted state ,of fusional perfection'." Blickle 2002, S. 92.

167 Freud 1986, S. 258-259.

168 Bland/Smale/Weiss-Sussex 2019, S. 7.

169 Vgl. Eigler/Kugele 2012 und Eigler 2014. Im Anschluss an raumtheoretische Konzepte der Cultural Studies erforscht Eigler, „how dynamic concepts of space shape prose fiction and, in particular, narrative renderings of Heimat“. Eigler 2014, S. 7. Eigler bespricht literarische Texte von 
mit neueren Raumtheorien als dynamisches und insofern auch mit ideologisch unverdächtigen Werten wie der Gestaltung lebenswerter Räume zu verknüpfendes Konzept verstehen, versuchen Caroline Bland, Catherine Smale und Godela WeissSussex, den Begriff auch für feministische Ansätze verwertbar zu machen: „[A]n alternative understanding of Heimat as ,open and porous‘ establishes the potential for feminist readings of this space which favour relational thinking over the desire to fix oneself and others into stable and stabilising identity positions. "170 Ein historischer Schwerpunkt liegt dabei auf Autorinnen der Jahrhundertwende und der Weimarer Republik wie Claire Goll, Elisabeth Landau oder Erika Mann, die daraufhin untersucht werden, wie sie den herrschenden Heimatdiskurs unterlaufen und emanzipatorische Heimatvorstellungen entwerfen, „drawing out the themes of resistance to and self-liberation from the Heimat discourse“". ${ }^{171}$ Diese Blickrichtung könne demonstrieren, „that, in the hands of female writers, Heimat could be [...] a catalyst for change“. ${ }^{172}$

Es liegt auf der Hand, dass ein solcher Ansatz, der unterstellt, Frauen seien die Urheberinnen von als ,progressiv‘ eingeschätzten Heimatvorstellungen, weder erklären kann noch will, warum es ,subversive' Heimatentwürfe genauso und, da mehr Männer schrieben, sogar in weitaus größerer Anzahl bei männlichen Autoren gibt und, noch viel wichtiger, warum weibliche Autorinnen mehrheitlich an dem vorherrschenden, geschlechterpolarisierenden Heimatnarrativ mitarbeiteten und es keinesfalls subversiv unterliefen. Solange ein spezifisch weibliches Schreiben unterstellt wird, wird an Gendernarrativen interessierte Forschung dazu neigen, weibliches mit subversivem Schreiben zu korrelieren und damit an den eigentlich interessanten Fragen von Macht und Geschlecht vorbeizugehen.

Festzuhalten bleibt, dass die Konstellation Heimat - Frau sich auch in feministischer Perspektive als historisch beweglich erweist. Sie hat zahlreiche Transformationen durchlaufen, wie noch einmal abschließend in Bezug auf das Text-Bild-Verhältnis der von Liebermann illustrierten Lyrikanthologie gezeigt werden soll, die ja zum überwiegenden Teil romantische Gedichte enthält. ${ }^{173}$ Zwischen der Effeminierung von Heimat in der Lyrik der Romantiker und derje-

den 1970ern bis in die Gegenwart, die sich dem Thema von Flucht und Vertreibung aus den ehemalig deutschen Ostgebieten nach 1945 widmen.

170 Bland/Smale/Weiss-Sussex 2019, S. 5.

171 Bland/Smale/Weiss-Sussex 2019, S. 8.

172 Bland/Smale/Weiss-Sussex 2019, S. 13.

173 Mit Gedichten von C. F. Meyer, Emanuel Geibel, Otto Ludwig, Victor von Scheffel einerseits und Nikolaus Lenau, Joseph von Eichendorff, Ludwig Uhland, Hoffmann von Fallersleben andererseits sind etwa die Hälfte der für die Anthologie ausgewählten Autoren romantische, vgl. Liebermann 1901. 
nigen der Anthologieillustrationen liegen entscheidende Differenzen. Während sich Heimat in romantischen Gedichten mit dem unerreichbaren, transzendenten Weiblichen verbindet, arbeiten Liebermanns Illustrationen an einer retrospektiven Verbürgerlichung romantischer Heimaten, die wenig mit den Texten der romantischen Autoren zu tun hat. Die Darstellung von Heimat als ländlich-dörflicher, idyllischer Raum und der Frau als Repräsentantin dieses Raums ist eine ausgesprochen wirkmächtig gewordene Auslegung des romantischen Heimatbegriffs, der sich an den Texten der Romantiker aber gar nicht belegen lässt, ebenso wenig wie das damit verbundene Weiblichkeitskonzept. Das Jahrhundert, das die Texte und ihre Illustrationen voneinander trennt, hat einen Wandel im Gefüge von Heimat und Geschlecht mit sich gebracht.

Die Verbindung von Heimat und Weiblichkeit um 1900 erschöpft sich nun ihrerseits nicht in der biederen Version der liebermannschen Lyrikanthologie, auch wenn diese ausgesprochen repräsentativ für den Zeitgeist ist. Von Richard Dehmel über Stefan George bis Robert Walser, ${ }^{174}$ von Clara Viebig (vgl. II.3.3) über Ilse Frapan bis Helene Voigt-Diederichs (vgl. II.3.3) ist das Spektrum an möglichen Perspektiven auf Heimat auch in ihrem Bezug auf Weiblichkeitsentwürfe sehr viel breiter und wird in dieser Arbeit weiterverfolgt.

\subsection{Heimat und Fremde: Exil, Migration, Diaspora}

Die Geschichte der Heimat ist immer auch eine Geschichte der Fremde. Erst die Fremdheitserfahrung bringt Heimatbewusstsein hervor - aber dieses birgt im historischen Bewusstsein des 19. Jahrhunderts schon einen Verlust, denn Heimat wird in dieser Perspektive nie wieder so sein wie zuvor. Das 19. Jahrhundert ent-

174 In Dehmels Gedicht Heimat von 1891 vollzieht sich die Assoziation von Heimat und Mutter ohne jede Mehrdeutigkeit: „Und höre sacht die Türe klinken, / Mutter tritt mit der Lampe ein; / Und alle Sehnsüchte versinken, / O Mutter, in dein Licht hinein." Richard Dehmel: Heimat, in: Dehmel 1913, S. 51. Stefan Georges Gedicht Muenchen von 1907 spielt mit dem Doppelsinn der Münchner Liebfrauenkirche und erotischen Konnotationen: „Du stadt von volk und jugend! heimat deucht / Uns erst wo Unsrer Frauen türme ragen“. George 1941, S. 204. Und Robert Walsers kurzer Prosatext An die Heimat von 1905 ist ironisch gemeint, jedenfalls lässt sich die Repetitio („der Heimat, der Heimat“) als eine Hyperbel verstehen, die die Aussage im Ganzen in Frage stellt: „Heute morgen umarmt sie mich, und ich vergesse mich in ihrer üppigen Umarmung. Keine Frau hat so weiche, so gebieterische Arme, keine Frau, auch die schönste nicht, küßt mit so unendlicher Inbrunst, wie meine Heimat mich küßt. Tönt Glocken, spiele Wind, braust Wälder, leuchtet Farben, es ist doch alles in dem einzigen, süßen Kuß, welcher in diesem Augenblick meine Sprache gefangen nimmt, in dem süßen, unendlich köstlichen Kuß der Heimat, der Heimat enthalten.“ Walser 2020, S. 15. 
wickelt aus dieser nostalgischen Konstellation eine Dialektik, die sich als (geschichts-)philosophische Denkfigur genauso wie als Erzähltopos niederschlägt. In diese Topoi des Denkens und Erzählens gehen die unterschiedlichen historischen Erfahrungen des Jahrhunderts ein. Die jüdische Diaspora, das politische Exil, Auswanderung und die Abwanderung in die wachsenden Städte sind die sozialgeschichtlichen Gründe des Verhältnisses von Heimat und Fremde, eines Verhältnisses, das zugleich seine religiöse Dimension hat - denn nach christlicher Ansicht ist der Mensch immer nur Gast auf Erden (vgl. II.1.1) - und auch seine rechtliche Seite, denn das Heimatrecht bringt nicht nur Heimat, sondern eben auch Heimatlosigkeit im juristischen Sinn hervor, nach der der Heimatlose keinen Anspruch auf Versorgung hat - nirgendwo (vgl. II.2.1). All diese Aspekte hängen vielfältig miteinander zusammen.

\section{Heimat und Fremde als Dialektik}

Heimat und Fremde zeigen sich im 19. Jahrhundert zunächst als zwei Seiten eines dialektischen Reflexionsmodells, das sich auch in einer spezifischen Färbung des (älteren) Narrativs von Aufbruch, Wanderung und Heimkehr niederschlägt. Die im Kapitel zu Heimat und Volk (I.2.2) diskutierten Bienen-Bilder zeigen die Veränderung. Bei Friedrich Spees Bienen ist die Bewegung von Heimat zu Fremde zu neuer Heimat eine lineare: Die alte Heimat wird verlassen, um eine neue $\mathrm{zu}$ gründen. Bei von Kleists und bei Herders Bienen gibt es eine Rückkehrbewegung aus der Fremde in die Heimat: Die Heimat profitiert von dem, was aus der Fremde mitgebracht wird, ohne sich aber selbst substantiell dabei zu verändern. Aus dieser Bewegung entwickelt sich im 19. Jahrhundert eine geradezu topische Dialektik, nach der Heimat die Notwendigkeit in sich birgt, in die Ferne zu ziehen, und die Ferne diejenige, in die Heimat zurückzukehren. Heimat ist dann nicht mehr dieselbe, genauso wenig wie der Zurückgekehrte noch der Alte ist. Diese Veränderung kann positiv gedeutet werden, etwa in den Versen Clemens Brentanos von 1801, in denen die Heimat an Größe in dem Maß gewinnt, in dem sie Fremde in sich aufnimmt: „So weit als die Welt, / So mächtig der Sinn, / So viel Fremde er umfangen hält, / So viel Heimath ist ihm Gewinn. “175 Sie kann auch negativ oder melancholisch als Verlust gedeutet werden.

Wie stark die Bewegung von der Heimat in die Fremde und wieder zurück in die Heimat im 19. Jahrhundert in allen diesen Fällen durch die hegelsche Reflexionsfigur geprägt ist, zeigt mit denkbarer Deutlichkeit eine Passage aus Berthold

175 Clemens Brentano: So weit als die Welt, in: Brentano 2007, S. 26. Das Gedicht entstand 1798 und erschien zuerst 1802 als Teil des Romans Godwi oder Das steinerne Bild der Mutter. 
Auerbachs Literaturprogrammatik Schrift und Volk von 1846. Die Bewegung von Entzweiung und Vermittlung zur Synthese fasst Auerbach ins Bild eines Heimkehrers, dem sich über den Gegensatz von Heimat und Fremde eine neue Heimat erschließt:

Er hat das Ferne ganz mit heimischem Auge gesehen, weiß es den Seinen so lebendig vor die Seele zu führen, daß sie es mit ihm sehen, denn es ist ihr eigener Blick, der darauf geruht, es ist ihr eigener Standpunkt, von dem aus es betrachtet, es ist ihre eigene Empfindung, die dadurch erweckt wurde. Und nun tritt er hinaus, schaut die Pracht der Alpen, hört den Bergstrom rauschen und die Lieder klingen; er sieht das Heimische fast mit fremdem Auge, mit einem Blick, der auf Entferntem geruht und dem sich das Heimische neu erschließt, er empfindet seine Schönheit und Eigenthümlichkeit selbständiger, er war aus sich hinausgerissen, seine eigenthümlichste Seele an Fremdes hingegeben, er war zum Gegensatze, zur Entzweiung und so zur Vermittlung gelangt; er war in der Fremde zu Hause und ist nun in der Heimat fremd und doch wieder heimisch. Fremde und Heimat verschlingen sich in ihm $\mathrm{zu}$ einer neuen Heimat. ${ }^{176}$

Direkt im Anschluss überträgt Auerbach dieses Heimkehrerbild auf Johann Peter Hebels Alemannische Gedichte. Hebel ist der Fixstern von Auerbachs literaturtheoretischer Schrift, ihm gilt seine rückhaltlose Verehrung und an dessen Werk entfaltet er die eigene Programmatik:

Aehnlich ist Hebel von weiten Gedankenfahrten im klassischen und biblischen Alterthum, aus den Allgemeinheiten der Naturwissenschaften, aus Staats- und Lehrgeschäften zurückgekehrt zur Heimat, und was er Fremdes mitbringt, hat sich in ihm zum Heimischen ausgebildet und wird als solches von den Seinigen empfangen. Das Heimische aber ersteht in ihm und um ihn her in neuer Glorie. Er sieht und verkündet auch in dem Alemannischen sowohl die Schönheit der klassischen als auch die religiöse Weise des biblischen Alterthums. Und warum sollten dem allemannischen Bauernleben diese beiden Momente weniger innewohnen als dem Bauern- und Hirtenleben der Juden und Griechen? ${ }^{177}$

Die Synthese von Heimat und Fremde zu einer neuen Heimat sieht Auerbach durch Johann Peter Hebels volksaufklärerische Schriften verwirklicht. Auerbachs Darstellung von Hebels „Gedankenfahrten“ ins Altertum und in die Wissenschaften und deren für die Heimat fruchtbringender Anwendung durch den Rückkehrer, die die Heimat zu „neuer Glorie“ führe, erinnert in vielen Einzelheiten an das bei Ewald Christian von Kleist und vor allem Herder gewählte

176 Berthold Auerbach: Schrift und Volk. Grundzüge der volksthümlichen Literatur, angeschlossen an eine Charakteristik J.P. Hebel's (1846), in: Auerbach 2014, S. 7-173, hier S. 29. Auch Rohde weist auf die Nähe des Zitats zu Hegel hin, vgl. Rohde 2014, S. 78-79.

177 Berthold Auerbach: Schrift und Volk. Grundzüge der volksthümlichen Literatur, angeschlossen an eine Charakteristik J. P. Hebel's (1846), in: Auerbach 2014, S. 7-173, hier S. 29-30. 
Bienen-Bild (vgl. I.2.2), übersteigt es aber zugleich. Denn Heimat und Fremde spiegeln sich ineinander - ,in der Fremde zu Hause‘ und ,in der Heimat fremd ‘ und bringen, indem sie sich ineinander ,verschlingen', ein neues, größeres Ganzes hervor, eine ,neue Heimat'.

Die gleiche Gedankenfigur ist in Ludwig Feuerbachs einflussreicher Schrift Das Wesen des Christentums von $1841 \mathrm{zu}$ finden, in der er bekanntlich die „sittliche Heilkraft und die theoretische Wahrheit der Religion“ als Möglichkeit des Menschen bestimmt, sich selbst ,in seiner absoluten Freiheit und Unbeschränktheit“ zu erkennen. Der Mensch ist ihm Anfang, Mittelpunkt und Ende der Religion. ${ }^{178}$ Der Glaube an das Jenseits ist nach Feuerbach Glaube an „das abstracte Dießseits“, ${ }^{179}$ also an ein Diesseits, das aller vom Menschen als negativ bestimmter Aspekte ledig ist: ein Diesseits, das nicht endlich ist und das kein Leiden und keine Verfehlungen kennt. Durch die im Glauben an ein solches Jenseits stattfindende Besinnung wird sich demnach der Mensch in seinem irdischen Dasein inne. Eben diese Idee fasst Feuerbach ins dialektische Bild von Heimat, Auszug in die Ferne und geläuterter Rückkehr in die Heimat:

Der natürliche Mensch bleibt in seiner Heimath, weil es ihm hier wohlgefällt, weil er vollkommen befriedigt ist; die Religion, die in einer Unzufriedenheit, einer Zwietracht anhebt, verläßt die Heimath, geht in die Ferne, aber nur um in der Entfernung das Glück der Heimath um so lebhafter zu empfinden. Der Mensch trennt sich in der Religion von sich selbst, aber nur, um immer wieder auf denselben Punkt zurückzukommen, von dem er ausgelaufen. Der Mensch negirt sich, aber nur um sich wieder zu setzen, und zwar jetzt in verherrlichter Gestalt $[\ldots] .{ }^{180}$

Solchen literaturprogrammatischen und religionsphilosophischen Überlegungen stehen erzählerische Umsetzungen an der Seite, beispielsweise in Zwischen Himmel und Erde (1856), einer gemeinhin als repräsentativ für das realistische Erzählen geltenden Novelle ${ }^{181}$ Otto Ludwigs, die durch die Stationenabfolge von Heimat, Auszug in die Fremde, gereifter Rückkehr in die Heimat strukturiert ist. Der Held sieht eigentlich keinen Anlass, die Heimat zu verlassen. ${ }^{182}$ Aber die Er-

178 Feuerbach 1841, S. 247.

179 Feuerbach 1841, S. 246.

180 Feuerbach 1841, S. 242.

181 Vgl. etwa das Kapitel zu Otto Ludwig in: Brinkmann 1957, S. 145-216.

182 „Es ist die Frage, ob sich unser Held freiwillig hätte entfchließen können, die Heimath zu verlaffen, er, der nicht begriff, wie Jemand wo anders leben könne, als in seiner Vaterstadt, dem es immer wie ein Mährchen vorgekommen war, daß es noch andere Städte gäbe und Menschen drin wohnten, der sich das Leben und Thun und Treiben dieser Menschen nicht als ein wirkliches, wie 
fahrung der Fremde stellt sich als notwendig heraus, um seine Heimatliebe von der Sohnes- zur Mannesliebe reifen zu lassen:

Die Liebe zur Heimath war noch so stark in ihm als je, aber es war nicht mehr die des Knaben, dem die Heimath eine Mutter ist, die ihn hätschelnd in die Arme nimmt; es war die Liebe des Mannes. Die Heimath war ihm ein Weib, ein Kind, für das zu schaffen es ihn trieb. $^{183}$

Heimatliebe drückt sich bei den bürgerlichen Realisten wie Ludwig - auch bei Gustav Freytag wird das noch zu sehen sein (vgl. 3.1.2 und 3.2.2) - vor allem im Arbeitsethos aus. Das männlich konnotierte tätige Schaffen, Grundlage patriarchaler Ordnung, bildet Ziel und Erfüllung des idealen bürgerlichen Mannes: „Er durfte für die geliebte Heimath schaffen und anwenden, was er in der Fremde gelernt.“184

Die hier in drei Varianten vorgestellte Denk- und Erzählfigur einer am Fortschrittsmodell orientierten Heimatdialektik geht nicht immer so harmonisch auf wie hier bei Auerbach, Feuerbach und Ludwig. ${ }^{185}$ Mindestens genauso häufig findet sich ein nostalgisches Modell dieser Dialektik, nach dem die Heimat nur noch ein trauriges ,Zu spät!‘ für den Heimkehrer übrighat. Ein literaturgeschichtlich prominenter Leidender an einer so aufgefassten Dialektik ist Gottfried Kellers Grüner Heinrich: Als in der Fremde gänzlich Gescheiterter glaubt Heinrich, mit der Rückkehr in die „Heimat“ werde sich sein „Geschick“ erfüllen und sei das „höchste Gut“ erreicht. ${ }^{186}$ Aber dem über weit mehr als hundert Seiten beschriebenen Rückweg in die sehnsüchtig beschworene Heimat stehen dann nur ein paar knappe Seiten gegenüber, auf denen die Ankunft als Kollaps sämtlicher

die Bewohner seiner Heimath es führten, sondern als eine Art Schattenspiel vorgestellt hatte, das nur für den Betrachter existirte, nicht für die Schatten selbst.“ Ludwig 1856, S. 21-22.

183 Ludwig 1856, S. 35.

184 Ludwig 1856, S. 66.

185 Gabi Kathöfer beschreibt eine ganz ähnliche Figur in Bezug auf Märchentexte des 19. Jahrhunderts, allerdings nicht als dialektische, sondern als zyklische, und orientiert sich dabei an Theorien der jüngeren Kulturwissenschaft. Das Märchen schaffe mit seiner zyklischen Struktur von „Heimat-Auszug-Heimkehr“ einen „Alteritäts(t)raum“, als „Vision einer Überschreitung sozialer Grenzen“ und „der Auflösung starrer Gesellschaftsstrukturen“, Kathöfer 2008, S. 10 -11. 186, „[...] von glänzenden Vorstellungen der Heimat getränkt und durchdrungen, und die einfache Rückkehr nach derselben erschien ihm jetzt nach all den Hoffnungen und Bestrebungen das wünschenswerteste und höchste Gut“. Keller 1985, S. 759. Die Rückkehr in die „Heimat“ erscheint Heinrich als eine Erfüllung seines ,Geschicks‘ : „nun dünkte ihn, daß sein Geschick die zur Rückkehr notwendige klare und feste Form angenommen habe“. Keller 1985, S. 786. Zu Kellers Grünem Heinrich vgl. auch die kurzen Ausführungen in 2.2.3. 
Hoffnungen und zugleich von Heinrichs Lebenswillen beschrieben wird; „er starb in wenigen Tagen“. ${ }^{187}$

Die Unmöglichkeit, die alte Heimat jemals wiederzuerlangen bzw. die mit ihr verknüpften Hoffnungen einzulösen, nachdem sie einmal verlassen wurde, macht Nikolaus Lenaus Gedicht Einst und Jezt zum Thema (1829/31). Es setzt ein mit dem Wunsch, wieder „in die Gegend“ zu ziehen, wo das lyrische Ich „einst so selig war".
Also sehnt' ich in der Ferne Nach der Heimat mich zurück, Wähnend, in der alten Gegend Finde sich das alte Glück.

Aber die „Wiederkehr ins traute Thal“ bringt nur ein schweres Herz; die Mutter kommt dem Klagenden „Nimmermehr entgegen“, der Freund ist „verloren“, die Nachtigallen singen nicht mehr und die Blumen blühen nicht mehr. Das Gedicht schließt:

\footnotetext{
Blumen fort und Nachtigallen, Und das gute Mädchen auch! Meine Jugend fort mit ihnen, Alles wie ein Frühlingshauch!188
}

Am Ende besitzen viele literarische Protagonisten, die aus der Heimat auszogen und wieder in sie zurückkehren, gar nichts mehr - nicht die alte, aber auch keine neue Heimat. Die an den Verlust geknüpfte Sentimentalität und Nostalgie, für die Lenaus Gedicht steht, ist die vorherrschende Gefühlslage des 19. Jahrhunderts. Ein sehr viel selteneres Beispiel für den Versuch, sich der optimistischen Heimatdialektik zu entziehen, ohne dabei sentimental zu werden, stellt Franz Grillparzers In der Fremde (1843) dar, in dem es überall nur Fremde und nirgends Heimat gibt:

\footnotetext{
Schon bin ich müd zu reisen, Wärs doch damit am Rand! Vor Hören und vor Sehen Vergeht mir der Verstand.

So willst Du denn nach Hause?

Ach nein, nur nicht nach Haus!
}

187 Keller 1985, S. 897.

188 Nikolaus Lenau: Einst und Jezt, in: Lenau 1995, Bd. 1, S. 119-120. 
Dort stirbt des Lebens Leben

Im Einerlei mir aus.

Wo also willst du weilen,

Wo findest du die Rast,

Wenn übrall du nur Fremde,

Die Heimat nirgend hast. ${ }^{189}$

Die Vorstellung, Heimat verlieren zu können, schlägt immer wieder ins Unheimliche und Bedrohliche um. Heimatlosigkeit ist ein Angstszenario des 19. Jahrhunderts; die später von Freud beschriebene Unheimlichkeit der Heimat liegt vor allem in der Möglichkeit begründet, sie zu verlieren. ${ }^{190}$ Die Fremde ist dann kein temporärer Zustand, sondern birgt die Gefahr, irreversibel den endgültigen Verlust von Heimat zu bedeuten. Der teils auch schlagartig sich vollziehende Wechsel von Heimat in Heimatlosigkeit ist als literarischer Effekt des Schauders vielfach in der Literatur des 19. Jahrhunderts genutzt; in Eichendorffs und in Droste-Hülshoffs Texten wird Heimat teilweise als verdrängte Erinnerung und Todesangst mit dem Gespenstischen verknüpft (vgl. II.1.2). Und auch Gottfried Kellers und Adalbert Stifters Texte beschreiben, wie Heimat ins Unheimliche

189 Franz Grillparzer: In der Fremde, in: Grillparzer 1960, S. 292.

190 Das Unheimliche ist ein zentrales Moment der Literatur des 19. Jahrhunderts, zum theoretischen Konzept wird es mit Beginn des 20. Jahrhunderts durch Sigmund Freuds Aufsatz Über das Unheimliche (1919), und zwar mit ausführlichen Bezügen auf die Literatur des 19. Jahrhunderts, besonders E.T.A. Hoffmanns Sandmann. Freuds Aufsatz war nicht die erste Beschäftigung mit dem Unheimlichen (vgl. den früheren psychologischen Aufsatz von Ernst Jentsch, Zur Psychologie des Unheimlichen von 1906), aber der einflussreichste und wird zum Ausgangspunkt insbesondere der angloamerikanischen Cultural Studies, die den Begriff des Unheimlichen seit Beginn der 1990er Jahre intensiv bearbeiten. Martin Jay stellt in seinem Aufsatz The Uncanny Nineties fest, das Unheimliche sei zur „master trope“ avanciert. Jay 1995, S. 20. Neben Freud wird dabei auch regelmäßig auf Martin Heideggers fundamentalontologisches Verständnis des Begriffs rekurriert, das er in Sein und Zeit (1927) entwickelt. Für einen Überblick über die kulturwissenschaftliche Auseinandersetzung mit dem Begriff des Unheimlichen vgl. die Einleitung von Florian Lehmann in dem von ihm herausgegebenen Band zu den Ordnungen des Unheimlichen, vgl. Lehmann 2016, S. 9-28. Auch aus literaturwissenschaftlicher Sicht wurde vielfach an den Zusammenhang von Heimat und Unheimlichkeit angeknüpft. Florentine Strzelczyks Studie Un-heimliche Heimat macht das Verhältnis von Unheimlichkeit und Heimat, anders als der Titel erwarten lässt, allerdings nicht zum systematisch verfolgten Ansatz, bis auf einige einleitende Überlegungen, vgl. Strzelczyk 1999, S. 26. W.G. Sebalds Aufsatzsammlung Unheimliche Heimat interpretiert österreichische Literatur von Charles Sealsfield über Franz Kafka bis zu Peter Handke vorwiegend aus der Perspektive der Nicht-Dazugehörigkeit, vgl. Sebald 2004. Der Sammelband Unheimliche Heimaträume versammelt eine Vielzahl von literaturwissenschaftlichen Aufsätzen zum Thema, vgl. Bescansa 2020. Eine kunsthistorische Annäherung an das Thema bietet eine Studie über Das unheimliche Heim. Zur Interieurmalerei um 1900: Krämer 2007. 
umschlagen kann (vgl. II.2.2). Ein so geartetes, bedrohliches Immer-in-derFremde-Sein drückt sich im 19. Jahrhundert auch in unzähligen Bearbeitungen des Ahasver-Mythos aus. Die literarisch ausgesprochen produktiv gewordene Erzählung des Ewigen Juden personifiziert die Unmöglichkeit, Heimat zu haben; Heimatlosigkeit wird zum Stigma des Juden und der heimatlose Jude zum Gespenst (vgl. II.1.3.2).

\section{Heimat und Fremde als Erfahrung des politischen Exils}

Dem stehen anders motivierte Erfahrungen zur Seite, als Fremder im eigenen Land angesehen zu werden. Den Besitz- und Heimatlosen gilt in diesem Buch ein ausführliches Kapitel (vgl. II.2). Es gibt auch die Einwanderer nach Deutschland, die ihre Erfahrungen teilweise literarisch verarbeiten wie Adelbert von Chamisso und Friedrich de la Motte Fouqué, bei denen es um die Gespaltenheit zwischen französischer und deutscher Identität geht. Chamisso war noch als Kind mit seinen Eltern vor der Revolution in Frankreich geflohen, Fouqués hugenottische Familie schon seit vielen Generationen in Deutschland. Fouqués Roman Der Refugié oder Heimat und Fremde zeigt, wie den deutsch gewordenen Hugenotten trotz des Wunsches nach Zugehörigkeit diese immer wieder verweigert wird. ${ }^{191}$

Neben der historischen Erfahrung, gar keine Heimat zu haben bzw. haben zu dürfen und als Fremder im eigenen Land behandelt zu werden - sei es als Jude, sei es als Einwanderer oder als rechtlich Heimatloser -, steht die Erfahrung, nicht in die Heimat zurückkehren zu dürfen, wie sie das politische Exil mit sich brachte. Der Umfang an deutscher Erzählliteratur im zeitlichen Umfeld der Französischen Revolution, die sich mit der Fluchterfahrung der französischen adligen Emigranten beschäftigt, ist außerordentlich groß. ${ }^{192}$ In Folge der Revolution gingen die Bewegungen der politischen Exilanten zwischen Frankreich und den deutschen Staaten in beide Richtungen: Georg Forster, der 1792/93 an der Gründung der Mainzer Republik beteiligt war und nach deren Scheitern nicht dort bleiben konnte, war einer von Tausenden politischen Emigranten, die in den 1790er

191 Fouqué entwirft in seinem Roman Der Refugié oder Heimat und Fremde (1824) ein Szenario, nach dem seit Generationen in den deutschen, linksrheinischen Gebieten lebende Hugenotten in den Napoleonischen Kriegen auf deutscher Seite gegen die Franzosen kämpfen, nach dem Sieg Napoleons wieder von dort fliehen müssen und wieder als Flüchtlinge behandelt werden. Zum zweiten Mal werden sie damit „exsul, das heißt ein Ausgewanderter, ein Vertriebener, ein Emigrant!“. Fouqué 1824, Teil 1, S. 294.

192 Harro Zimmermanns umfassender Aufsatz zu den Emigranten der Französischen Revolution in der deutschen Erzählliteratur und Publizistik um 1800 gibt Einblick ins Thema, vgl. Zimmermann: Auswanderung ist Heimkehr, 1999. 
Jahren ins Pariser Exil flohen; eine zweite Emigrationswelle folgte nach den Karlsbader Beschlüssen von 1819, eine dritte in den 1840er Jahren im Umfeld der revolutionären Bewegungen; allein in Paris sollen in diesem Jahrzehnt zwischen fünfzig- und achtzigtausend politische Exilanten aus Deutschland gelebt haben. ${ }^{193}$

Exilanten beziehen sich auf eine ihnen unerreichbar gewordene Heimat auf unterschiedliche Weise. Heinrich Heine schreibt 1827 selbstironisch aus dem Londoner Exil an einen Freund:

Wie wird es mir noch gehn in dieser Welt! Ich werde es, trotz meiner bessern Einsicht, nimmermehr lassen können, dumme Streiche zu machen, d.h. freysinnig zu sprechen. Ich bin begierig von Dir zu erfahren ob keine Regierung mir mein Buch übel genommen. Am Ende will man doch ruhig am Heerde in der Heimath sitzen, und ruhig den deutschen Anzeiger oder die hallische Liter. Zeitung lesen und ein deutsches Butterbrod essen - Es ist hier so fürchterlich feucht $\mathrm{u}$ unbehaglich, und kein Mensch versteht einen, kein Mensch versteht deutsch. ${ }^{194}$

Und in seiner literarischen Verarbeitung der Zeit in England in den Englischen Fragmenten (1828), einem Teil seiner Reisebilder, wendet er die Frage nach Heimat (sowie in diesem Fall synonym: Vaterland) und Fremde wieder gut dialektisch:

Gar wunderlich sind doch die Menschen! Im Vaterlande brummen wir, jede Dummheit, jede Verkehrtheit dort verdrießt uns, wie Knaben möchten wir täglich davon laufen in die weite Welt; sind wir endlich wirklich in die weite Welt gekommen, so ist uns diese wieder zu weit, und heimlich sehnen wir uns oft wieder nach den engen Dummheiten und Verkehrtheiten der Heimath, und wir möchten wieder dort in der alten, wohlbekannten Stube sitzen und uns, wenn es anginge, ein Haus hinter den Ofen bauen, und warm drin hocken, und den allgemeinen Anzeiger der Deutschen lesen. So ging es auch mir auf der Reise nach England. Kaum verlor ich den Anblick der deutschen Küste, so erwachte in mir eine kuriose Nachliebe für jene teutonischen Schlafmützen- und Perückenwälder, die ich eben noch mit Unmuth verlassen, und als ich das Vaterland aus den Augen verloren hatte, fand ich es im Herzen wieder. $^{195}$

1840 preist Heine in seiner Börne-Schrift, die Ironie hat sich in Sarkasmus gewandelt, die Glücklichen, „welche in den Kerkern der Heimath ruhig hinmodern“. Gemeint sind die politischen Gefangenen in Deutschland und sie sind in ihrem Gefängnis zu beneiden, da durch diese „Heimath“ deutsche Luft weht und der Kerkermeister „die deutsche Sprache“ spricht. Dass Heine bei aller uneigentli-

193 Vgl. Beutin/Beilein/Ehlert 2019, S. 455.

194 Heinrich Heine, Brief an Friedrich Merckel, 23.4.1827, in: Heine 1970, Brief Nr. 218, S. 284. 195 Heinrich Heine, Englische Fragmente, in: Heine 1986, S. 211-212. 
chen Rede hier doch wirklich als leidender Exilant spricht, wird im Folgenden deutlich: „Ihr habt vielleicht einen Begriff vom leiblichen Exil, jedoch vom geistigen Exil kann nur ein deutscher Dichter sich eine Vorstellung machen, der sich gezwungen sähe, den ganzen Tag französisch zu sprechen [...]. Auch meine Gedanken sind exiliert, exiliert in eine fremde Sprache. "196 Immer wieder ist es die deutsche Sprache, die sich beim Exilanten Heine mit der vermissten Heimat verbindet. Aber Heimat ist bei aller Dringlichkeit des Leidens unter dem Exil immer ein Wort, das zugleich an den Grund des Exils gebunden bleibt: Heimat ist eben nicht nur die deutsche Sprache, sondern auch der Zeitung lesende und Butterbrot essende Philister und der im Kerker hinmodernde Gefangene.

Viele andere Schriftsteller und Intellektuelle der Restaurationszeit verarbeiten ihre Exilerfahrungen als Verlust von Heimat, teils auch dialektisch als Neugewinn einer sei es auch nur imaginären Heimat. Im Pariser Exil lebten neben Heine auch Ludwig Börne oder Georg Büchner. Die politischen Exilanten Georg Herwegh und Richard Wagner flohen nach Zürich, Karl Marx und Ferdinand Freiligrath nach London. Aber auch innerhalb des deutschen Kleinstaatengebildes lebten viele Autoren als Exilanten: Hoffmann von Fallersleben oder Theodor Storm stehen für Tausende, die aus politischen Gründen nicht bleiben konnten, wo sie herkamen. ${ }^{197}$ Während des Ersten Weltkriegs emigrieren pazifistische Autoren wie Stefan Zweig oder Walter Benjamin in die Schweiz. Und nach der Machtergreifung durch die Nationalsozialisten beginnt eine Massenemigration, deren Ausmaß in der deutschen Geschichte beispiellos ist, so dass hier nicht mehr von einzelnen Exilerfahrungen, sondern von einer eigenständigen Exilliteratur gesprochen wird, die mit der „Spaltung der deutschen Literatur“198 nach 1933 entsteht. Der Schwerpunkt literaturwissenschaftlicher Erforschung des Zusammenhangs von Heimat und Exil liegt dementsprechend auch in diesem Zeitraum. ${ }^{199}$ Allerdings wurde bisher noch wenig Augenmerk darauf gerichtet, dass die deutschsprachige Exilliteratur vielfach auf die im 19. Jahrhundert ausgebildete Semantik von Heimat im Allgemeinen und auf die ambivalenten Heimat-Deutungen der politischen Exilanten des 19. Jahrhunderts im Speziellen zurückgreift. Dazu gehört die Thematisierung von Sprache als Heimat, etwa bei Thomas Mann,

196 Heine 1978, S. 114-115.

197 Den Zusammenhang des Heimatdiskurses im 19. Jahrhundert mit den Erfahrungen des Exils untersucht aus literaturwissenschaftlicher Perspektive Koopmann 2005. Die von Koopmann unterstellte zwingende Verbindung von Heimat und Verlust (vgl. Koopmann 2005, S. 28) übersieht allerdings die positive Dialektik, die sich im 19. Jahrhundert oft an diese Verbindung anschließt und die nicht beim Verlust stehenbleibt, sondern auf den Wiedergewinn der Heimat zielt.

198 Streim 2015, S. 13.

199 Vgl. Wegner 1967; Sagmo 1988; Streim 2016. 
die bei Heinrich Heine vorgebildet ist. ${ }^{200}$ Dazu gehört die Idee einer utopischmessianischen Heimat wie die Ernst Blochs, die auch Richard Wagner im Pariser Exil entwickelt (vgl. II.1.3.3). ${ }^{201}$ Dazu gehört, dass Heimat den Charakter religiöser Verheißung gewinnen kann wie bei Johannes R. Becher, wie aber auch schon beim Exilanten Theodor Storm (vgl. I.2.5). ${ }^{202}$ So abenteuerlich diese Verbindungslinien hier erscheinen mögen, man müsste ihnen nachgehen, um den teils historisch zu isolierten Blick der Exilliteraturforschung zu weiten.

\section{Heimat und Fremde als Erfahrung von Migration}

Sozialhistorisch besonders bedeutsam für die Beziehung von Heimat und Fremde sind im 19. Jahrhundert die vielfältigen historischen Erfahrungen von ökonomisch bedingter Migration. In diesem Jahrhundert bewegten sich im deutschsprachigen Raum genauso wie in ganz Europa so viele Menschen gleichzeitig und dauerhaft wie nie zuvor, und dass gerade dieses Jahrhundert zum Jahrhundert von Heimat wurde, kann leicht als Reaktion auf die zunehmende Absenz dessen begriffen werden, was nun Anlass zur Emphase bot: Heimat. Annette von Droste-Hülshoff, deren Werk intensiv an der literarischen Semantisierung von Heimat mitwirkt (vgl. II.1.2), eröffnet ihre (Fragment gebliebene) Kriminalerzählung Joseph (1845) mit einem humoresken Kommentar zur zunehmenden Mobilität:

\footnotetext{
200 Repräsentativ ist hier Thomas Manns Ansprache im Goethejahr, in der er 1949 von seiner auch im Exil stets gewahrten „Treue zur deutschen Sprache, dieser wahren und unverlierbaren Heimat, die ich mir mit ins Exil genommen und aus der kein Machthaber mich vertreiben konnte“ spricht. Mann 2009, S. 672. Zu Sprache als Heimat im Exil vgl. Sagmo 1988, Streim 2015, S. $195-$ 199; Streim 2016, S. 223-227.

201 Ernst Blochs emphatischer Heimatbezug seines im amerikanischen Exil geschriebenen Hauptwerks Das Prinzip Hoffnung wird einerseits als politische Utopie der verwirklichten kommunistischen Gesellschaft interpretiert, andererseits aber auch mit der Tradition jüdisch-messianischen Denkens in Verbindung gebracht, gl. Voßkamp 1986. Zur Verbindung des Begriffs der Heimat mit messianischen Erlösungserwartungen im Exildiskurs deutsch-jüdischer Autoren vgl. Kuhlmann 1999.

202 In Bechers Gedicht Heimkehr erweist sich der heimkehrende Exilant als „[d]er deutschen Heimat unverlorner Sohn“, gerade weil er das Exil wählte. Die Heimkehr als Lohn fürs Leiden wird ins christliche Bild von Kreuzigung und Auferstehung gekleidet: „Wenn ich auch noch so schwer darniederlag, / Warst, Deutschland, du mein Auferstehungstag.“ Die Rückkehr in die Heimat hat religiöse Dimensionen: „Sah fern die Berge, wie noch nie so klar, / Ihr deutschen Berge wart mein Hochaltar. / Und heimatlich klang es und mütterlich / Und feierlich - nannt ich beim Namen dich!“ Johannes R. Becher: Heimkehr, in: Becher 1967, S. 325-328. Zu Bechers Gedicht vgl. Streim 2016, S. 229-231.
} 
In meiner Kindheit, wo das Sprichwort: „Bleib im Lande und nähre Dich redlich“ seine strenge Anwendung fand; wo die Familien aller Stände ihre Sprossen wie Banianenbäume nur in den nächsten Grund steckten und die Verwandtschaften so verwickelt wurden, daß man auf sechs Meilen Weges jeden Standesgenossen frischweg: „Herr Vetter“ nannte und sicher unter hundert mal kaum einmal fehlte; in jener Zeit kannte ein ordinairer Mensch mit zehn Jahren jeden Ort, den seine leiblichen Augen zu sehn bestimmt waren und er konnte achtzig Jahre nach einander sich ganz bequem seinen Pfad austreten.

Aber, so fährt die Erzählerstimme fort: „Jetzt ist es anders.“ Noch „das ruhigste Subjekt“ müsse inzwischen „sein Leben auf Reisen zubringen“ und „nur die Todtkranken und die Bewohner der Narrenspitäler dürfen zu Hause bleiben“. ${ }^{203}$ Die Mobilitätsstatistiken der zweiten Hälfte des 19. Jahrhunderts lassen erkennen, dass Droste-Hülshoffs literarischer Kommentar erst den Beginn einer sich in der Folge noch deutlich dramatisierenden Entwicklung anzeigt. Demnach entwickelt sich die Binnenmigration ab den späten 1860er Jahren und insbesondere ab dem Gründungsdatum des Deutschen Reiches 1871 zu einem Massenphänomen bisher ungekannten Ausmaßes. Im Zeitraum von der Reichsgründung bis zum Ersten Weltkrieg vollzieht sich, bezogen allein auf die Binnenwanderung, die größte Bevölkerungsbewegung der deutschen Geschichte überhaupt: ${ }^{204}$ Mindestens sechzig Millionen Menschen sind in diesem Zeitraum innerhalb Deutschlands gewandert. $^{205}$ Die Volkszählung von 1907 ergab, dass fast die Hälfte der Bevölkerung nicht an ihrem Geburtsort lebte, also mindestens einmal den Wohnsitz gewechselt hatte. ${ }^{206}$ Für die Habsburgermonarchie zeigt sich dasselbe Bild, und dank statistischer Daten lässt sich hier zeigen, dass dies auch sehr konkrete heimatrechtliche Auswirkungen hatte. Da das Heimatrecht für Männer nicht am Aufenthalts-, sondern am Geburtsort galt (für Frauen galt der Geburtsort des Ehemannes), aber immer mehr Menschen nicht mehr an ihrem Geburtsort lebten, stiegen die Bevölkerungsanteile ohne Heimatrecht am Aufenthaltsort beispielsweise in Niederösterreich (inklusive Wien) von zwanzig Prozent im Jahr 1851 auf sechzig Prozent im Jahr 1900. In Statistiken, die nur die Städte zeigen, ist das Bild noch dramatischer, in Graz liegt der Heimatlosenanteil um 1900 etwa bei achtzig

203 Alle Zitate Droste-Hülshoff 1978: Joseph. Eine Criminalgeschichte, S. 151-168, hier S. 153. 204 Vgl. Köllmann 1976, S. 9.

205 Vgl. Ehmer 2004, S. 19.

206 Vgl. Ehmer 2004, S. 19. Nach Sachße/Tennstedt lebten 1907 von 60,4 Millionen im Deutschen Reich Geborenen 29 Millionen, also 48 Prozent, außerhalb der Gemeinde ihrer Geburt. Sachße/ Tennstedt 1980, S. 195. Zum komplexen Bedingungsgefüge der Wanderungsbewegungen im 19. Jahrhundert insgesamt vgl. Hochstadt 1999, S. 107-134; Moch 2003, S. 102-160, Grant 2005, S. 56-79; Fahrmeir 2016; Oltmer 2016 und 2017, S. 75-106. 
Prozent. ${ }^{207}$ Migration und Heimatlosigkeit hängen im rechtlichen Sinn somit im 19. und teils auch noch im frühen 20. Jahrhundert unmittelbar zusammen (vgl. II.2.1).

Die Gründe für die zunehmende Mobilität der Bevölkerung wurden als gesamteuropäisches Phänomen von der Geschichtswissenschaft intensiv aufgearbeitet, sie reichen von der Aufhebung der Leibeigenschaft im ersten Drittel des 19. Jahrhunderts, die selbstbestimmte Mobilität für Teile der Bevölkerung überhaupt erst möglich machte (vgl. II.2.1), über das generelle Bevölkerungswachstum bis zu den neuen ökonomischen Strukturen einer sich industrialisierenden Gesellschaft, die mehr Arbeiter in den Städten und weniger Arbeiter auf den Feldern benötigte. ${ }^{208}$ Auch der Ausbau der dazugehörigen Infrastrukturen, insbesondere des Eisenbahnnetzes, war eine Voraussetzung für die Intensivierung der Mobilität. Darüber hinaus spielten im deutschen Fall die nationale Einigung und die damit zusammenhängende Neugestaltung bürokratischer Regelungen zur Personenfreizügigkeit eine stimulierende Rolle.

Heimat, verstanden als Geburtsort und Ort vertrauter Lebenszusammenhänge, ist also für so viele Menschen wie nie zuvor abwesend. Heimat zeigt sich für sie auch nur sehr bedingt als Ort, an den man zurückkehren kann. Denn der Ort des Herkommens bietet kein ökonomisches Auskommen mehr. Viele literarische Texte des 19. Jahrhunderts, die sich dem Phänomen der zunehmenden Mobilität und ihrer Kollateralschäden widmen, zeigen Heimat deswegen als etwas, das als emphatischer Sehnsuchtsort erst in den Köpfen derer entsteht, die sie verlassen haben. Ein Beispiel hierfür ist Clara Viebigs Roman Das Weiberdorf: Die männliche Bevölkerung arbeitet in der nahen Industriestadt und kehrt nur zweimal im Jahr für wenige Feiertage zurück; während die abwesenden Männer von Heimat sprechen, tun das die dagebliebenen Frauen nicht (vgl. II.3.3.2).

Das 19. Jahrhundert ist nicht nur das Jahrhundert der Binnenwanderung, sondern auch das der transatlantischen Mobilität, und hier dramatisiert sich das Verhältnis von Heimat und Fremde noch einmal, denn die Fremde ist fremder und die Heimat weiter entfernt, als es eine Abwanderung vom Land in die Stadt oder von Württemberg nach Thüringen mit sich bringen konnte. Die schwere Agrarkrise von 1816/17, ausgelöst durch den Ausbruch des Vulkans Tambora auf Sumbawa 1815 und begleitet von einer der letzten Hungersnöte in Teilen Europas, löste

207 In Oberösterreich stieg in demselben Zeitraum der Anteil von $5 \%$ auf 57 \%, in Böhmen von $5 \%$ auf $56 \%$. In den Städten ist der Anteil der Bevölkerung ohne Heimatrecht teilweise noch höher: In Graz liegt er im Jahr 1869 bei 64,3\% und im Jahr 1900 bei 80,8 \%, in Prag in denselben Jahren erst bei 64,3 \% und dann bei 79,3\%, in Marburg (Steiermark) erst bei 68,7 \%, dann bei 89,7 \%. Vgl. Hahn 2005, S. $30-33$.

208 Zur gesamteuropäischen Perspektive vgl. Bade 2000 und Bade/Emmer/Lucassen 2008. 
eine erste Auswanderungswelle aus verschiedenen europäischen Staaten nach Amerika aus - innerhalb eines Jahres wanderten allein aus Südwestdeutschland 20.000 Menschen in die USA aus. ${ }^{209}$ Ab den 1830er Jahren wurde die transatlantische Auswanderung, überwiegend in die Vereinigten Staaten, zu einem Massenphänomen, das zunächst noch hauptsächlich von Südwestdeutschland, bald aber auch von vielen anderen deutschen Regionen ausging. Strukturelle ökonomische Krisen und sich verschlechternde Perspektiven für die Landbevölkerung - vom Niedergang der Heimgewerbe über Steuerlasten bis zu Repressionen - bildeten in Verbindung mit den Verheißungen einer neuen Welt das dominante Ausreisemotiv, während religiöse Gründe im Verhältnis marginal waren und politische Dissidenz eine wichtige symbolische, aber eine relativ geringe quantitative Rolle spielte. ${ }^{210}$

Nach hohen Spitzenwerten in den 1850er und 1880er Jahren ging die deutsche Auswanderung stark zurück und das Reich wurde sogar zu einem Raum der Nettozuwanderung aus anderen europäischen Ländern. Dennoch folgten seit 1914 noch einmal allein zwei Millionen deutsche Auswanderer in die USA, so dass in dem gesamten Zeitraum zwischen 1820 und 1920 rund sechs Millionen Deutsche nach Übersee gingen; davon fünfeinhalb Millionen in die USA. ${ }^{211}$ Die Bewegung über den Atlantik war ein gesamteuropäisches Phänomen, wenn auch zeitlich nicht synchron. So setzte die Massenauswanderung aus Österreich-Ungarn erst im letzten Drittel des 19. Jahrhunderts ein, wobei zwischen 1870 und 1910 etwa 3,5 Millionen Auswanderer den Ozean überquerten, wiederum meist mit dem Ziel USA. Die kollektive Erfahrung der Auswanderung betraf im 19. Jahrhundert nicht allein die Auswanderer selbst, sondern auch die Zurückbleibenden, deren Welt sich durch die Möglichkeit der Auswanderung, durch die Berichte aus Übersee und auch durch die Heimkehrer veränderte. Die Rückwanderung, bisher weniger gut erforscht, ${ }^{212}$ war, auch wenn hier keine belastbaren Statistiken vorliegen, ebenfalls ein Massenphänomen.

Die Frage nach dem Einfluss der transatlantischen Migrationsbewegungen auf die Semantisierung von Heimat stellt sich im 19. Jahrhundert zunächst auch

209 Behringer 2015, S. 181. Wolfgang Behringer beschreibt die durch den Ausbruch des Vulkans Tambora im Jahr 1816 ausgelöste, weltweite Klimakatastrophe als Ursache für Missernten, Hunger und in der Folge die erste gesamteuropäische Auswanderungswelle ab 1816. Die Zahl der britischen Auswanderer wird in den Jahren zwischen 1816 und 1818 auf über hunderttausend geschätzt; vgl. Behringer 2015, S. 176.

210 Vgl. Plaß 2016, S. 293-294.

211 Vgl. Helbich/Kamphoefner/Sommer 1988, S. 11-39; zugrundegelegt sind die Landesgrenzen des 1871 zum Deutschen Reich vereinigten Gebietes.

212 Vgl. Schniedewind 1993; Panther 2021; Middelhoff 2021. 
als heimatrechtliche dar. ${ }^{213}$ Denn Auswanderung bedeutete oft den Entzug des Heimatrechts und damit auch die Unmöglichkeit einer einfachen Rückkehr (vgl. II.2.1). Tatsächlich konnte dies den Strom der Remigranten aber nicht bremsen. So erlässt Württemberg 1816 ein Rückkehrverbot, erreicht aber nur, dass die von den Gemeinden Abgewiesenen vagabundieren, so dass die Gemeinden schließlich teils gezwungen werden, die Rückkehrenden wieder aufzunehmen. ${ }^{214}$ Heimat ist demnach lebensweltlich für die (Re-)Migranten sehr konkret die Bedingung eigener sozialer und ökonomischer Existenz.

Für die Auswanderer wird der Brief an die zurückgelassenen Verwandten zum zentralen Medium der Heimatreflexion. Die massenhaft geschriebenen und zum Teil archivierten Auswandererbriefe des 19. Jahrhunderts dokumentieren, dass insbesondere die erste Auswanderergeneration ihr Heimatverständnis intensiv thematisiert. Diese Briefe werden in Deutschland gelesen, vorgelesen und weitergereicht und wirken somit direkt auf die Heimatsemantik im deutschsprachigen Raum zurück. Auswandererbriefe verbinden die alten und neuen Lebenswelten ganz real, indem sie den Atlantik überqueren, Verbindungen herstellen, Kontakte halten und eben auch Raum für die Reflexion über Heimat und Fremde bieten. Hier wird besonders anschaulich, dass der Heimatbegriff im 19. Jahrhundert nicht nur von einer eher abstrakten Dialektik von Heimat und Fremde zehrt, sondern auch eine sehr konkrete transnationale Dimension hat. Die Briefe zeigen zudem, wie Migrationserfahrung ganz konkret den modernen deutschsprachigen Heimatdiskurs von Anfang an mitprägt. In ihnen fällt besonders die Herausbildung der Vorstellung einer ,ersten‘ und ,zweiten‘ Heimat auf, einhergehend mit der Vorstellung der ,alten' und der ,neuen` Welt - mithin einer Pluralisierung der Semantik von Heimat und Welt. ${ }^{215}$

Schon Georg Forster spricht in seiner Beschreibung einer Südsee-Expedition zwischen 1772 und 1775 von Tahiti als einer zweiten Heimat. ${ }^{216}$ Aber zur stehenden Wendung wird die Rede von der ersten und zweiten Heimat erst Mitte des 19. Jahrhunderts, von den Auswandererbriefen über Familienzeitschriften wie die

213 Vgl. dazu das Sonderheft von The Germanic Review zum Thema German, Heimat' in the Age of Migration, das sich schwerpunktmäßig mit dem 19. Jahrhundert beschäftigt. Althammer/Oesterhelt 2021.

214 Vgl. Behringer 2015, S. 213-215.

215 Zur Bedeutung des Auswandererbriefs für den Heimatdiskurs im 19. Jahrhundert vgl. Oesterhelt 2021.

216 „Da wir mit dem guten Willen der dortigen Bewohner sicher rechnen und uns die beste Aufnahme von ihnen versprechen konnten, sahen wir diese Insel gleichsam als unsere zweite Heimat an.“ Forster 1988, S. 249. 
Gartenlaube ${ }^{217}$ bis zu Kolonialzeitschriften, ${ }^{218}$ und beruht damit wohl ganz konkret auf den zunehmend kollektiven Mobilitätserfahrungen der Zeit.

Das Phänomen Auswanderung wird auch in der deutschsprachigen Literatur intensiv thematisiert und steht in engem Zusammenhang mit einem Heimatdiskurs, der an der Vorstellung von erster und zweiter Heimat arbeitet (vgl. II.2.2.2). In der Perspektive der deutschprachigen Schriftsteller wird Migration dabei in der Regel eher als Phänomen der Aus- und Rückwanderung, nicht der Einwanderung geschildert, das heißt, nicht die ,zweite Heimat' steht mehrheitlich im Fokus, sondern, gut dialektisch, vielmehr eine ,dritte Heimat', die nach der Rückkehr erlangt wird. Demnach bleibt die zweite Heimat eben doch immer Fremde und die Auseinandersetzung mit ihr zielt auf den Rückgewinn der alten, aber geläuterten Heimat. Mit anderen Worten erzählen die Texte mehrheitlich von der Rückkehr aus der Fremde, von den Auswanderern, die - geläutert oder gebrochen - zurückkommen, manchmal auch nur von den Auswanderern im Geiste, deren Verhältnis zur Heimat sich schon allein durch die Vorstellung, auszuwandern, verändert, wie bei Berthold Auerbach und Wilhelm Raabe ${ }^{219}$ beschrieben und von Edgar Reitz in Die andere Heimat ins Bild gesetzt.

Neben den in dieser Arbeit behandelten Texten Berthold Auerbachs (vgl. II.2.2.2) zeigt sich diese Tendenz auch in den zahlreichen Romanen und Erzählungen Wilhelm Raabes, die von Auswanderung erzählen. Auswanderung wird hier meist aus der Perspektive der Daheimbleiber oder Rückkehrer geschildert, in Zum Wilden Mann (1874) etwa oder in Alte Nester (1880). Hier erinnert der Erzähler

217 Heimat ist für die Auslandsdeutschen eine zentrale Referenzgröße. Das zeigen auch die Heimat- und Auswanderungsdiskurse in den Familienzeitschriften, die sich nicht zuletzt an ein auslandsdeutsches Publikum richten. Die Gartenlaube etwa verstand sich explizit als Organ auch für die Auslandsdeutschen und imaginiert ihre Leserschaft als Teil eines ,global village‘. Vgl. Stockinger 2018, S. 273-276. Auch die Idee der ,ersten und der ,zweiten Heimat‘ findet sich in Familienzeitschriften wie dieser.

218 In Kolonie und Heimat, der Zeitschrift des Frauenbundes der Deutschen Kolonialgesellschaft wird 1912 die „endliche Schaffung des schon lange ersehnten Gesetzes über die Erhaltung der Reichsangehörigkeit“ der Auslandsdeutschen gefordert. Man könne nicht klagen, „,wenn viele Deutsche, die gezwungen sind, sich Uebersee eine neue Heimat zu suchen, dem Deutschtum verloren gehen“, da das Deutsche Reich nichts unternehme, sie diesem zu erhalten. Anonym 1911/ 12, S. 4. Die Tragweite des Problemfelds ,Heimat und Kolonie/Kolonialismus ‘ wird in dieser Arbeit in Kap. II.3.3.1 angerissen.

219 Raabes Zum Wilden Mann thematisiert, wie die Verheißungen der Fremde auch denen, die nie die Heimat verließen, zum Verhängnis werden können. Der Heimkehrer entpuppt sich zu spät als Hochstapler, der „die Ordnungen der alten Heimat“ zerstört, indem er seinen gutgläubigen Zuhörern „von der Herrlichkeit seiner neuen Heimat“ vorlügt. Beide Zitate Raabe 1973, S. 233 und S. 242. Damit weist Raabes Text einige Parallelen zu Auerbachs Dorfgeschichte Der Viereckig oder die amerikanische Kiste auf (vgl. II.2.2). 
seine Kinder- und Jugendzeit und die einer Reihe von Freunden, deren verschiedene Lebenswege zugleich unterschiedliche Beziehungsmodelle von Heimat und Fremde vorführen. Von ihren jeweiligen „Verhältnissen zu der Heimat“"220 handelt das ganze Buch. Die Erzählerfigur, die ein bürgerliches Leben in Berlin aufgenommen hat, beschreibt ihr Verhältnis zum „Heimatdorf“ als eines der „Resignation“. ${ }^{221}$ Die Figur Just von Everstein ist der Einzige aus dem ehemaligen Freundeskreis, der nach seiner Heimkehr aus Amerika an das Alte auf neue Weise anknüpfen kann. Gerade für ihn war die alte verlassene Heimat keine Idylle; erst als in und an Amerika gewachsener, stark veränderter Mann kann er sie zu einer solchen machen.

Schon der Roman Die Leute aus dem Walde (1863), der teilweise im ,Wilden Westen' spielt, findet sein Telos in der alten Heimat. Der Roman schöpft aus der Dialektik von Heimat und Fremde wesentliches Kapital. Zwischen dem Herkunftsort der Brüder Robert und Friedrich Wolf im ,wilden Winzerwald“ und dem amerikanischen ,Wilden Westen', in den es beide verschlägt, bestehen vielfache Parallelen. Beide stehen für das Undomestizierte, aber auch Utopische und Leidenschaftliche, dem die bürgerliche kleinstädtische Welt als eigentlicher Antipode gegenübersteht. Friedrich kann seine Leidenschaften nicht mit der bürgerlichen Welt versöhnen, er stirbt in Amerika. Robert aber durchläuft, nachdem er die „Wildnis seiner Heimat"“222 hinter sich gelassen hat, beide Formen der Fremde, die bürgerliche Welt und die des Wilden Westens, um dann geläutert in die alte Heimat zurückzukehren. Nach dem Durchgang durch die Fremde erscheint sie ihm veredelt und verklärt.

In Stopfkuchen. Eine See- und Mordgeschichte (1891) kehrt der nach Südafrika ausgewanderte Eduard für einen Besuch in die „Jugendheimat“'223 zurück. Er trifft auf eine enge Heimat der „dürren Subalternenbeamtengefühle“, 224 in der es „dickdeutsch-gemütlich ${ }^{\text {“2225 }}$ zugeht, aber trotzdem erscheint ihm die neue Begegnung mit den vermeintlich alten Vertrauten am Ende als das größte Abenteuer seines Lebens: „Ich aber, hatte ich darum draußen soviel zu Wasser und zu Lande erlebt, um in dem stillen Heimatwinkel vor Stopfkuchen und Storzhammel zu stehen wie vor etwas weder von mir noch von irgendeinem andern Menschen je Erlebten?“226 Erstaunen erregt neben der Aufklärung eines verjährten Mordes vor allem die

220 Raabe 2005, S. 166.

221 Beide Zitate Raabe 2005, S. 196.

222 Raabe 1971, S. 39.

223 Raabe 1969, S. 206.

224 Raabe 1969, S. 132.

225 Raabe 1969, S. 143.

226 Raabe 1969, S. 195. 
Wandlung des alten Bekannten Heinrich Schaumann, genannt Stopfkuchen, der zum skurrilen, aber auf seine Art weisen Mann geworden ist, ohne je fort gewesen zu sein. Der ehemalige Außenseiter ist zum geheimen Zentrum des Dorfes und zum Monument des Angekommen-Seins geworden, vor dem die Erzählerfigur Eduard trotz seiner Weltgereistheit verblasst. Das paradoxe Lebensmotto „Gehe heraus aus dem Kasten!“'227 des dicken, daheimgebliebenen Schaumann zeigt die Verinnerlichung der Dialektik von Heimat und Fremde an, die des Auswanderns nicht bedarf.

Im späten, radikal skeptischen Roman Die Akten des Vogelsangs (1896) geht die Dialektik von Heimat und Fremde dann gar nicht mehr auf. Hier stellen sich der Auszug in die Fremde wie die Rückkehr in die Heimat als sinnlos heraus. Der heimgekehrte Auswanderer Andreas Velten stirbt am Ende des Romans, ohne ,Heimat‘ gefunden zu haben (vgl. II.2.2.2).

\title{
Heimat und Fremde in der deutsch-jüdischen Literatur
}

Das diskursive Bedingungsverhältnis von Heimat und Fremde zeigt sich auch in der deutsch-jüdischen Literatur. Die Spannbreite reicht von Berthold Auerbachs Hoffnungen auf eine Synthese von Heimat und Fremde, zumindest in der Literatur (vgl. II.2.2.2), bis zu denjenigen deutsch-jüdischen Ausgestaltungen des AhasverMythos, in denen Heimat uneinholbar ist (vgl. II.1.3.2). Dabei stellt sich die Frage nach Identität und Zugehörigkeit für die deutsch-jüdische Literatur in besonderem $\mathrm{Maß}^{228}$ - wobei es weniger um eine bipolar vorstellbare Identitätsproblematik zwischen deutscher und jüdischer Existenz geht ${ }^{229}$ als um eine Dialektik, die beide umfasst:

\begin{abstract}
Nur wenige Autoren haben die Dialektik von Heimat und Fremde so internalisiert wie der doppelt - als Jude und als Demokrat - exilierte Heine: Die Liebe zur deutschen Sprache wird geradezu zur Bedingung der Kritik an der deutschen Misere im Zeichen eines kosmopolitischen Universalismus. Trotz aller Enttäuschung bewahrt sich Heine seinen aufgeklärten Optimismus: Das tragische „vergeblich“, das am Ende der Laufbahn Berthold Auerbachs als eines schwäbisch-jüdischen Schriftstellers preußisch-nationalliberaler Gesinnung steht und das auch Jakob Wassermann rückblickend auf seinen Weg als Deutscher und Jude als Fazit
\end{abstract}

227 Raabe 1969, S. 75.

228 Hans Otto Horch hat das in vielen seiner Studien nachgewiesen. Für ihn zählt „die komplexe Verschlungenheit von Fremd- und Selbstbild“ zu den wichtigsten Problemen der deutsch-jüdischen Literaturgeschichte. Horch 1989, S. 53.

229 Vgl. Horch 1989, S. 54. Horch argumentiert, es gehe nicht um einen „Dualismus zwischen Judentum und Deutschtum“ (S. 54), so wenig wie es angemessen sei, alle Texte deutsch-jüdischer Autoren als Produkt ihrer Außenseiter-Existenz zu deuten. Vgl. Horch 1989, S. 55. 
festhält, bleibt ihm erspart; noch hat sich die zunächst aufsteigende Linie deutsch-jüdischen Dichtertums nicht nach unten umgekehrt. ${ }^{230}$

Diese aufsteigende Linie beginnt Hans Otto Horch zufolge spätestens mit Kafkas Werk zu sinken. Die Dialektik von Heimat und Fremde scheitert. Dagegen wird mit Kafka die „über die jüdische Existenz hinausreichende Thematisierung einer universalen Heimatlosigkeit“ zum Paradigma „moderner Existenzproblematik schlechthin“. ${ }^{231}$ Für Horch liegt deshalb der Beitrag der jüdischen Schriftsteller deutscher Sprache zur deutschen Literaturgeschichte im Kern in der Reflexion einer Existenzproblematik des Menschen an sich, der „Conditio judaica als paradigmatische[r] Conditio humana“. 232

Tatsächlich zeigt sich in sehr vielen literarischen wie philosophischen Texten deutsch-jüdischer Autoren ab 1900 die jüdische als allgemeinmenschliche Heimatlosigkeit. Ernst Tollers 1919 uraufgeführtes Drama Die Wandlung deutet schon in seinem Untertitel darauf hin: Das Ringen eines Menschen (vgl. II.1.3.2). Und auch Georg Lukács’ Theorie des Romans, die 1914/15 geschrieben und 1920 veröffentlicht wurde, lässt sich vor dem Hintergrund von Lukács' jüdischer Herkunft u. a. als unausgewiesene Verarbeitung einer jüdischen Diaspora-Erfahrung lesen. Mit den Wendungen von der ,transzendentalen Obdachlosigkeit" und der ,transzendentalen Heimatlosigkeit‘ identifizieren sich ganze Generationen von Intellektuellen (vgl. III). Innerhalb seiner stark an Hegel orientierten Gattungstypologie von Epos und Roman ist Heimat in der Theorie des Romans historisch dem Epos und somit einer für immer verlorenen historischen Epoche zugeordnet. Denn Heimat verbindet sich nach Lukács mit einem Zustand der ,Wesenhaftigkeit', der im antiken griechischen Epos seinen Ausdruck fand. ${ }^{233}$ Der moderne Mensch habe keinen Zugang mehr zu dieser Substantialität, ihm bleibe nur der „Heimatdrang“. ${ }^{234}$ Die Uneinlösbarkeit dieses Drangs findet nach Lukács im modernen

230 Horch 1989, S. 57.

231 Beide Zitate Horch 1989, S. 58. Zu Heimat im Werk Kafkas vgl. auch Kugele 2011, Weinberg 2014 und Anz 2000. Peter André Alt weist kurz auf „Kafkas Sympathien für die HeimatkunstBewegung“ hin (Alt 2008, S. 113); insgesamt wird aber in der Forschung eher auf einer klaren Trennung zwischen literarischer Moderne und ihrer Darstellung von Heimatlosigkeit (mit Kafka als ihrem Repräsentaten) und der zeitgleichen antimodernen Heimatkunst mit einem affirmativen Heimatverständnis bestanden. Dass diese dichotomische Trennung für die Zeit um 1900 so nicht haltbar ist, soll II.3. zeigen, vgl. auch Kramer 2006, allerdings nicht in Bezug auf Kafka.

232 Horch 1989, S. 59.

233 Vgl. Lukács 1920, S. 25.

234 Lukács 1920, S. 76. 
Roman ihren Ausdruck. ${ }^{235}$ Die Moderne zeichne sich durch ihre ,Grunddissonanz des Daseins' aus:

Denn Verbrechen und Wahnsinn sind Objektivationen der transzendentalen Heimatlosigkeit; der Heimatlosigkeit einer Tat in der menschlichen Ordnung der gesellschaftlichen $\mathrm{Zu}$ sammenhänge und der Heimatlosigkeit einer Seele in der seinsollenden Ordnung des überpersönlichen Wertsystems. Jede Form ist die Auflösung einer Grunddissonanz des Daseins, eine Welt, in der das Widersinnige an seine richtige Stelle gerückt, als Träger, als notwendige Bedingung des Sinnes erscheint. ${ }^{236}$

Heimatlosigkeit ist nach Lukács „Verlassenheit der Welt von Gott“237 und das Apriori der Moderne. ${ }^{238}$ Seine scheinbar schonungslose Moderne-Diagnose geht allerdings mit religiös aufgeladenen Sinnangeboten einher, ${ }^{239}$ die - immer wieder auch explizit - an romantisches Denken anknüpfen. Denn auch bei Lukács ist es eine sakralisierte Kunst, die eine Brücke zur verlorenen Heimat schlagen kann. In seinem metaphysisch aufgeladenen lebensphilosophischen Vokabular ist eine wenn auch hoffnungslose - Annäherung an die als Heimat bezeichnete „Totalität des Seins“240 nur mehr über die Kunst möglich und ihre „Weihe der Form: die Sinnlosigkeit wird, als Sinnlosigkeit, zur Gestalt: sie ist ewig geworden, von der Form bejaht, aufgehoben und erlöst““. ${ }^{241}$ Vor dem Hintergrund deutsch-jüdischer Reflexion von Heimatlosigkeit erweist sich somit auch diese lukácssche Heimatlosigkeit als quasi-religiöse Conditio humana der Moderne.

Heimat bleibt trotz aller teils emphatischen Sinnbesetzungsversuche ihres Antipoden, der Heimatlosigkeit, auch in der deutsch-jüdischen Literatur um 1900 eine zwar ambivalente, aber ihrerseits teils emphatische Bezugsgröße. Galt etwa die Großstadt Berlin um 1900 vielen als Stätte der Entwurzelten, wurde gerade für viele Juden Berlin im eigenen Selbstverständnis zu Heimat und wurde auch in literarischen Texten mit diesem Begriff belegt. ${ }^{242}$ Auch das Buch oder die Sprache wird um 1900 als Heimat der Juden verstanden. Schon Heine formuliert, den

235 Vgl. Lukács 1920, S. 31-32.

236 Lukács 1920, S. 52-53.

237 Lukács 1920, S. 83.

238 Vgl. Lukács 1920, S. 53.

239 Justus H. Ulbricht deutet Lukács’ Theorie des Romans als „Quelle für die religiöse Situation der Jahrhundertwende“ und den Versuch ihrer ästhetischen Bewältigung. Für seine Deutung spielt es allerdings keine Rolle, dass Lukács keinen christlichen, sondern jüdischen Hintergrund hat. Ulbricht 1998, S. 47.

240 Lukács 1994, S. 26.

241 Lukács 1994, S. 42.

242 Vgl. Schütz 1996. 
exilierten Juden sei die Heilige Schrift ihr „portatives Vaterland“243 gewesen. Der neuhebräische Schriftsteller Chaim Nachman Bialik fordert in seinem Aufsatz Das hebräische Buch von 1913, der 1919 auf Deutsch erschien, „gegen die historische Plage der Vielsprachigkeit der jüdischen Literatur“ eine Rückführung der jüdischen Diaspora-Literatur in „ihre Urheimat“ des hebräischen Buches. ${ }^{244}$ Vor dem Hintergrund von Holocaust und Exil gewinnt einerseits die Selbstdiagnose deutsch-jüdischer Autoren, heimatlos zu sein, an Gewicht. Andererseits steht dieser Diagnose der positive Wert von Heimat oft nicht entgegen, etwa wenn Jean Améry in seinem Essay Wieviel Heimat braucht der Mensch zu dem Fazit gelangt: „Es ist nicht gut, keine Heimat zu haben.“245

\subsection{Heimat und Dichtung}

Dichtung und Heimat gehen bei Lukács, wie gesehen, eine enge Verbindung ein: Das antike Epos ist Ausdruck von Heimat, der moderne Roman steht im Zeichen der Heimatlosigkeit und nähert sich Heimat immer nur an, ohne sie je wieder erreichen zu können (vgl. I.2.4). Das Verhältnis von Dichtung und Heimat wird also als historisch variables verstanden und der diagnostizierte Verlust von Heimat auch als literaturgeschichtliche Verlustgeschichte bzw. als Bewegung der Moderne auf einen - freilich als uneinholbar erkannten - Ursprung hin aufgefasst. Lukács steht in einer langen Tradition der Assoziation von Heimat und Dichtung. Ein frühes Beispiel dafür ist in Joachim von Sandrarts im 17. Jahrhundert einflussreichen kunsthistorischen Schriften zu finden:

Daß der Himmel (gedachte ich hier auf bey mir) der Dicht-Kunst wahre Heimat sey / erscheinet auch hieraus: daß wir bey günstigen Blicken seines enthüllten Angesichts zu derselben / wo nit glücklicher doch fertiger seyn / und unsern Geist von seinem Liecht / wie ein Buler von den Reitz-blicken seiner Liebstinn / ermuntert wissen. ${ }^{246}$

Während bei Sandrart ganz im religiösen Heimatverständnis der Zeit der ,Himmel die ,wahre Heimat‘ ist (vgl. II.1) und in dieser himmlischen Heimat auch der wahre

243 Heinrich Heine in Geständnisse (1854), Heine 1995, S. 483.

244 Bialik 1919, S. 31-32. Der Aufsatz erschien zuerst 1913 in der hebräischen Zeitschrift HaShiloach. Vgl. dazu Kilcher: Jüdische Renaissance, 2016, S. 103.

245 Améry 2002, S. 117. Zu Amérys Essay vgl. Sebald 2004, S. 140 -142; Doll 2008.

246 Sandrart 1680, S. XVII. Der Maler, Kupferstecher und Kunsthistoriker Joachim von Sandrart der Ältere war auch als Übersetzer tätig. Hier ist zitiert aus Iconologia deorum, oder Abbildung der Götter, welche von den Alten verehret worden, seiner Übersetzung von Vincenzo Cararis Le imagini colla sposizione degli dei degli antichi. 
Ort der ,Dicht-Kunst“ vermutet wird, während also die schöpferische Inspiration des Künstlers der Gnade Gottes entspringt, kehrt Clemens Brentano diesen Schöpfungsgedanken um 1800 radikal um und eröffnet damit die moderne Semantisierung des Begriffs: Hier ist es dem Menschen schon auf Erden gegeben, Heimat zu erstreben, und zwar im Medium der Kunst: „Entwickle dich in Form, und Licht, und Tönen, / So wird der Heimath Bürgerkranz dich krönen. “247 Heimat wird bei Brentano geradezu Produkt der Kunst, und so wird es möglich, Heimat als eine selbstbezügliche Figur zu denken. Viele literarische Heimattexte reflektieren den Umstand, dass Heimat erst durch denjenigen hervorgebracht wird, der sie besingt, oder, alternativ, dass der Dichter ein Mittler ist, der den Menschen (göttliche) Heimat bringen kann (vgl. II.1.2). Die Figur des Dichters als Propheten der Heimat wird dann verstärkt wieder um 1900 im Rahmen der Heimatkunstbewegung aufgegriffen, etwa bei Friedrich Lienhard, aber auch bei Rainer Maria Rilke. Kunst und Heimat werden damit einem gegenüber gesellschaftlichen $\mathrm{Zu}$ sammenhängen weitgehend autonomen Bereich zugeordnet. ${ }^{248}$ Aber auch die realistische Epoche, deren Literaturverständnis ganz anderen Paradigmen unterliegt als die an autonomieästhetischen Maßstäben ausgerichteten rahmenden Jahrhundertwenden, ${ }^{249}$ bildet ein teils ungewusstes, teils reflektiertes Verhältnis $\mathrm{zu}$ Heimat als etwas aus, das sich eigentlich erst selbst hervorbringt.

Gerade im Kontext des 19. Jahrhunderts ist das Phänomen einer selbstreflexiven Heimat nicht lediglich als ästhetisches Spiel zu verstehen. Es hängt grundsätzlicher mit der geschichtlichen und kulturellen Selbstbegründung des Bürgertums zusammen. ${ }^{250}$ So wie sich das Bürgertum auf der Suche nach Selbstlegitimierung durch den Bezug auf eine Vorgeschichte auszeichnet, die oft durch den Akt der Berufung erst hervorgebracht wird, ist auch Heimat Teil des bürgerlichen Konstitutionsprozesses. Das ideologiegeschichtlich vielfach wirksame Modell der ,invention of tradition' (Eric Hobsbawm) ${ }^{251}$ wurde schon 1935 von Helmuth Plessner in seiner später unter dem Titel Die verspätete Nation bekannt gewordenen politischen Analyse als Versuch des traditionslosen deutschen Kleinbürgertums beschrieben, der eigenen ideellen Zentrumslosigkeit entgegen-

247 Clemens Brentano: Als hohe in sich selbst verwandte Mächte, in: Brentano 2007, S. 101-102. 248 Vgl. Oesterhelt 2019.

249 Vgl. das Vorwort in Mellmann/Reiling 2016.

250 Zur Definition von Bürgerlichkeit in Deutschland und im internationalen Kontext vgl. Conze/ Kocka 1985, Kocka 1988. Einen Überblick und eine dezidierte Einschätzung der Bürgerlichkeitsforschung der Geschichtswissenschaften gibt Fahrmeir 2010.

251 Eric Hobsbawm und Terence Ranger zeigen in ihrem Buch The Invention of Tradition von 1992 den fiktiven Charakter von vermeintlichen Traditionen auf, die eine historische Legitimität konstruieren, tatsächlich aber erst in der eigenen Gegenwart erfunden wurden. 
zuwirken. Dieser Versuch bestehe insbesondere in einer Rückversenkung in eine Vergangenheit, in einem „Historismus des deutschen Bewußtseins“, der sich nicht auf als gut und richtig Erkanntes, sondern auf (angeblich) Immer-schon-soGewesenes und daher Notwendiges beruft:

\begin{abstract}
Was rational nicht (nicht mehr) zu rechtfertigen ist, kann sich so auf sein Heimatrecht berufen, auf ein wesentlich der abstrakten moralischen Beurteilung entzogenes Herkommen. Das Faktum seines allmählichen Gewordenseins und das Verständnis für die in ihm waltende ,organische“ Notwendigkeit verstärken das Gewicht der einmal vorhandenen Zustände, sie geben den Blick auf die jeder revolutionären Rabulistik überlegene, in der Wirklichkeit verschwiegene Vernunft frei. ${ }^{252}$
\end{abstract}

Das Bestehen auf „der Unverrückbarkeit des Menschlichen in jedem landschaftlichen, völkischen und kulturellen Umkreis“, so Plessner weiter, „gehört besonders zum Bilde einer Zeit, die durch beständige Neuerungen auf allen Gebieten die alten Lebensgewohnheiten und Ideale rasch entwertet sieht.“ Die „Rückversenkung in die Vergangenheit“ biete „dem Menschen einen beruhigenden Ausgleich". 253

Wie die Heimatsemantik gerade von dem Jahrhundert, in dem die eigene Traditionslosigkeit am stärksten ins Auge fiel, mit neuen, emphatischen Bindungen an vorgeblich alte Traditionen überlagert wird, zeigt beispielsweise die enge Verknüpfung eines sentimentalen Heimat- und Weihnachtsfest-Diskurses. Der Weihnachtsbrauch des geschmückten Tannenbaumes verbreitete sich ja erst im 19. Jahrhundert und war vorher keinesfalls breite volkstümliche Praxis, gehört also zu den ,erfundenen“ Traditionen, von denen Eric Hobsbawm spricht. ${ }^{254}$

Theodor Storms Novelle Unter dem Tannenbaum steht wie viele andere seiner Novellen in nuce für den ,bürgerlichen Wertehimmel ${ }^{\text {255 }}$ des 19. Jahrhunderts, u. a. auch in Hinblick auf Rituale, Feste und Traditionen - hier das Weihnachtsfest -, die sich, mit Plessner, auf ein Herkommen berufen, um ihre Legitimität zu belegen. Die Weihnachtsgeschichte, eine Auftragsarbeit für die Leipziger Illustrirte Zeitung, die am 20.12.1862 erschien, beschreibt den Weihnachtstag eines Amtsrichters und seiner Familie, der aus Schleswig-Holstein stammt und in der Folge

252 Plessner 1982, S. 109.

253 Alle Zitate Plessner 1982, S. 110.

254 Wie das Bürgertum des 19. Jahrhunderts seine eigenen Traditionen erfindet, ist beispielhaft in den Artikeln Weihnachten, Feierabend oder Der deutsche Wald in den dreibändigen, von Etienne François und Hagen Schulze herausgegebenen Deutschen Erinnerungsorten nachzulesen, vgl. François/Schulze 2003, Bd. 3. Hier findet sich auch ein zweiseitiger kurzer Eintrag zu ,Heimat', S. 361-362.

255 Vgl. Hettling/Hoffmann 2000. 
des Krieges mit Dänemark ins mitteldeutsche Exil gehen musste. Somit enthält die Novelle deutlich autobiographische Elemente aus dem Leben des von Husum zunächst nach Potsdam, dann ins thüringische Heiligenstadt emigrierten Storm und ist auch als Exilgeschichte lesbar (vgl. I.2.4).

Die Handlung, die in der Schilderung der Vorbereitungen auf den Weihnachtsabend und des eigentlichen Festes besteht, ist grundiert vom Heimweh der Familie nach ihrem eigentlichen Zuhause. „Es tut nicht gut, in die Fremde zu gehen“, resümiert der Amtsrichter, „wenn man daheim schon am eigenen Herd gesessen hat.“256 Er und seine Familie erinnern sich an das Verlorene: „Sie sprachen von den Großeltern drüben in der alten Heimat; dann von den letzten Weihnachten, die sie dort erlebt hatten. “257 Erinnert wird das über Generationen Tradierte: die „braunen Weihnachtskuchen nach dem Rezept der Urgroßmutter“, 258 das „alte Haus“, das, so erzählt der Vater dem Sohn, „[e]iner Deiner Urahnen“ einst für seinen Sohn gebaut habe. ${ }^{259}$ Erinnert wird eine Familiendynastie von Kaufherren, Senatoren, Bürgermeistern und Rechtsanwälten, die „wurzelfest geworden in der Heimat [...] sie kannten sich alle, über Geburt und Tod hinaus, denn sie kannten Art und Geschlecht der Jungen, die geboren wurden, und der Alten, die vor ihnen dagewesen waren.“260 Das Stadthaus und die Gruft der angesehenen Familie stehen für eine sich über Leben und Tod des Einzelnen hinaus konstituierende Heimat, die unverrückbar und unverlierbar ist und nicht vom Einzelnen neu begründet werden muss: „[D]as ist die Not der Fremde, daß man den Boden, worauf man steht, sich in jeder Stunde neu erschaffen muß.“261

Ein ominöser Alter, den das Kind für Knecht Ruprecht hält, liefert am Abend des Festes unerwartet den noch fehlenden Weihnachtsbaum und Baumschmuck; das Geschenk stammt von einer Gönnerin und offenbart, dass man ,auch nicht undankbar gegen die Fremde“ sein darf. Aber das eine aufbewahrte „Stück von dem Zuckerzeug des letzten heimatlichen Weihnachtsbaums“262 löst Wehmut aus. Die Erzählung endet damit, dass der Amtsrichter seinem Sohn von dem Tag erzählt, als er in der Gruft seiner Familie stehend „den Segen der Heimat sich leibhaftig auf [sich] niedersenken“ fühlte. ${ }^{263}$ Der Blick des Ehepaares aus dem Fenster zu den vorüberjagenden Wolken, die dorthin jagten, „wo in unsichtbarer

256 Storm 1987, S. 600.

257 Storm 1987, S. 607.

258 Storm 1987, S. 610.

259 Alle Zitate Storm 1987, S. 616.

260 Storm 1987, S. 617.

261 Storm 1987, S. 595.

262 Beide Zitate Storm 1987, S. 616.

263 Storm 1987, S. 617-618. 
Ferne ihre Heimat lag“, im Hintergrund die alte Magd, die „die allmählich niederbrennenden Weihnachtskerzen“ hütet, ist das letzte Bild. ${ }^{264}$

Das Telos der Erzählung ist somit die Transzendierung von Heimat in ihrem Verlust. Heimat, auch oder gerade als verlorene, wird zur Quelle der Trauer und Melancholie, aber auch der Kraft, ja zur Quelle (göttlicher) Gnade. Auch nach der Vertreibung bleibt die segnende Kraft der Heimat im eigenen Inneren unverlierbar. Insofern erscheint Heimat im bürgerlichen Zeitalter einmal mehr als Surrogat der Religion. So wie die Weihnachtskultur des 19. Jahrhunderts ihre Rituale zunehmend nicht mehr an die Kirche und Gemeinde, sondern an das bürgerliche Haus und die Familie band und entsprechend die Erzählung in der Wohnstube der Familie spielt, wird am Weihnachtsabend nicht Jesu, sondern der Heimat gedacht und von dieser, nicht von jenem, stammt der Segen, von dem der Familienvater spricht und den er durch seine Erzählung weitergibt.

Heimat schöpft somit ihre Evidenz aus einem Herkommen, das das Bürgertum eigentlich gerade erst auszubilden beginnt. ${ }^{265}$ Schon zeitgenössisch ist dabei völlig klar, dass es bei der Verbindung von Heimatgefühl und Weihnachtsfest auch um literarische Wirkung geht. Ein Freund gratuliert Storm zu seinem „Griff“, Weihnachtsfest und Heimweh zu kombinieren: „Äußerst glücklich ist [...] für den Weihnachtsabend der Griff, die Feier dieses einzigen Festes mit dem Heimatgefühle, oder vielmehr der Heimatsehnsucht zu kombinieren.“ Denn „der Effekt“

264 Beide Zitate Storm 1987, S. 618.

265 Ein Freund des Autors bewertet den „Schluß, wo das Heimatsgefühl sich als ein bewußtes in längerer Auslassung und Motivierung Kund gibt“ einerseits als „ganz hübsch“ und „von Wirkung“. Andererseits moniert er, dass hier „die Liebe zur Heimat zurückgeführt [werde] auf die Achtung, die man in der Heimat in Folge der Verdienste seiner Vorfahren genieße, also auf eine sehr aristokratische Grundlage. Das mag recht gut sein für diejenigen Einzelnen unter Tausenden, die eine Heimat da haben, wo auch ihre Vorfahren geachtet waren; aber wir Anderen Tausende, wir parvenus, haben wir denn kein Recht darauf, unsere Heimat zu lieben? Vielleicht nicht, aber dann ist es kein allgemein menschliches Gefühl, wert, durch die Poesie verklärt zu werden.“ Hartmuth Brinkmann an Theodor Storm, 19. März 1863 nach Heiligenstadt, in: Storm 1987 (Kommentar), S. 1171. Brinkmann kritisiert an der Novelle also, dass das Heimatgefühl zu sehr auf einer Besinnung auf die Verdienste der Vorfahren und damit auf einer ,aristokratischen Grundlage' basiere und daher nicht tauglich für diejenigen sei, die ihre Vorfahren nicht herzählen könnten. Hier einen Gegensatz zwischen Adel und Bürgertum konstruieren zu wollen, wäre aber falsch. Im Gegenteil konstituiert sich das Bürgertum der Zeit gerade anhand der Einschreibung in tradierte (oder als solche behauptete) historische Zusammenhänge, wie auch das Kapitel zu Gustav Freytags ,Ahnen zeigen wird. Am Ende der fiktiven Reihe der Ahnen steht der Bürger Victor König, und nur noch dessen Nachname zeugt von der Genealogie der Könige, in die er sich einreiht (vgl. II.3.1.2). 
werde „dadurch von selbst unendlich gesteigert“. ${ }^{266}$ Heimatgefühl und Heimatsehnsucht sind demnach auch literarische Mittel, die bestimmte Wirkungen erzielen - unter anderem die, so wäre im Anschluss an das Vorhergehende anzufügen, sich in Traditionen einzuschreiben, die durch dieses Einschreiben eigentlich erst hervorgebracht werden.

Tendenzen der bürgerlichen Selbst(re)produktion von Heimat lassen sich im 19. Jahrhundert auch am wichtigsten Medium der Öffentlichkeit ablesen, den Zeitungen und Zeitschriften, die vom gebildeten Bürgertum herausgegeben, geschrieben, gekauft und gelesen wurden. Auch Storms Novelle ist ja eine Auftragsarbeit für die Leipziger Illustrirte Zeitung, ein weit verbreitetes Wochenblatt, das mit seiner noch neuen Verbindung von Text und Illustration auf dem Zeitschriftenmarkt erfolgreich um Aufmerksamkeit konkurrierte. ${ }^{267}$

Wie eng der medial verbreitete bürgerliche Wertekanon mit Heimat und Haus, dem Heimeligen und dem Daheimsein verknüpft ist, zeigen schon die Titel der Zeitschriften, die ab den 1850er Jahren auf dem Markt erscheinen: Unterhaltungen am häuslichen Herd (1852-1864); Die Gartenlaube. Illustrirtes Familienblatt (ab 1853, ab 1938 unter dem Titel Die neue Gartenlaube); Aus der Heimat (1859-1866); Daheim. Ein deutsches Familienblatt mit Illustrationen (1864-1942); Die Heimat. Illustriertes Familienblatt (1876-1901) oder Heimgarten (1877-1918; ab 1919 unter dem Titel Roseggers Heimgarten). Auch die Frequenz, in der Heimat als Begriff in diesen Publikationen auftaucht, belegt die Popularität von Heimat beim bürgerlichen Publikum. Die Omnipräsenz der Heimat führt zu einer Art milieuspezifischer Selbstbezüglichkeit des Themas, die sich auch auf das Bildprogramm der Zeitschriften niederschlägt. Die in Wien gedruckte Zeitschrift Die Heimat. Illustrirtes Familienblatt, deren Redakteur über einige Jahre Ludwig Anzengruber war, ${ }^{268}$ zeigt als Titelvignette eine lorbeerbekränzte Figur, welche die Zeitschrift Die Heimat in die Höhe hält, um sie herum Putten, die nach der Zeitschrift greifen

266 Hartmuth Brinkmann an Theodor Storm, 19. März 1863 nach Heiligenstadt, in: Storm 1987 (Kommentar), S. 1171.

267 Die Illustration zu Storms Novelle stammt von Ludwig Pietsch, war aber für den Abdruck in der Zeitung nicht mehr rechtzeitig fertig geworden und erschien in der ersten Buchauflage unter dem Titel Zwei Weihnachtsidyllen 1865; vgl. auch den Kommentar von Band 1 der Werkausgabe von Dieter Lohmeier in Storm 1987, S. 1167-1168.

268 Ludwig Anzengruber (1839-1889) war von 1882 bis 1885 leitender Redakteur - in den Jahren, in denen er weniger erfolgreich als Schriftsteller war. Zuvor hatte er durch Bühnenstücke in der Tradition des österreichischen Volksstücks wie Der Pfarrer von Kirchfeld (1870), Der Meineidbauer (1871) oder Die Kreuzelschreiber (1872) große Wertschätzung als sozialkritischer Bühnenautor erfahren. Auch seine Dorfgeschichten, die zu Lebzeiten zwischen 1879 und 1888 erscheinen, widmen sich dem bäuerlichen Milieu in realistischer, später naturalistischer Drastik und in volksaufklärerischer Tradition. 
und teilweise schon in ihr lesen (Abb. 29). ${ }^{269}$ Und der Daheim-Kalender, ein Jahreskalender der Zeitschrift Daheim. Ein deutsches Familienblatt mit Illustrationen, trägt als Titelbild einen Knaben, der den Daheim-Kalender in seiner Tasche trägt und ein zweites Exemplar einem Mädchen schenkt (Abb. 30). Diese hier ins Bild gesetzte Autoreferentialität der sich selbst zeigenden Heimatzeitschriften entspringt der Logik eines literarischen Marktes, der die Bedürfnisse erst schaffen muss, von denen er lebt, und der Logik einer bürgerlichen Kultur, die sich auf die Sehnsucht nach einer Authentizität beruft, die sie selbst erst herstellt und die zeitgenössisch durchaus auch kritisch gesehen wurde.

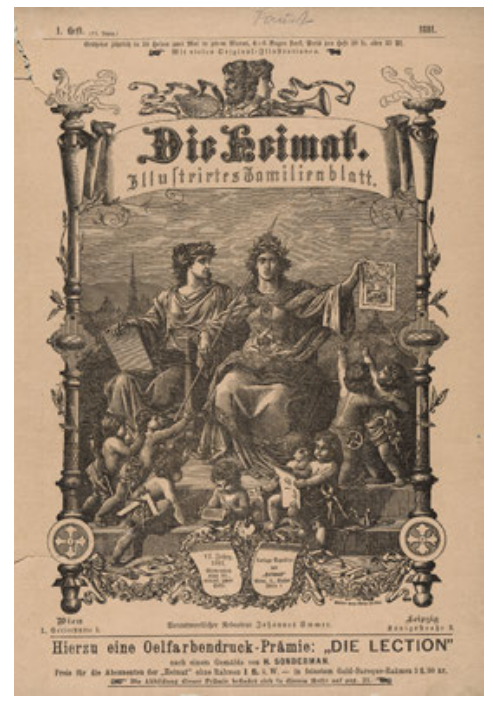

Abb. 29: Titelkupfer von „Die Heimat. Illustrirtes Familienblatt“ VI. Jg., 1. Heft (1881) (Klassik Stiftung Weimar)

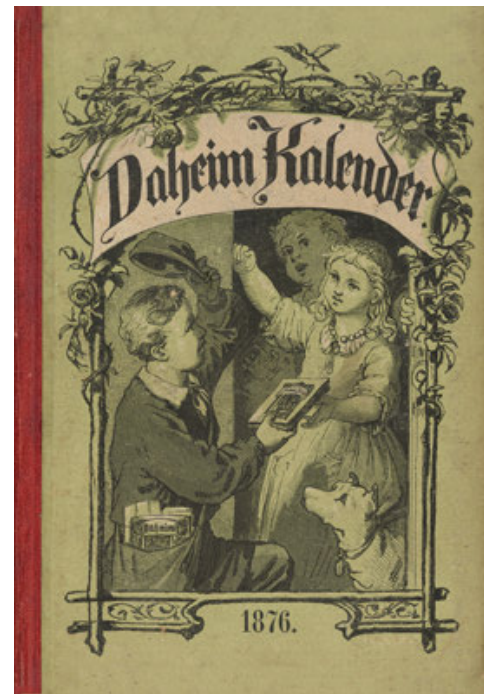

Abb. 30: Titelkupfer vom Daheim-Kalender 1876 (Klassik Stiftung Weimar)

Ein anonymer Autor mokiert sich 1858 im Morgenblatt für gebildete Leser etwa über die ausufernde Produktion mundartlicher Texte im Gefolge des Erfolgsautors Klaus Groth, die „allein schon deßhalb beklatscht“ würden, „weil sie auf Plattdeutsch gesprochen“ würden - deren Authentizität aber zutiefst zweifelhaft sei. „Jeder dieser Schriftsteller singt und spricht selbstverständlich im platten Patois seines Heimathsdorfes und bestrebt sich, dasselbe so treu und ächt wiederzu-

269 Die Abbildung stellt eines der seltenen bildgraphischen Beispiele für die Kombination von Klassizismus und Heimat dar. 
geben, als es ihm nur möglich ist“; mit dem Effekt, dass der eine „nur mit Mühe den andern“ verstehe. ${ }^{270}$ Dass vieles auch dem Einheimischen geradezu unverständlich sei, rühre daher, dass es eine einheitliche plattdeutsche Sprache nie gegeben habe. „So wollen z. B. die berühmten plattdeutschen Poesien von Klaus Groth höchst populäre Schriften seyn, welche die Volkssprache treu und unverfälscht wiedergeben, allein in Wirklichkeit sind sie dieß durchaus nicht. “271 Nicht nur die Authentizität der mundartlichen Literatur, sondern auch ihre Berechtigung wird in Frage gestellt. „Der Hauptzweck aller dieser platten Bestrebungen ist nun angeblich der, das Plattdeutsche vor dem ihm drohenden Untergange zu bewahren“. Diese Befürchtung sei „aus der Luft gegriffen“, denn die „bäuerische Bevölkerung“ hänge „zäh an ihrem heimischen Patois“. Davon abgesehen sei es aber „eine erfreuliche Thatsache für die Sache der Bildung und Aufklärung im Volke“ ${ }^{272}$ wenn sich die Kenntnis des Hochdeutschen durchsetze. Sinnvoll wäre es zwar durchaus,

eine plattdeutsche Zeitung zu gründen, die vom gemeinen und ungebildeten Volke gelesen werden könnte. Daran scheint man aber nicht zu denken, sondern es vorzuziehen, in gebildeten Kreisen gelesen zu werden und auf den Toilettentischen eleganter Damen zu verkehren, so wie denn überhaupt bei Lichte besehen alle diese plattdeutschen Schriften und Poesien, die sich ihrer Naturwüchsigkeit rühmen, nichts anderes sind als künstlerische Erzeugnisse der Unnatur und Treibhausgewächse, der ganze durch sie hervorgerufene Enthusiasmus nichts weiter als eine neue Art von Blasirtheit, worin sich gewisse gebildete Kreise der Gesellschaft gefallen. ${ }^{273}$

Nach dieser zeitgenössischen Deutung bringen die Bedürfnisse einer ,blasierten“ bildungsbürgerlichen Schicht die Produktion von heimatlicher Mundartdichtung überhaupt erst hervor oder befördern sie zumindest stark, wobei es dabei nicht im Mindesten um die Interessen der Ungebildeten geht, deren angebliche literarische Zeugnisse man goutiert.

(Heimat-)Literatur ist freilich nicht nur Produkt solcher Selbstproduktionsmechanismen des bürgerlichen Literaturmarktes, sondern reflektiert diesen Produktstatus ihrerseits mit literarischen Mitteln. Ein Beispiel für die reflexive Selbstbezüglichkeit von Heimat ist Peter Roseggers Text „Wenn du noch eine

270 Alle Zitate Anonym 1858, S. 118.

271 Anonym 1858, S. 118-119. Groth habe sich ,große sprachliche Willkürlichkeiten erlaubt, die ihn nöthigten, seinen Gedichten einen eigenen Commentar zu ihrer Erklärung und ihrem rechten Verständnis beizugeben“; selbst echte Kenner des Plattdeutschen könnten seine Texte nicht verstehen. Die Freunde des Niederdeutschen, so der Kommentator polemisch, sollten besser gleich ins Holländische wechseln. Anonym 1858, S. 119.

272 Alle Zitate Anonym 1858, S. 119.

273 Anonym 1858, S. 120. 
Heimath hast ...“. Rosegger war selbst Herausgeber des heimataffinen Periodikums Heimgarten und anlässlich seines 50. Geburtstags von den Herausgebern der Gartenlaube gebeten worden, „ein weniges aus [s]einem Leben zu plaudern“. Das autobiographische Erzähler-Ich weist schon zu Beginn des Textes darauf hin, dass Die Gartenlaube im Folgenden selbst Gegenstand seines Textes werde: „Ein Engel, der mir an bedenklichen Lebenswenden stets so freundlich beigestanden, hat auch einmal nach der ,Gartenlaube‘ gegriffen und sie zu meinem Wegweiser gemacht - nach dorthin, wohin ich gehörte.“ Als er nämlich als junger Mann seine „Waldheimath“274 verlassen hatte, habe ihn „Sehnsucht nach Daheim wie höllisches Feuer“275 gefoltert. Im Augenblick höchster Not fällt ihm ein Band der Gartenlaube in die Hand:

[E]in Band der ,Gartenlaube، war's, und dort, wo einem Blatt im Falle die Ecke geknickt worden war, fiel mein Auge auf ein Gedicht: „Wenn Du noch eine Heimath hast ...“

Was war das? Auf der untersten Stufe kauernd, las ich:

,Wenn Du noch eine Heimath hast,

So nimm den Ranzen und den Stecken

Und wandre, wandre ohne Rast,

Bis Du erreicht den theuren Flecken.

Weiter las ich nicht mehr in dem Gedicht, denn ich war schon erlöst. Heim! Heim! Kein Klagen mehr. Mein Herz war leicht, mein Wille befreit. Unausgesprochen hatte ich die Nothwendigkeit der Umkehr tagelang in mir getragen wie eine Unmöglichkeit. Weltfern war mir die Heimath gewesen, und jetzt war sie nur einige Stunden weit, und es bedurfte nicht einmal des Ranzens und des Steckens. So mächtig ist oft ein einziges Wort - das Wort hat ja die Welt erlöst. ${ }^{276}$

In der Erzählung ist es also ein Heimatgedicht der Gartenlaube, das den Erzähler wieder in die Heimat bringt. Sie stellt die Selbstbezüglichkeit einer Sehnsucht nach der Heimat dar, die sich durch die Rede von ihr eigentlich erst hervorbringt. Wichtig ist hierbei, dass das Gedicht in der Erzählung nicht als intertextueller Verweis funktioniert. Vielmehr geht es eigentlich um einen innermedialen Verweis: Ein Text in der Gartenlaube handelt von der Lektüre eines Textes aus der Gartenlaube - und ihren Folgen, nämlich dem Gewinn von Heimat. Das Gedicht, von dem Roseggers Text die erste Strophe wiedergibt, darauf weist er in einer Fußnote hin, gibt es wirklich. Es stammt von einem der ,Hauslyriker der Gartenlaube, Albert Traeger, und ist im Heft 52 von 1856 erschienen (das beigefügte

274 Alle Zitate Rosegger 1893, S. 589.

275 Rosegger 1893, S. 589.

276 Rosegger 1893, S. 590. 
Bild stammt von Gottfried Kühn und wird in einem anderen Zusammenhang noch erwähnt; Abb. 34). Rosegger nennt den Autor Traeger in seiner Erzählung nicht. Stattdessen wird die Gartenlaube zum Urheber und die individuelle Autorschaft zugunsten des Kollektivorgans, das die Heimat überindividuell und allgemein repräsentiert, zurückgenommen. Und die abschließende direkte Aufforderung an den Leser des Textes, seiner Heimat treu zu bleiben, ist insofern auch als Aufforderung zu verstehen, der Gartenlaube als ihrem Medium und Organ die Treue zu halten. ${ }^{277}$ Es geht also nicht nur um ein intertextuelles Spiel, in dem ein Autor auf den Text eines anderen Autors verweist, sondern um die Geburt von Heimat aus der Gartenlaube.

Insoweit ist Roseggers Text auch Teil jenes Programms der Gartenlaube, nach dem sich die „Gartenlauben-Realität und die ,Realität in der Gartenlaube““ immer wieder überlagern. Die Zeitschrift wollte die Welt des Lesers nicht nur abbilden, sie wollte identisch mit dieser Welt werden. ${ }^{278}$ Indem sich die Texte der Gartenlaube einerseits permanent aufeinander bezogen, andererseits auf die Gartenlaube als ihr Medium sowie den Gartenlauben-Leser, konstituierte sich, so Claudia Stockinger, eine ,imaginäre Gemeinschaft‘ der Gartenlaube. ${ }^{279}$ Nach denselben Regeln vollzieht sich die Konstitution von Heimat durch die Gartenlaube, an deren Ende die Gartenlaube Heimat ist. Der Begriff der Heimat bezieht sich also nicht nur auf ein Ensemble anderer Begriffe wie Vaterland, Volk, Heimweh oder Fremde. Er ist selbst ein Begriff in diesem Ensemble, der in der Art seiner Selbstbezüglichkeit seine Bedeutung hervorbringt und verändert. Das macht die enorme Bedeutung von Literatur und ihrer populären Medien aus, die häufig die Form und der Ort sind, an dem diese Selbstbezüglichkeit ausgetragen wird.

Festgehalten werden muss, dass sich das Verhältnis von Heimat und Literatur nicht allein in ästhetisch $\mathrm{zu}$ verstehenden Selbstbezüglichkeitsschleifen erschöpft, dass Heimat nicht in der Gemengelage von Herkunftsort, Erinnerung, Melancholie und Dichtung aufgeht und entsprechend von Literaturwissenschaftlern als harmlos-unpolitische Manifestation der mit ihren räumlichen Be-

277 „Seit jener kritischen Zeit sind achtundzwanzig Jahre vergangen. Das Heimathland, welchem der Dichter mich damals zurückgegeben hat, habe ich seither nicht mehr aus den Augen gelassen, sondern habe mich mit beiden Händen an dasselbe geklammert, wie ein erschrecktes Kind sich festhält an den Rockfalten der Mutter. Dem Stamme und der Scholle treu in Lust und Leid, auch dir, mein lieber Leser, rathe ich es - wenn du noch eine Heimath hast!“ Rosegger 1893, S. 590. 278 Dies ist die These von Claudia Stockinger, die den ,seriellen Effekten über Selbstbespiegelung‘ ein eigenes Kapitel ihrer Studie zur Gartenlaube widmet, Stockinger 2018, S. 257-272, hier S. 258.

279 Stockinger 2018, S. 267. 
zugswelten und sich selbst spielenden Dichtung behandelt werden könnte. ${ }^{280}$ Die Konstruktionen von Selbstbezüglichkeit verweisen vielmehr auch auf die selbstkonstitutiven Mechanismen einer bürgerlichen Kultur, die ihre eigenen Traditionen erst erfinden muss. Und sie verweisen auf die ökonomischen Regeln eines literarischen Marktes, der die Bedürfnisse erst schafft, die er dann befriedigt, wie es Adorno und Horkheimer im Anschluss an Hegels und Marx' zeitgenössische Diagnosen formulierten.

280 Eher unproblematisch verwendet in diesem Sinn Heinrich Detering in seinem Buch über Herkunftsorte Heimat als „Herkunftsort der Melancholie, im doppelten Sinne des Genitivs: als ein Ort, aus dessen erinnernder Vergegenwärtigung die Melancholie der Verlusterfahrung aufsteigt, und als ein Ort, der aus ebendieser Erfahrung heraus selbst erst in Fiktion verwandelt wird“. Detering 2001, S. 13. Heimatdefinitionen von Literaturwissenschaftlern sind selbst historische Produkte, die als solche nicht immer erkannt werden. 